\title{
Studien über einen Hemicephalus, mit Beiträgen zur Physiologie des menschlichen Centralnervensystems.
}

\author{
I. Anatomischer Theil. \\ Von \\ Privatdocent Dr. Maximilian Sternberg in Wien. \\ (Mit 6 Abbildungen im Text.)
}

Als Anencephalus pflegt man eine Missbildung zu bezeichnen, bei welcher keine makroskopisch erkennbaren Theile des Gehirns vorhanden sind. Fehlt das Gehirn nicht vollständig, ist insbesondere ein ansehnlicher Theil der Medulla oblongata oder noch mehr vorhanden, so spricht man gewöhnlich von Hemicephalie.

Diese in Deutschland meist üblichen Bezeichungen stammen aus der Zeit der rein makroskopischen Betrachtung der Missbildungen und werden auch heute noch fast allgemein beibehalten, obgleich sie sowohl sachlich als sprachlich nicht zutreffen. Die Bezeichnung "Anencephalus“" ist ungenau, da sich bei mikroskopischer Untersuchung stets Reste der Anlage des Grosshirns nachweisen lassen. Der Name „Hemicephalus" ist geeignet irrezuführen, denn wir pflegen in der Pathologie des Nervensystems und in der Teratologie die Zusammensetzung mit „Hemi" sonst in einem ganz anderen Sinne zu verwenden, nämlich um Störungen der bilateralen Symmetrie zu bezeichnen. Aber diese Namen sind nun einmal so eingebürgert, dass sie auch im Folgenden beibehalten werden, um die Continuität mit den früheren einschlägigen Arbeiten nicht zu verlieren. ${ }^{1}$ )

Die genannte Missbildung des Hirns gehört zu den allerhäufigsten beim Menschen und ist schon seit alter Zeit bekannt. Ihre gröbere

1) Ziegler spricht in seinem bekannten Lehrbuche von „partieller Anencephalie" anstatt von Hemicephalie. Veraguth, der neuestens an den herkömmlichen Namen Kritik übt, zieht „Pseudencephalie“" vor. Nach der systematischen Eintheilung von J. Geoffroy St. Hilaire (Histoire genérale et particulière des anomalies de l'organisation chez l'homme et les animaux. Bruxelles 1837. II. p. 213-270) wäre diese Missgeburt, "Thlipsencephalus" zu nennen, während „Derencephalus" und „Anencephalus" ausgedehntere Mängel im Centralnervensystem bezeichnen.

Dentsche Zeitschr. für Nervenheilkunde. XXIV. Bd. 
Anatomie haben im 18. Jahrhundert A. v. Haller ${ }^{1}$ ), Sandifort ${ }^{2}$ ) und Soemmering ${ }^{3}$ ) sehr genau untersucht. Die Entwicklungsstörung des Gehirns ist in der Regel mit Veränderungen des Skelets verbunden, insbesondere einem gänzlichen oder theilweisen Mangel des Schädeldaches (A cranie), Missbildung der Keilbeine, Verringerung der Zahl der Halswirbel, abnormen Krümmungen der Wirbelsäule u. s. w., ferner häufig mit Abnormitäten der Eingeweide, worunter Soemmering besonders die Hypoplasie der Nebennieren betonte.

Die Monographie Sandifort's enthält eine sehr sorgfältige Zusammenstellung der einzelnen beschriebenen Fälle aus der alten Literatur. Die Casuistik ist jetzt ungeheuer angewachsen. Der Anatom J. F. $\mathrm{Meckel}^{4}$ ) führte 1812 bereits 125 Beobachtungen an; im Laufe des 19. Jahrhunderts sind weitere sehr zahlreiche Fälle, insbesondere in geburtshülflichen Zeitschriften, veröffentlicht worden.

Eine wesentliche Vertiefung unserer Kenntnisse über diese Missgeburten hat erst die neuere Zeit durch die mikroskopische Untersuchung ihres Centralnervensystems gebracht. Die erste Mittheilung auf diesem Gebiete rührt von Flechsig ${ }^{5}$ ) her, die erste ausführlichere Arbeit von Leonowa ${ }^{6}$ ).

Seitdem ist das Studium der Teratologie des Centralnervensystems zu einer eigenen Methode der Hirnforschung geworden, der sich zahlreiche Kräfte, namentlich aber v. Monakow und seine Schüler, gewidmet haben. Eine Uebersicht über das, was in den letzten Decennien hierin geleistet worden ist, bietet eine Zusammenstellung C. v. Monakow's "Ueber die Missbildungen des Centralnervensystems $\left.{ }^{14} .7\right)$

Speciell mit Anencephalie und Hemicephalie haben sich

1) A. v. Haller, De fetu humano septimestri sine cerebro edito. D.XXI. April. MDCCXLV. In Opuscula anatomica. Gottingae MDCCLI p. 279.

2) E. Sandifort, Anatome infantis cerebro destituti. Lugduni Batavorum 1784 .

3) S. Th. Soemmering, Abbildungen und Beschreibungen einiger Missgeburten. Mainz 1791.

4) J. F. Meckel, Handbuch der pathologischen Anatomie. Leipzig 1812. S. 195-260: „Vom Schädelmangel".

5) P. Flechsig, Die Leitungsbahnen im Gehirn und Rückenmark des Menschen. Leipzig 1876. S. 120.

6) O. v. Leonowa, Ein Fall von Anencephalie. Du Bois' Archiv f. Anatomie und Physiologie. Anatom. Abtheilung. 1890. S. 403.

7) In: O. Lubarsch und R. Ostertag, Ergebnisse der allgemeinen Pathologie und pathologischen Anatomie des Menschen und der Thiere. Sechster Jahrgang. Wiesbaden 1901. S. 513. 
Ueb. einen Hemicephalus, mit Beitr. z. Phys. d.menschl. Centralnervensyst. 211

beschäftigt: Dana1), Leonowa ${ }^{2}$ ), Arnold ${ }^{3}$ ), Schürhoff ${ }^{4}$ ), Gade ${ }^{5}$ ), Darvas ${ }^{6}$ ), Bulloch 7 , Raffone ${ }^{8}$ ), K. Petrén und G. Petrén ${ }^{9}$, Muralt ${ }^{10}$ ), Veraguth ${ }^{11}$ ), Vaschide und Vurpas ${ }^{12}$ ).

Von grundlegender Bedeutung für einige Fragen auf diesem Gebiete war die Arbeit v. Recklinghausen's ${ }^{13}$ ) über Wirbelspalten, der sich die seines Schülers Muscatello ${ }^{14}$ ) anschliesst.

Der Grad der Verkümmerung des Centralnervensystems ist in

1) Ch. L. Dana, Report of a case of anencephaly, with a microscopical study bearing on its relation to the sensory and motor tract. The Journal of Nervous and Mental Disease. 1888. Vol. XIII. p. 21.

2) O. v. Leonowa, Ein Fall ron Anencephalie. Du Bois' Archiv f. Anatomie und Physiologie. Anatom. Abtheilung. 1890. S. 403. - Ein Fall ron Anencephalie combinirt mit totaler Amyelie. Neurol. Centralblatt 1893, Nr. 7.

3) J. Arnold, Gehirn, Rückenmark und Schädel eines Hemicephalus von dreitägiger Lebensdauer. Ziegler's Beiträge zur pathologischen Anatomie und zur allgemeinen Pathologie 1892. Bd. XI. S. 407.

4) C. Schürhoff, Zur Kenntniss des Centralnervensystems der Hemicephalen (Bibliotheca medica C. Heft 3). Cassel 1894.

5) F. G. Gade, Et tilfaede of anencefalie og total amyelie med flere andre dannelsesfeil. Norske Magazin for Laegevidenskaben. 55 Aargang, 1894, sid 715 (referirt bei Gebr. Petrén).

6) Darvas, Ueber das Nervensystem eines Anencephalen verglichen mit dem Nervensystem normaler Neugeborener. Verhandlungen der anatomischen Gesellschaft 1894. Anatomischer Anzeiger, Ergänzungsheft zum IX. Bd. (1894.) S. 187.

7) $\mathrm{Wm}$. Bulloch, The central nervoussystem of an anencephalous foetus. The Journal of Anatomy and Physiology. Vol. 29. (1895.) p. 276.

8) S. Raffone, Moëlle d'un monstre humain anencephale. Académie de Messine, 6 mai 1898. Revue.neurologique. 1898. p. 628.

9) K. Petrén und G. Petrén, Beiträge zur Kenntniss des Nervensystems und der Netzhaut bei Anencephalie und Amyelie. Virchow's Archiv. Bd. 151 (1898). S. 346 und 438.

10) L. v. Muralt, Ueber das Nervensystem eines Hemicephalen. Archiv für Psychiatrie und Nervenkrankheiten. Bd. 34. (1901.) S. 869.

11) O. Veraguth, Ueber nieder differenzirte Missbildungen des Centralnervensystems. Archiv für Entwicklungsmechanik der Organismen. Bd. 12. (1901.) S. 53.

12) Vaschide et Vurpas, Contribution à l'étude psycho-physiologique des actes vitaux en l'abscence totale du cerveau chez un enfant. Comptes rendus 1901. I. p. 641.

Dieselben, Recherches sur la structure anatomique du système nerveux chez un anencéphale en rapport avec le mécanisme fonctionel. Nouv. Iconographie de la Salpêtrière. T. 14. (1901.) p. 388.

13) F. v. Recklinghausen, Untersuchungen über die Spina bifida. Vírchow's Arch. Bd. 105. (1886.) S. 243.

14) G. Muscatello, Ueber die angeborenen Spalten des Schädels und der Wirbelsäule. Archiv für klinische Chirurgie. Bd. 47. (1894.) S. 162. 
den einzelnen Fällen recht verschieden, aber der Grundtypus bleibt derselbe.

Auf der Schädelbasis liegt eine schwammige, weiche, blutreiche Masse, die von v. Recklinghausen und Muscatello die Area cerebro-vasculosa genannt wird und den Rest der Hirnanlage bildet. In ihr endigen blind die Hirnnerven, soweit sie nicht aus dem entwickelten Theile des Centralnervensystems entspringen. Die Area. cerebro-vasculosa wird dorsal von einem geschichteten Epithel bedeckt, welches am Rande in das Stratum corneum der Epidermis der Kopfhaut ïbergeht. Unter dem Eipithel fehlen die Cutis und das subcutane Gewebe, das knöcherne Schädeldach und die Dura, dagegen findet sich darunter meist ein gefässreiches Gewebe, die Anlage der Pia mater. Die ventrale Begrenzung der Area cerebro-vasculosa bildet ein stärkeres Bindegewebe, die Fortsetzung der Dura, welches sich am vorderen Rande in das subcutane Gewebe der Kopfhaut, nach hinten in das Periost des Wirbelkanals fortsetzt. Die Area cerebrovasculosa enthält fast stets cystische Gebilde, in manchen Fällen auch grössere und kleinere Knollen, welche namentlich im Leben Windungsabschnitte des Grosshirns vortäuschen können (Arnold). Die genaue mikroskopische Untersuchung macht es nahezu jedesmal möglich, die Form dieser abnormen Bildungen auf den Typus eines frühen Embryonalstadiums des Hirns zurückzuführen (Veraguth). Die Art, wie der untere ausgebildete Antheil des Centralnervensystems mit der Area cerebro-vasculosa zusammenhängt, ist in den einzelnen Fällen verschieden. Entweder endet das Rückenmark, beziehungsweise das verlängerte Mark stumpf, meist mit einer kolbigen Anschwellung und steht durch fädige Fortsätze und Membranen mit der Area in Verbindung, oder es geht die normale Hirnsubstanz allmählich in die unvollständig oder abnorm differenzirte Masse der vorderen Hirntheile über.

Was rom Centralnervensystem ausgebildet ist, seien es nun Rückenmark und Theile der Medulla oblongata, oder auch Antheile des Mittelhirns und Kleinhirns, das ist im Ganzen verkleinert und ärmer an Fasern. Die Pyramidenbahnen fehlen oder sind äusserst reducirt $\left(\right.$ Arnold $\left.{ }^{1}\right)$ ). Ebenso sind einige andere lange Bahnen reducirt oder fehlen gänzlich, wie Kleinhirnseitenstrangbahn, Schleife u. s. w. Dagegen ist das hintere Längsbündel, wenn das verlängerte Mark bis in seine Region reicht, stets gut entwickelt, seine Fasern gehören immer zu denjenigen, die am weitesten cerebralwärts zu verfolgen sind. Kerne und Wurzeln der Hirnnerven zeigen die grössten Verschiedenheiten der Ausbildung. Einzelne Nerven sind oft ganz oder theilweise gut

1) Die Deutung Arnold's wird mehrfach bestritten. 
Ueb. einen Hemicephailus, mit Beitr. z. Phys.d. menschl. Centralnervensyst. 213

entwickelt, andere höchst rudimentär, kaum zu identificiren. Die topographischen Verhältnisse sind mitunter erheblich gestört, zusammengehörige Gebilde in verschiedene Höhen auseinandergezogen, andere zusammengedrängt, einzelne Nervenkerne in mehrere Theile zersprengt oder der intrabulbäre Verlauf der Nerren, wie des Facialis, geändert. Manchmal sind die Nervenkerne auffallend stark in der Richtung der Wurzeln gestreckt (Muralt).

Wenn in dem ansgebildeten Theile des Centralnervensystems ein einzelnes Gebilde fehlt, so kann es sich entweder so verhalten, dass es spurlos verschwunden ist, oder so, dass an seine Stelle ein zartes reticuläres kern- und gefässärmeres Gewebe tritt, dessen Umrisse mehr oder weniger die Form jenes Gebildes haben. So tindet sich meist ein der markhaltigen Fasern nahezu oder völlig entbehrendes Rudiment des Pons, wenn der obere Theil der Medulla oblongata entwickelt ist.

Das Rückenmark ist stets verkleinert (Mikromyelie), der Markmantel in den Vorderseitensträngen stark verringert, weniger in den Hintersträngen. Im Halsmarke und im oberen Dorsalmarke findet sich nicht selten eine seitliche Furche, welche, von der Pia überbrückt, im hinteren Theile der Seitenstränge gelegen ist und nach oben und unten allmählich seichter wird und verschwindet. Sie entspricht ungefähr der Gegend der Pyramidenbahnen. ${ }^{1}$ )

Ein constanter Befund sind Blutungen, die nach oben zunehmen, Muralt bezieht sie auf die Geburtstraumen.

Ausgesprochen abnorme Bildungen nervöser Natur sind in dem gut differenzirten Antheil des Centralnervensystems nicht häufig angetroffen worden. Am bemerkenswerthesten ist die „hintere Kreuzung“"Schürhoff's, das sind quer verlaufende markhaltige Fasern im dorsalen Theil der Oblongata und zwar in der Höhe des Hypo-

1) Sie ist zuerst von Flechsig (loc. citat. S. 287) und zwar als Befund am normalen Rückenmark beschrieben, dann von Anton bei Missbildung des Hirns mit Agenesie der Pyramidenbahn beobachtet worden. Neuestens wurde sie von Paltauf bei Poreneephalie beschrieben und von Obersteiner und Zappert eingehender studirt.

G. Anton, Ueber angeborene Erkrankungen des Centralnervensystems. Sammlung medicinischer Schriften. XV. Wien 1890. - R. Paltauf, Ueber das Vorkommen lateraler Furchen am Rückenmarke bei Porencephalie. Wiener klinische Wochenschrift 1901. S. 1036. - H. Obersteiner, Ein porencephalisches Gehirn. Arbeiten aus dem neurolog. Institute an der Wiener Universität. 1902. S. 46. - G. Zappert, Ueber eine Rückenmarksfurche beim Kinde. Ibidem S. 281. - H. Obersteiner, Nachträgliche Bemerkung zu den seitlichen Furchen am Rückenmark. Ibidem \$. 396. 
glossus und Vagus. Sie stammen aus den Hintersträngen und deren Kernen. Die Bildung ist in mehreren Fällen beobachtet worden.

Der Centralkanal zeigt häufig Abnormitäten. Oft öffnet ex sich erst viel höher als normal zur Rautengrube. Oft tritt eine Vermehrung auf mehrere Kanäle ein, sie beginnt in einer Anzahl von. Fällen im Halsmark, meist aber in der Oblongata. Sehr hänfig ist Vermehrung der umgebenden Glia, warzenartige Vorbuchtung von Glia ins Innere des Kanals, Versprengung von Ependymzellen in die Nachbarschaft, vielfache Höhlenbildung um den Kanal herum - Befunde, die man seit Schürhoff mit der Entstehung der Syringomyelie in Zusammenhang zu bringen pflegt. ${ }^{1}$ )

Die Spinalganglien entwickeln sich vollständig $\left(\mathrm{Manz}^{2}\right)$, Monakow ${ }^{3}$, Leonowa, Gade, Schürhoff, Dana, Petrén), doch sind sie etwas kleiner und markärmer, ebenso die sympathischen. Ganglien.

Die Hirnnerven, die in der Area cerebro-vasculosa blind endigen, sind fast immer marklos, sehr dünn. Nur Veraguth hat markhaltige Fasern in motorischen Hirnnerven (im Hypoglossus, Facialis und Oculomotorius) gefunden, deren centrale Ursprungskerne nicht vorhanden waren. In einem anderen Falle fand er solche im Glossopharyngeus und Vagus. Hier war jedoch das Ganglion jugulare gut ausgebildet.

Der Opticus ist marklos, in der Netzhaut fanden de $\mathrm{Wahl}^{4}$ ), Manz ${ }^{5}$, Leonowa, Hegler ${ }^{6}$ ), Gade, Petrén, v. Muralt keine Nervenfasern und Ganglienzellen, Ritter ${ }^{7}$ ) fand die Nervenzellen sehr verkleinert. Vaschide und Vurpas ${ }^{8}$ ) beschreiben die Netzhäute eines Falles als normal.

1) Neueste Beschreibung des Rückenmarks eines Anencephalus unter Hinweis auf diese Frage bei J. Zappert, Kinderrückenmark und Syringomyelie. Wiener klinische Wochenschr. 1901. S. 949.

2) W. Manz, Das Auge der hirnlosen Missgeburten. Virchow's Archiv. Bd. 51. (1870.) S. 313.

3) C. v. Monakow, Nervensystem eines anencephalischen siebenmonatlichen Footus. Gesellschaft der Aerzte in Zürich, 19. December 1891. Correspondenzblatt für Schweizer Aerzte 1892. S. 252.

4) E, de Wahl, De retinae textura in monstro anencephalico disquisitones microscopicae. Diss. Dorpat 1859.

5) Manz, 1. c.

6) J. Hegler, Das Auge bei Anencephalie. Diss. Würzburg 1892.

7) C. Ritter, Das Auge eines Acranius histologisch untersucht. Archiv f. Augenheilkunde. Bd. II. (1882.) S. 215 .

8) N. Vaschide et Cl. Vurpas, De la constitution histologique de la rétine en l'abseance congénitale du cerveau. Comptes rendus 133. I. (1901.) p. 504. 
Die Riechschleimhaut fand $v$. Muralt ${ }^{1}$ ) fast normal. Im inneren Ohre eines 7 monatlichen Anencephalen sah Veraguth ${ }^{2}$ ) die inneren und äusseren Haarzellen, die Hensen'schen und Deiters'schen Zellen nicht entwickelt, sonst normale Verhältnisse.

Die Hypophyse entwickelt sich, wie schon die alten Beobachter (z. B. Ollivier ${ }^{3}$ )) wussten, unabhängig von dem Verhalten des Hirns, manchmal ist sie bei solchen Monstren etwas vergrössert.

Man sieht, dass wir in der That von der Anatomie der hirnlosen Missgeburten bereits recht gute Kenntniss besitzen; jedoch ist diese noch keinerwegs erschöpfend, wie man sofort erfährt, wenn man sich aus der Literatur über Einzelheiten des anatomischen Befundes Aufschluss holen will. Da zeigen sich alsbald mancherlei Lücken. Gerade v. Monakow, aus dessen Laboratorium höchst verdienstliche Arbeiten über diesen Gegenstand hervorgegangen sind, hat betont, dass noch „eine exacte descriptive Vorarbeit" geleistet werden müsse, bevor die Aufklärung dieser Missbildungen möglich sei. ${ }^{4}$ )

Das Studium der Missbildungen des Hirns hat nun eine sehr grosse allgemeine Bedeutung, die weit über die descriptive Teratologie hinausreicht. Die nähere Betrachtung soleher Monstren führt auf eine Fülle von Problemen, auf Grundfragen der Morphologie und der Biologie.

Vor Allem sollte, so scheint es, die Hirnanatomie Nutzen aus dieser Arbeitsrichtung ziehen. In der That hat schon Flechsig die Monstren bei der Untersuchung der Pyramidenbahnen mit Glück verwerthet, und bis in die allerletzte Zeit hat sich die Bearbeitung von Missbildungen für das Studium der Bahnen als fruchtbar erwiesen; es sei z. B. nur an die jüngsten Arbeiten von Arnold Pick ${ }^{5}$ ) und Schupfer ${ }^{6}$ ) erinnert.

Doch hat das Studium der Missbildungen der normalen Hirnanatomie bisher eigentlich nicht den grossen Gewinn gebracht, den

1) L. v. Muralt, Zur Kenntniss des Geruchsorgans bei menschlicher Hemicephalie. Neurol. Centralblatt 1901. S. 51.

2) O. Veraguth, Ueber das innere Ohr bei Anencephalie. Neurol. Centralblatt 1898. Nr. 12.

3) G. P. Ollivier, Ueber das Rückenmark und seine Krankheiten. Uebers. von J. Radius. Leipzig 1824. S. 94.

4) Ergebnisse der allg. Pathologie, 1. c.

5) A. Pick, Ueber den Fasciculus intermedius (Löwenthal) mit Bemerkungen über den Fasciculus marginalis anterior desselben Autors. Beiträge zur Pathologie und pathologischen Anatomie des Centralnervensystems. Berlin 1898. \$. 288.

6) F. Schupfer, Ueber Porencephalie. Monatsschrift für Psychiatrie und Neurologie. Bd, 10. (1901.) S. 32. 
man erwarten konnte und auch thatsächlich erwartet hat. Das hat im Wesentlichen zwei Ursachen. Zunächst einen einfachen Grund. Es hat grosse Schwierigkeiten, ja es ist überhaupt jetzt noch nicht möglich, die Bilder, welche ein solches rudimentäres Gehirn liefert, in allen Einzelheiten zu deuten. Hier ist eine der Lücken, wo „exacte descriptive Vorarbeit" noch Manches zu leisten haben wird, bevor eine ausgedehnte Anwendung der teratologischen Befunde auf die normale Hirnanatomie erfolgen kann.

Die andere Ursache, warum man von den Ergebnissen der Teratologie bisher weniger erhalten als erwartet hat, liegt tiefer. Man hat mehrfach die Anencephalen mit „Gudden'schen Experimenten im Grossen" verglichen und auf Grund dieser Auffassung sich auch grosse Aufklärungen über den Bau des Centralnervensystems, namentlich über die Beziehungen der Hirntheile zu einander versprochen. Bereits Schürhoff hat aber betont, dass die Analogie mit den Operationen v. Gudden's nur bis zu einem gewissen Grade rorhanden sei und nicht zur Erklärung der Befunde an den hirnloseu Missgeburten ausreiche. Er wies insbesondere auf die Störungen in der Ausbildung des Nervensystems hin, die durch Behinderung in den Wanderungen der Zellgruppen während des Wachsthums entstehen müssten.

Vor Allem ist es das Verdienst v. Monakow's und seiner Schüler, durch Heranziehung ron entwicklungsgeschichtlichen und entwicklungsmechanischen Thatsachen eine andere Auffassung begründet zu haben, welche das Wesen der Vorgänge besser trifft. Von grossem Werthe für das Verständniss der einschlägigen Fragen ist auch eine Arbeit von Bertacchini $\dot{1}^{1}$ ), in welcher ein 6 Wochen alter menschlicher Embryo mit Hemicephalie beschrieben wurde.

Der Standpunkt, den man bei der Betrachtung der hirnlosen Missgeburten heute einnehmen muss, ist der folgende.

Form und Bau des Nervensystems der Missgeburten werden nicht so sehr ron dem Zugrundegehen oder der Nichtentwicklung einzelner Theile bestimmt, als vielmehr hauptsächlich von der selbständigen Entwicklung der nerrösen Einzelanlagen, die in einem gewissen Grade unabhängig von der Gesammtentwicklung ist. Die Untersuchung eines solchen Geschöpfes zeigt uns also nicht das, was rom Nervensystem nach dem Ausfall bestimmter Theile übrig geblieben ist, sondern das, was sich unter einer das Medullarrohr betreffenden Schädigung entwickelt hat.

1) P. Bertacchini, Alcune considerazioni su un embrione umano emicefalo con "spina bifida" e sulle principali teorie dello sviluppo normale e teratologico. Internationale Monatsschrift für Anatomie und Physiologie. Bd. XVI. (1899.) \$. 65. 
Ueb. einen Hemicephalus, mit Beitr. z.Phys. d. menschl.Centralnervensyst. 217

Deswegen kann die Anatomie der Monstren für die Erkenntniss der normalen Beziehungen zwischen den Hirntheilen nur bei eingehender Berücksichtigung der Entwicklungsgeschichte des Hirns verwerthet werden. Deswegen vermag aber gerade die Anatomie der menschlichen Monstren wichtige Aufschlüsse über das Wachsthum und die trophische Abhängigkeit der einzelnen nervösen Gebilde im intrauterinen Leben und über den morphogenetischen Einfluss des Centralnervensystems auf die Peripherie zu geben. Dadurch bietet sie der Entwicklungsmechanik, die an experimentell erzengten Missbildungen begründet wurde, werthvolle Stützen und Ergänzungen, wie dies namentlich Veraguth ${ }^{1}$ ) in einer schönen Arbeit gezeigt hat. So stellt sich sofort der Zusammenhang der teratologischen Hirnforschung mit grossen biologischen Problemen her.

Die Untersuchung des Nervensystems unserer Missgeburten lehrt uns also nicht wie die Gudden'schen Experimente die gegenseitigen Beziehungen der Hirntheile im extrauterinen Leben, sondern ihre Entwicklung und ihre Beziehungen im intrauterinen Leben kennen. Sie zeigt, dass die Verbältnisse in den beiden Lebensphasen zum Theile nicht nur in topographischer, sondern auch in functionell-trophischer Hinsicht verschieden sind. Das wird namentlich bei Betrachtung noch tieferer Formèn von Missbildung deutlich.

So entwickeln sich durch "Selbstdifferenzirung", wie es Roux genannt hat, die Spinalganglien selbst bei gänzlichem Fehlen des Rückenmarks (Amyelie) und entsenden die hinteren Wurzeln in den leeren Wirbelkanal, indem sie eine Strecke weit hinaufziehen, gewissermassen das Rückenmark "suchend" (v.Mona kow). Ein Gleiches zeigen die cranialen sensorischen Nerven, die in der Area cerebro-rasculosa der Anencephalen blind endigen. Den Vagus fand Veraguth mit dem Ganglion jugulare im Zusammenhang, beim Glossopharyngeus desselben Falles ist das Vorhandensein seiner beiden Jugularganglien zwar nicht nachgewiesen worden, wohl aber nach berechtigter Analogie anzunehmen.

Dieses Verhalten der Spinalganglien und der hinteren Wurzeln entspricht völlig den bekannten Thatsachen der Entwicklungsgeschichte.

C. v. Monakow und seine Schüler, neuestens Veraguth, haben besonderes Gewicht darauf gelegt, dass diese Befunde eine feste Stütze für die Neuronlehre bildeten. Das ist aber vielleicht etwas zu viel bewiesen: denn es besteht doch ein beträchtlicher Unterschied zwischen dem, was die Neuronlehre das periphere sensible Neuron nennt, und den

1) Ueber nieder differenzirte Missbildungen des Centralnervensystems. 1. c. 
Stümpfen, die bei Amyelie und Anencephalie von den Spinalganglien zur Area medullo-raseulosa ziehen. Hier steckt wohl noch ein Problem dahinter.

Die vorderen Wurzeln fehlen bei der Amyelie. Dagegen kommen, wie oben erwähnt, markhaltige Fasern in rein motorischen Hirnnerven vor, deren Ursprungskerne fehlen. Vexaguth, der dieses Verhalten beschreibt, stellt zwei Möglichkeiten für die Erklärung hin. Entweder waren die Kerne ursprünglich vorhanden und sind erst später zu Grunde gegangen, oder die Markfasern gehören sensiblen Antheilen der Nerven an. Sie können beim Oculomotorius dem Ganglion ciliare, beim Hypoglossus ${ }^{1}$ ) frühembryonalen hinteren Wurzeln entstammen, die später wieder schwinden.

Man sieht, dass nicht nur der Befund kein Analogon in dem Verhalten der Nerven des Erwachsenen hat, sondern dass auch die. Erklärungsversuche Verhältnisse heranziehen müssen, welche dem postembryonalen Leben völlig fremd sind.

Bemerkenswerth ist das Verhalten der Musculatur. Die Musculatur der Extremitäten ist bei Anyelie, also trotz des Feblens der Vorderhörner and der motorischen Nerven, normal angelegt. Auch die Augenmuskeln können bei Abwesenheit der Oculomotoriuskerne normal sein $\left(\right.$ Leo no $\left.\mathrm{wa}^{2}\right)$ ). Umgekehrt fand Obersteiner $\left.{ }^{3}\right)$ bei angeborenem, fast völligem Fehlen des rechten Sternocleidomastoideus, der Clavicularportion des Cucullaris, des Pectoralis major, der Supra- und Infraspinati und der Rhomboidei keinen nachweisbaren Defect in den Zellen der Vorderhörner. Die trophische Abhängigkeit des Muskels vom motorischen Nerven besteht somit im intrauterinen Leben noch nicht: es erfolgt die Myotomdifferenzirung unabhängig von den Vorgängen im Medullarrohr.

Diese weitgehende Unabhängigkeit der Entwicklung der einzelnen Theile zeigt sich allerdings nur bei den niederen Missbildungen des Centralnervensystems so klar. Bei den eigentlichen Anencephalen und Hemicephalen sind die Verhältnisse weitaus verwickelter; doch lässt sich auch hier in manchen Gebilden Aehnliches nachweisen, wie später dargelegt werden soll.

1) Das von dem Autor nur füchtig angedentete Material über die Anatomie des Hypoglossus und seine hinteren Wurzeln findet sich zusammengestellt und vermehrt bei W.Beck, Ueber den Austritt des N. bypoglossus und N. cervicalis primus aus dem Centralnervensystem. Anatomische Hefte. I. Abtheilung. 1895. Bd.6.

2) Briefliche Mittheilung, angeführt bei C. Kunn, Die angeborenen Beweglichkeitsdefecte der Augen. Beiträge zur Augenheilkunde. XIX. 1885. S. 114.

3) H. Obersteiner, Rückenmarksbefund bei Muskeldefecten. Wiener klinische Rundschau. 1902. S. 302. 
Diese wenigen Zeilen haben schon eine Menge wichtiger Fragen aufgerollt. Die eingehende Betrachtung des Centralnervensystems entwickelterer Missbildungen, der Hemicephalen, führt wiederum auf eine Menge von Detailfragen. So bietet das eigenthümliche Verhalten des Centralkanals, die in den meisten Fällen eintretende multiple Höhlenbildung um ihn her, ein noch zu lösendes Problen. Ebenso muss der Umstand, dass mit einer gewissen Gesetzmässigkeit manche Gebilde überhaupt nicht zur Entwicklung gelangen, während ron anderen, ebenso markfaserlosen, stets Rudimente nachweisbar sind, auf bestimmten Gesetzen der Entwicklung und Differenzirung beruhen, die noch unbekannt sind. Es ist klar, dass erst diese und ähnliche Fragen beantwortet sein müssen, bevor die Entstehung dieser Missgeburten, über die bereits eine Menge von Arbeiten und Hypothesen existirt ${ }^{1}$ ), wirklich erklärt werden kann.

Eine weitere Reihe von Fragen knüpfen sich an die Function des missbildeten Hirns. Da eine Anzahl solcher Missbildungen einige Zeit am Leben bleibt, hat die Physiologie des Nervensystems Gelegenheit zu mancher Bereicherung.

Der im Folgenden zu beschreibende Fall ist von uns im Leben studirt worden. Es war daher nothwendig, sein Centralnervensystem so genau als möglich zu untersuchen, ein vollständiges „Inventar" seiner anatomisch nachweisbaren Bahnen und Centren aufzunehmen und so eine einigermassen verwerthbare Grundlage für Schlüsse über die Leistungen dieses Nervensystems zu gewinnen.

In Hinsicht auf die physiologische Verwerthung ist unser Fall bearbeitet, daher für die Untersuchung mancher der früher angeführten, speciell morphologischen Fragen unvollständig. Aber auch das Inventar seines inneren Banes ist nicht so erschöpfend, als es wohl wünschenswerth wäre. Ausser der Unvollkommenheit der Untersuchungsmethoden liegt das zunächst daran, dass trotz der grossen Zahl von Arbeiten nur sehr wenige hinreichend detaillirte Beschreibungen von Hemicephalen vorhanden sind, daher die Identificirung mancher Theile, zu der nicht blos ein Vergleich mit normalen Präparaten, sondern auch mit analogen Missbildungen nöthig ist, nicht genügend sicher war. Ausserdem aber stösst man gerade bei den Deutungsversuchen schwierigerer Stellen nicht selten auf die Grenzen unserer gegenwärtigen Kenntniss von der normalen Hirnanatomie.

Sectionsbefund (Prof. Richard Paltauf):

Neugeborenes Kind von kräftigem Körperbau, gut genährt, ja fettreich; die allgem. Decke mit feinen Härchen besetzt, die Fingernägel hart; der

1) Siehe ihre Erörterung bei Gebr. Petrén. 
Kopf in typischer Weise missbildet, indem die Stirn und der ganze Hirnschädel fehlen, die Augen, über welchen sich nur noch die Augenbrauenbögen finden, krötenartig vertreten, und der Kopf flach zum Nacken abfällt. In dieser behaarten Fläche treten weiche geröthete knollige Gewebsmassen in der Grösse eines Taubeneies vor; dieselben gehen durch häutige Lamellen in die behaarte Kopfhaut über, welche, an sich sehr dick, daselbst einen über 4 kreuzerstückgrossen Substanzverlust zeigt. Bei der Präparation zeigt sich, dass jene knolligen Massen ans einer Lücke des Schädels vortreten. Der Schädel ist flach, die Stirnbeine sind ziemlich wohl geformt, trapezoid und ganz der Schädelbasis angedrückt, so dass hinter ihnen sofort die Sella turcica von einer faserigen Gewebsmasse bedeckt zu sehen ist; die rudimentären, je einen dicken plumpen Knochen darstellenden Scheitelbeine vereinigen sich median nicht, liegen ebenfalls der Schädelbasis ganz auf.

Jene Höcker und ein Ring lebhaft gerötheten, gefältelten, weichen, meningenartigen Gewebes begrenzen eine sich trichterförmig verengende grubige Höhle, welche nach Eröffnung and Herausnahme des Rückenmarks und eines dem Bulbus medullae und Resten der Brücke entsprechenden cylindrischen Gebildes sich als 4. Ventrikel erweist. An der Seite des walzenförmigen Gebildes treten relativ starke Nervenwurzeln aus. Dieses cylindrische Gebilde verschmälert sich nach abwärts rasch und erscheint am Ansatz des Rückenmarks scharf abgesetzt.

Der 4. Ventrikel ist in seinem unteren Abschnitte ausgebildet, aber breiter; der als Medulla oblongata anzusprechende Theil erscheint niedriger, aber breiter gegen die Norm; er grenzt sich ventral mit zwei durch eine Kerbe getrennten Höckern von einem dünnen in die Wand des Trichters übergehenden Theil ab: von beiden Höckern gehen nach aussen und unten ziemlich steil laufende Linien, in denen zwei Nervenwurzeln, eine mehr median und eine lateral gelegene entspringen. Jene Höcker setzen sich in längliche, flache, beiderseits von der Mittellinie verlaufende, eben merkbare Erhabenheiten, anscheinend die Pyramiden fort. In dem von jener Linie und dem lateralen Rande dieser Erhabenheiten begrenzten seitlichen Felde findet sich beiderseits eine hanfkorngrosse, rundliche Protuberanz.

An der Höhlenseite grenzt die Medulla oblongata sich durch eine horizontale Linie von dem ca. 4-5 mm dicken Wandtheil ab, welcher hier 2 durch eine mediane tiefe Furche getrennte, ca. $7-8 \mathrm{~mm}$ breite and bis $11 / 2 \mathrm{~cm}$ lange Längswülste zeigt.

Ventral setzt sich die mediane Rinne nach abwärts fort, um vor dem Ansatz des Rückenmarks auf eine kurze Strecke zu verschwinden, worauf die vordere Fissur des Riuckenmarks in normaler Weise beginnt.

Das Rückenmark hat eine Länge von $17 \mathrm{~cm}$, im Halsmark einen Durchmesser von $5 \mathrm{~mm}$, im Brust- und Lendenmark von $4 \mathrm{~mm}$.

\section{Mikroskopischer Befund.}

Das Centralnervensystem wurde in Müller'scher Flüssigkeit gehärtet und nach Weigert-Pál unter Anwendung der Collodium-Serienmethode gefärbt. Einzelne Schnitte wurden mit Carmin, die nasalsten Endschnitte, welehe die Weigert-Pál-Färbung nicht annahmen, mit Hämatoxylin-Eosin nachgefärbt. Die Färbung liess in Folge einer einigermassen ungünstigen Conservirung zum Theil im Stiche. 
In der nachfolgenden Beschreibung der Befunde ist wegen der Färbung manches Detail übergangen worden, insbesondere was die Form und den feineren histologischen Aufbau der Zellen betrifft.

Oberes Lendenmark.

Sagittaler Durchmesser . . . . . . .

Frontaler Durchmesser . . . . . . . 3,38 "

Sagittale Ausdehnung der Hinterstränge . links 2,12 "

" " " rechts $2,00 "$

Breite des Hinterstrangs an der Basis . . links 1,34 "

" " "rechts $1,02 "$

Breite des Hinterstrangs an der Spitze. . links 0,48 "

Sagittale " " " " rechts $0.40 "$

" " " " rechts $0,89 "$

Breite des Vorderstrangs. . . ". . . . links $0,36 "$

Die Pia mater "st von gewöhnlicher Breite rechts 0,24 enthält zahlreiche ziemlich weite und stark gefüllte Gefässe.

Die Form des Querschnittes ist nahezu kreisrund, der Querdurchmesser ist nur um ein Geringes grösser als der sagittale. Der Rand zeigt zahlreiche schmale Einsenkungen entsprechend den hineinziehenden Gliasepten und beiderseits ventral vom Kopfe des Hinterhorns eine grössere seichte Einbuchtung, in deren Bereiche je zwei ähnliche Einsenkungen der Oberfiäche, wie eben beschrieben, liegen. Der Sulcus anterior ist weit. Die ganze Zeichnung des Querschnitts weicht dadurch von der Norm $a b$, dass der quere Schenkel des $\mathrm{H}$ so stark nach vorne verschoben ist, dass der Abstand des Centralkanals vom ventralen Rande 1/3 des Sagittaldurchmessers beträgt. Dementsprechend bilden die Hinterstränge das am stärksten ausgebildete Querschnittsfeld der weissen Substanz, während die Vorderseitenstränge als ein nahezu gleich breiter Saum von 0,37 bis $0,40 \mathrm{~mm}$ die graue Substanz umbüllen. Thre Ausdebnung beträgt in sagittaler Richtung nur die Hälfte von der der Hinterstränge.

Bei Markscheidenfärbung erweisen sich die Hinterstränge als fast gleichmässig gut gefärbt. Am dichtesten sind die markhaltigen Fasern an der ventralen Spitze der Hinterstränge.

Die Vorderseitenstränge sind dagegen blass, und zwaristihr ventraler Antheil, die eigentlichen Vorderstränge und der angrenzende Theil der Seitenstränge noch relativ faserreicher, von da nimmt die Menge der markhaltigen Fasern gegen das Dorsum allmählich ab, bis sie an der Grenze der Lissauer'schen Randzone besonders spärlich wird. Im Bereiche der eingangs beschriebenen Einbuchtung ventral vom Kopfe des Hinterhorns befindet sich ein $0,06 \mathrm{~mm}$ breites markloses Säumchen am Rande der weissen Substanz, welches sich dorsal an der Lissauer'schen Randzone, ventral ungefähr an der Kuppe der seitlichen Convexität des Randes allmählich verliert. Im Bereiche des Vorderstranges fehlt dieser Saum, die Markfasern reichen bis an die äusserste Peripherie des Rückenmarks. Es findet sich nirgends ein umschriebenes markloses Feld in der weissen Substanz, insbesondere fehlt das helle Feld der Pyramidenseitenstrangbahn gänzlich.

Die graue Substanz nimmt eine verbältnissmässig grosse Fläche 
des Querschnitts ein, nur der auf die Commissuren entfallende Antheil ist perkleinert.

Im Vorderhorn liegt an der Spitze und dem angrenzenden medialen Theil eine Gruppe grosser Ganglienzellen, ferner zerstreut im Bereiche des ganzen Vorderhorns zahlreiche kleinere Ganglienzellen, die in einer seitenhornartigen Ausbuchtung dichter angeordnet sind.

Im Hinterhorn bilden die Clarke'schen Säulen ein deutlich erkennbares Gebiet. Ihre Ganglienzellen sind spärlich und klein. Die Zellen der Substantia Rolandi sind nicht mit Sicherheit zu erkennen. An einigen Schnitten ist ventral-lateral von der Clarke'schen Säule eine Gruppe grösserer Zellen sichtbar.

Die vorderen Wurzeln sind dünn.

Im Vorderhorn umspinnt ein spärliches Geflecht von Markfasern die grossen Zellen an der Spitze und am lateralen Rand, seine Fasern

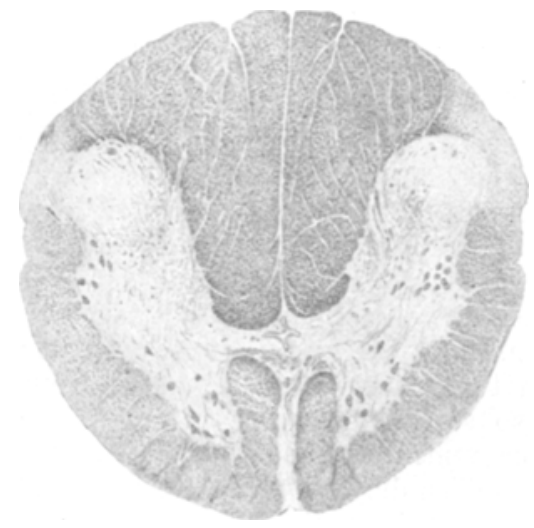

Fig. 1. Lendenmark. ${ }^{15} / 1$. setzen sich in die vordere Commissur fort. Aus dieser sieht man einzelne Fasern in die Vorderstränge eintreten. Das Markfasergeflecht der grauen Substanz wird weiter dorsalwärts und an lateralen Rande ganz dünn, so dass man im Bereiche der Vorderhörner und Seitenhörner nur dünne markhaltige Fäserchen ohne bestimmte Anordnung antrifft.

Die hintere Commissur ist an manchen Schnitten völlig marklos, in einzelnen Präparaten umkreisen eine oder zwei Fasern den ventralen Rand der Hinterstränge und ziehen gegen das Septum posticum.

Die Glarke'schen Säulen enthalten ein spärliches Geflecht von markhaltigen Fasern, verhältnissmässig zahlreiche quer geschnittene Längsfasern und einige Bündel dickerer Fasern, welche in die Hinterstränge eindringen. Lateral von den Clarke'schen Säulen liegt eine grössere Zahl von Längsfasern.

Die hinteren Wurzeln sind im medialen Theile gut ausgebildet, einige dicke Fasern strahlen aus ihnen bogenförmig in die Clarke'schen Säulen ein. Die Lissauer'sche Randzone enthält feine Längsfasern.

Der Centralkanal hat auf dem Querschnitte die Form eines unregelmässigen vierstrahligen Sterns.

Brustmark.

Sagittaler Durchmesser . . . . . . . . . $3,63 \mathrm{~mm}$

Frontaler Durchmesser . . . . . . . . . 3,75 "

Sagittale Ausdehnung der Hinterstränge . . . 2,65 "

Breite des Hinterstrangs an der Basis . . links 1,22 ",

$" \quad " \quad " \quad$ " . $\quad$ rechts 1,42 " 


$$
\begin{aligned}
& \text { Breite des Hinterstrangs an der Spitze } \\
& \text { Höhe der Vorderstränge . } \\
& \text { Breite des Vorderstrangs }
\end{aligned}
$$

Der äussere Contour ist leicht queroval. Im dorsalen Theil der Peripherie jederseits eine Einkerbung. In Bezug auf Quer- und Längsdurchmesser liegen sie symmetrisch, aber asymmetrisch zur Zeichnung des Schnittes. Rechts ist die Einkerbung seichter und breiter und liegt an der Grenze zwischen Seitenstrang und hinterer Wurzel, links ist sie beträchtlich tief, bis zu $0,75 \mathrm{~mm}$, einen schmalen Spalt darstellend, und liegt im unteren Brustmark ebenfalls an der Grenze zwischen Seitenstrang und hinterer Wurzel, lässt sich aber weiter aufwärts in das Innere der hinteren Wurzel verfolgen (s. Abbildung).

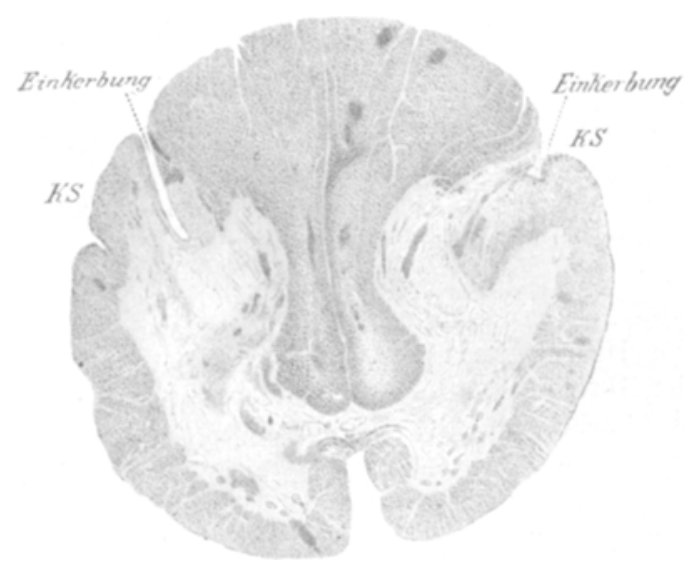

Fig. 2. Brustmark. ${ }^{15} / 1$.

KS Kleinhirnseitenstrangbahn. Die dunkeln Flecke sind Blutungen.

Den grössten Theil des Querschnitts nehmen auch hier die mächtigen Hinterstränge und die graue Substanz ein, die Vorderseitenstränge bilden einen nahezu gleich breiten Raum von $0,40 \mathrm{~mm}$.

Von der weissen Substanz sind die Hinterstränge am reichsten an Fasern and zwar besonders in ihrem ventralen Abschnitte und jenem Theil, welcher dem medianen Septum zunächst liegt. Im Gebiete des Vorderseitenstrangs stehen auch hier die Fasern im eigentlichen Vorderstrang, und zwar an seinem medialen Rande, am dichtesten und nehmen dorsalwärts immer mehr an Zahl und Grösse des Querschnitts ab. Am Rande der Seitenstränge findet sich im dorsalen Theil ein schmaler Streifen dickerer, dunkel gefärbter Fasern. Er begrenzt an der rechten Einkerbung ihren ventralen Rand. An seinem dorsalen Ende ist der Streifen verhältnissmässig am breitesten und verliert sich von da ventralwärts allmählich. Nach der Localisation, der Anordnung und dem Aussehen der Fasern handelt es sich offenbar um die sehr schwach ausgebildete Kleinhirnseitenstrangbahn. Der im Lendenmark vorhandene marklose Saum 
an der Peripherie ist hier auf $0,02 \mathrm{~mm}$ Breite reducirt, nur bei stärkerer Vergrösserung kenntlich, and umgrenzt die Kleinbirnseitenstrangbahn nach aussen. In ventraler Richtung zieht er noch ein wenig weiter als diese. Ein zusammenhängendes helles Feld von der Form und Lage der Pyra. midenseitenstrangbahn ist auch hier nicht sichtbar.

Die Zeichnung der grauen Substanz ist hier noch mehr als im Lendenmark verändert, indem der quere Schenkel des $H$ noch weiter ventralwärts verschoben ist. Die Mitte des Centralkanals liegt um $1 / 4$ des Sagittaldurchmessers vom ventralen Rande des Rückenmarks entfernt. Die Vorderhörner enthalten grosse Ganglienzellen, welche am ventralen und lateralen Rande eine zusammenhängende Gruppe bilden. Mittelzellen sind spärlich vorhanden. Das Seitenhorn enthält eine Gruppe von Ganglienzellen. Die Clarke'schen Säulen weisen zahlreiche kleinere Blutungen auf, doch sind ihre Ganglienzellen in einzelnen Schnitten deutlich nachweisbar.

Die vordere Commissur ist wie im Lendenmark ausgebildet, das Markfasergeflecht des Vorderhorns spärlich.

Die hintere Commissur enthält wenige zarte markhaltige Fasern. Im Seitenhorn und Hinterhorn sowie in den Clarke'schen Säulen findet sich ein zartes Netz markhaltiger Nervenfasern.

Der Querschnitt des Centralkanals bildet eine frontal gestellte Raute, das Lumen ist allenthalben mit Epithel ausgekleidet.

Halsmark.

Sagittaler Durchmesser . . . . . . . . 4,32 mm

Frontaler Durchmesser . . . . . . . . 4,36"

Sagittale Ausdehnung der Hinterstränge . links 2,97"

" " " . rechts 2,71 "

Breite der Hinterstränge an der Basis . . links 1,26"

Breite des Hinterstrangs an der Spitze. . rechts $1,26 "$

Sagittale Ausdehnung der Vorderstränge . . 1,10 "

Breite der Vorderstränge . . . . . . je 0,28 "

Der Querschnitt ist fast kreisrund, um Weniges grösser als der des. Brustmarks. Die Vergrösserung beruht, wie aus den Maassen hervorgeht, nahezu ausschliesslich auf der Zunabme der grauen Substanz. Insbesondere gilt das von der Vergrösserung des Querdurchmessers. Hinter- und Vorderstränge haben in sagittaler Richtung gegen das Brustmark zugenommen, dagegen sind die Hinterstränge schmäler geworden. Ventral vom Kopfe des Hinterhorns befindet sich beiderseits eine seichte Einsenkung der Oberfläche, entsprechend den hineinziehenden Gliasepten.

In der weissen Substanz sind wieder die Hinterstränge der am stärksten ausgebildete und faserreichste Theil. Sie sind durch Septa deutlich in Goll'sche Stränge und Burdach'sche Stränge geschieden. Am dichtesten und zugleich am stärksten im Kaliber sind die Fasern der Wurzeleintrittszone und des unmittelbar am medianen Septum gelegenen Theiles des Goll'schen Stranges in seiner ventralen Hälfte. Sehr dicht stehen kleinkalibrigeFasern im ventralen Hinterstrangsfelde. Die Vorderseitenstränge haben nahezu durchwegs eine Breite von $0,40 \mathrm{~mm}$. Nur an der Spitzo des Seitenhorns verschmälern sie sich auf $0,25 \mathrm{~mm}$. Was die Vertheilung der Fasern be- 
trifft, so bestehen hier dieselben Verhältnisse wie im Brust- und Lendenmark. Die ganze weisse Substanz enthält, wie auch stellenweise im Brustmark erkennbar, zahlreiche kleine streifen- oder fleckförmige Blutungen. Am peripheren Rande des dorsalen Antheils der Seitenstränge, insbesondere kenntlich im Bereiche der Einsenkung, liegt ein schmaler Saum von dicken, dunkel gefärbten, locker an einander gereihten Fasern: die spärlich ausgebildete Kleinhirnseitenstrangbahn. Ganz an der Peripherie des Schnittes liegt auch hier ein schmales Streifchen marklosen Gewebes, welches am ventralen Ende der Kleinhirnseitenstrangbahn beginnt und über

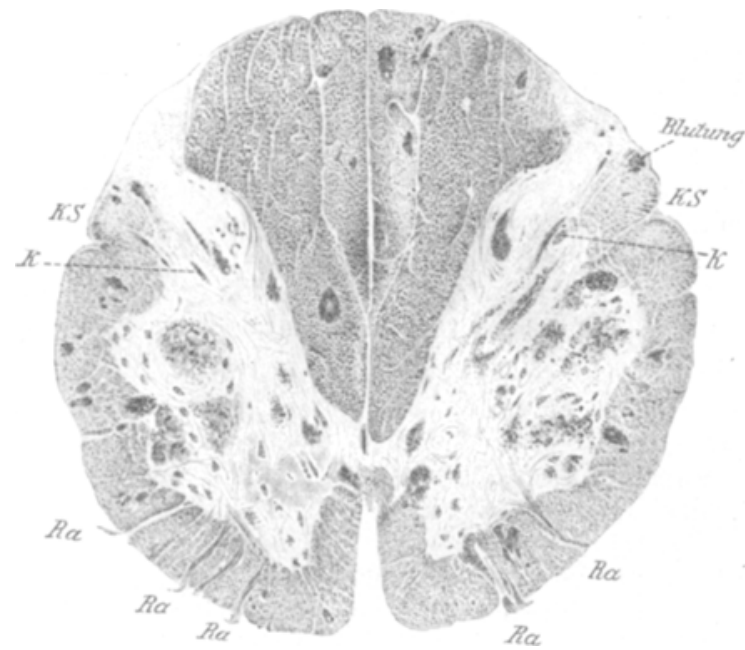

Fig. 3. Halsmark. $15 / 1$.

KS Kleinhirnseitenstrangbahn. $K$ Respirationsbündel von $\mathrm{K} \mathrm{rause;} \mathrm{die} \mathrm{unmittelbar} \mathrm{medial-}$ wärts davon gelegenen dunkeln streifenförmigen Flecke sind Blutungen. $R a$ vordere Wurzeln.

diese und die Lissauer'sche Randzone hinweg bis an den Hinterstrang reicht. Seine grösste Breite beträgt $0,04 \mathrm{~mm}$.

Der äussere Contour der grauen Substanz entbehrt zum grossen Theile der charakteristischen Gliederung, das Seitenhorn tritt wenig vor, der Processus reticularis fehlt nahezu gänzlich. Der Centralkanal ist etwas mehr dorsalwärts gerückt, seine Mitte theilt den sagittalen Durchmesser im Verhältnisse von 4:9, also gegen die Norm noch immer stark nach vorne verschoben. Dadurch ist der mediale Theil der grauen Substanz in sagittaler Richtung verzerrt und das Seitenhorn scheinbar in den Bereich des Hinterhorns gerückt.

Das Vorderhorn enthält eine kleine Gruppe von Ganglienzellen an seiner ventralen Spitze. Eine grössere Gruppe findet sich im Seitenhorn, vereinzelt sind auch sonst Ganglienzellen zerstreut. An der Basis des Hinterhorns liegt eine wohl abgegrenzte Gruppe von Ganglienzellen (Stilling'sche Zellen). In dem nur andeutungsweise vorhandenen Processus reticularis liegen spärliche kleine Ganglienzellen, ebensolche sind im Hinterhorn zerstreut. 
Die vordere Commissur enthält verhältnissmässig reichliche, sich in der Medianlinie kreuzende Fasern; ein starkes Bündel strahlt aus ihr ins Vorderhorn ein, ein ebensolches tritt aus ihr in den medialen Rand des Vorderstranges. An Stelle der hinteren Commissur finden sich, wie in den anderen Abschnitten des Rückenmarks, einzelne dünne markhaltige Fasern.

Das Markfasergeflecht der granen Substanz ist etwas reichlicher als in den caudaleren Theilen des Rückenmarks. Medialwärts rom rudimentären Processus reticularis liegt ein geschlossenes Bündel dicker Längsfasern von ovalem Querschnitt, die längere Axe mit der des Hinterhorns übereinstimmend - das Krause'sche Respirationsbündel. Den dickfaserigen medialen Theil der hinteren Wurzeln kann man in den Hinterstrang und das Hinterhorn verfolgen, einige laterale dünnere Fasern in die Lissauer'sche Randzone. In der grauen Substanz, insbesondere in den Hinterhörnern zahlreiche Blutungen.

Der Querschnitt des Centralkanals bildet ein sagittal gestelltes Oval, das Lumen enthält Blut.

Oberstes Halsmark.

Sagittaler Durchmesser

$4,05 \mathrm{~mm}$

Frontaler Durchmesser

4,36 ,

Der Umriss ist queroval. Der Centralkanal liegt ungefähr $1 / 5$ des Sagittaldurchmessers vom ventralen Rande entfernt. Sein Querschnitt bildet einen in sagittaler Richtung gestreckten Spalt, das dorsale Ende ist erweitert, das Lumen fast allenthalben mit schönem Epithei ausgekleidet.

Die Hinterstränge sind sehr breit, ihr ventraler Rand reicht über die Mitte des Schnittes hinaus. Der laterale Theil des Goll'schen Stranges ist blässer als der Burdach'sche Strang gefärbt. Am peripheren Rande des Burdach'schen Stranges liegt ein schmaler markloser Saum, welcher sich über die Lissauer'sche Randzone fortsetzt. Aus dem seitlichen Rande des Burdach'schen Stranges ziehen feine Fasern ventralwärts ins Hinterhorn. Sie lassen sich dorsalwärts geraden Verlaufs weit ins Innere des Burdach'schen Stranges verfolgen.

Der Vorderseitenstrang ist sehr faserarm. Die medialen Ränder der Vorderstränge sind $0,28 \mathrm{~mm}$ ron einander entfernt. Dieser Raum wird nur in seinem ventralen Drittel von dem breiten Sulcus longitudinalis anterior eingenommen, der übrige Theil ist von der vorderen Commissur erfullt. Nur ein ganz kleiner Antheil der Commissur reicht dorsal über die Vorderstränge hinaus. Der allergrösste Theil ihrer Fasern krenzt sich unter nahezu rechtem Winkel, nur vereinzelte ziehen quer über die Mittellinie. Auf jeder Seite entsendet die Commissur ein schräg dorsalwärts gerichtetes starkes Bündel, das fächerförmig ins Vorderhorn ausstrahlt. Ferner lassen sich aus der vorderen Commissur ventralwärts Fasern verfolgen, welche um den ventralen Rand der Vorderstränge einen sich nach aussen allmählich verschmälernden Saum bilden. Einige von den Fasern biegen am Rande des Vorderstrangs mit scharfer Krümmung dorsalwärts und dringen in den Vorderstrang ein. Die anderen scheinen, wie ans der Serie hervorgeht, weiter nasalwärts in die Längsrichtung umzubiegen und sich den Fasern des Vorderstranges anzuschliessen. 
Die vorderen Wurzeln des Cervicalnerven treten aus der grauen Substanz in frontaler Richtung aus und ziehen in flachem Bogen dorsalwärts gewendet durch die weisse Substanz, so dass ihre Austrittsstelle dorsal von der Spitze des Vorderhorns liegt.

Die Vordersträn ge bilden, wie im übrigen Rückenmark, einen nahezu gleich breiten Saum um das Vorderhorn, der hier 0,32 bis $0,36 \mathrm{~mm}$ misst. Der mediale Antheil des Vorderstranges enthält die dichteste Faseranordnung. An seinem ventralen Rande, etwa dort, wo die aus der vorderen Commissur hervorgegangenen ventralen Bogenfasern enden, ist der Vorderstrang faserärmer. Von dem hellen Felde der Pyramidenkreuzung, welches in dieser. Höhe beginnen müsste, ist nichts zu sehen.

Der Seitenstrang verbreitert sich dorsalwärts von der Austrittsstelle der vorderen Wurzel rasch bis auf $0,85 \mathrm{~mm}$. Zugleich nimmt die Zahl der Markfasern in ihm sehr stark ab. Am äusseren Rande liegt ein völlig markloser Saum, welcher an der Austrittsstelle der vorderen Wurzel mit einer ganz schmalen Spitze endet, an der Austrittsstelle der hinteren Wurzeln gleichfalls verschmälert in den Saum an der Peripherie der Lissauer'schen Randzone übergeht und ein wenig ventral von der Austrittsstelle der Accessoriusfasern seine grösste Breite von $0,12 \mathrm{~mm}$ erreicht. Hier begrenzen ihn nach innen zu die spärlichen dunkel gefärbten Faserquerschnitte des erhaltenen Restes der Kleinhirnseitenstrangbahn, die sich von da an ventral- und dorsalwärts allmählich verlieren.

Die Zeichnung der grauen Substanz weicht dadurch von der Norm ab, dass der Hals des Hinterhorns ganz breit ist. Die Vorderhörner enthalten grosse Ganglienzellen. Zwischen Centralkanal und ventralem Rand der Hinterstränge liegt ein breites markloses Gebiet, welches einzelne Ganglienzellen enthält. Unmittelbar vor den Hintersträngen finden sich einige zerstreute Längsfasern. Lateral von diesem Gebiete liegt beiderseits je ein grösseres und ein kleineres Längsbündel in der Basis des Hinterhorns, daneben zieht ein dunkel gefärbtes Faserbündel in der Schnittebene schief dorsalwärts durch den Seitenstrang zur Rückenmarksperipherie: Längsbündel und Wurzelfasern des Accessorius. Das Markfasergeflecht um die Zellen des Vorderhorns ist weniger dicht als in den caudaleren Ebenen des Halsmarks. In der Basis des Hinterhorns sind spärliche Längsfasern zerstreut.

In den folgenden Schnitten verbreitert sich die vordere Commissur in ventraler Richtung, so dass die Medianfurche fast gänzlich von ilır ausgefüllt wird. Zugleich werden ihre Fasern aber spärlicher. Die bogenförmig um den ventralen Rand der Vorderstränge verlaufenden Fasern verschwinden. An die Stelle der blassen feinfaserigen Lissauer'schen Randzone tritt ein Feld mit dunkleren, dichter stehenden Fasern, das sich dadurch als spinale Trigeminuswurzel bestimmen lässt. Von ihr ziehen zarte Fasern durch die Substantia gelatinosa zur Gegend des Hinterhorns. Ebensolche ziehen auch in geringer Anzahl aus dem Seitenstrange dahin. Die Fasern aus dem Burdach'schen Strange zum Hinterhorne haben zugenommen. Sie lassen sich im Burdach'schen Strange fast bis an den dorsalen Rand verfolgen. Lateral von ihnen zieht ein undeutlich begrenzter schmaler Streifen von feinen Längsfasern ungefähr von der Mitte des lateralen Randes des Burdach'schen Stranges bis zu den Längs- 
bündeIn des Accessorius, welche sich hier in mehrere zerspalten. Das Vorderhorn verliert seine charakteristische Gestalt.

Die nächsten Schnitte haben eine längsovale Gestalt. Es ändert sich hauptsächlich die Configuration des ventralen Theils. Die vordere Commissur wird immer faserärmer und beschränkt sich allmählich auf Kreuzungsfasern $z$ wischen den innersten Theilen des medialen Randes der Vorderstränge. Dafür ist hier der ganze Sulcus Iongitudinalis anterior von fast marklosem Gewebe ausgefüllt, welches den ventralen Rand der Vorderstränge noch etwas überragt und seitlich in den früher erwähnten markärmeren Theil am ventralen Rande der Vorderstränge übergeht. Dieses Gebiet ist breiter geworden, hat ungefähr ovale Gestalt, von $0,45 \mathrm{~mm}$ Länge und $0,24 \mathrm{~mm}$ Breite, und bildet $\mathrm{zwei}$ symmetrische flache Buckel am ventralen Rande. Die Vorderstränge sind flacher und breiter. Neben dem Centralkanal, der die Form einer langgestreckten Spalte annimmt, liegen Ganglienzellen von der Anordnung des Hypoglossuskernes. Das marklose Gebiet zwischen Centralkanal und Goll'schem Strange hat in sagittaler Richtung zugenommen. Der laterale Rand der Burdachschen Stränge endigt ventralwärts in eine Spitze. Die Längsbündel des Accessorius und die hinteren Wurzeln verschwinden.

Je weiter aufwärts in der Oblongata, desto zahlreicher werden fleckund streifenförmige Blutungen, welche im Folgenden nicht weiter beschrieben werden sollen.

\section{Beginn der Hinterstrangkerne.}

Sagittaler Durchmesser . . . . . . . . . $6,16 \mathrm{~mm}$

Frontaler Durchmesser . . . . . . . . . 5,42 ",

Die Gestalt des Schnittes ist längsoval. Der äussere Contour zeigt wenig Gliederung; der ventrale Rand verläuft fast geradlinig zwischen den Austrittsstellen der beiden Hypoglossi. Der Querschnitt des Centralkanals ist ein schmaler Spalt von 1,34 mm Länge und liegt ganz in der ventralen Hälfte des Medulla oblongata. Jer centrale Theil des Schnittes ist sehr arm an Markfasern.

Die Hinterstränge nehmen in der Sagittalrichtung etwa $1 / 3$ des Rückenmarksdurchmessers ein. Die Goll'schen Stränge sind in ihren medialen Antheilen in ungefähr $2 / 3$ ihrer Ausdehnung und bis an die Spitze hin faserärmer. In diesem unregelmässig begrenzten lichten Antheile finden sich vereinzelt grosse Zellen, die Ganglienzellen zu entsprechen scheinen. (Die mangelhafte Färbbarkeit ist der genauen Bestimmang sehr hinderlich.) Im linken Burdach'schen Strange liegt, unmittelbar an das Hinterhorn angrenzend, ein ovales helles Feld, das zahlreiche Ganglienzellen enthält. Um den Kern ziehen Fasern aus dem Burdach'schen Strange zum Hinterhorn. Der sonst dem Burdach'schen Kerne entsprechende rechte Kern tritt erst in den folgenden Schnitten auf; die Fibrae arcuatae externae posteriores fehlen gänzlich.

Die vordere Commissur besteht aus spärlichen Fasern, welche sich im dorsalen Theile des $Z$ wischenraumes zwischen den medialen Rändern der Vorderstränge kreuzen. Die längsverlaufenden Fasern der Vorderstränge und Seitenstränge sind in bogenförmig um den Centralkanal verlaufende Schichten geordnet, welche mit marklosen Schichten abwechseln. Die normalerweise zwischen ihnen verlaufenden B ogenfasern 
fehlen. Der Seitenstrang ist sehr arm an Fasern. Der Centralkanal reicht mit seiner ventralen Spitze bis hart an die vordere Commissur. Von dem charakteristischen Felde der Schleifenkreuzung ist nichts zu sehen.

Die Faserbündel des Hypoglossus durchsetzen schief getroffen den Vorderseitenstrang. Ihr intramedullärer Verlauf ist äusserst kurz. Das marklose Feld am ventralen Rande der Vorderstränge ist kleiner geworden.

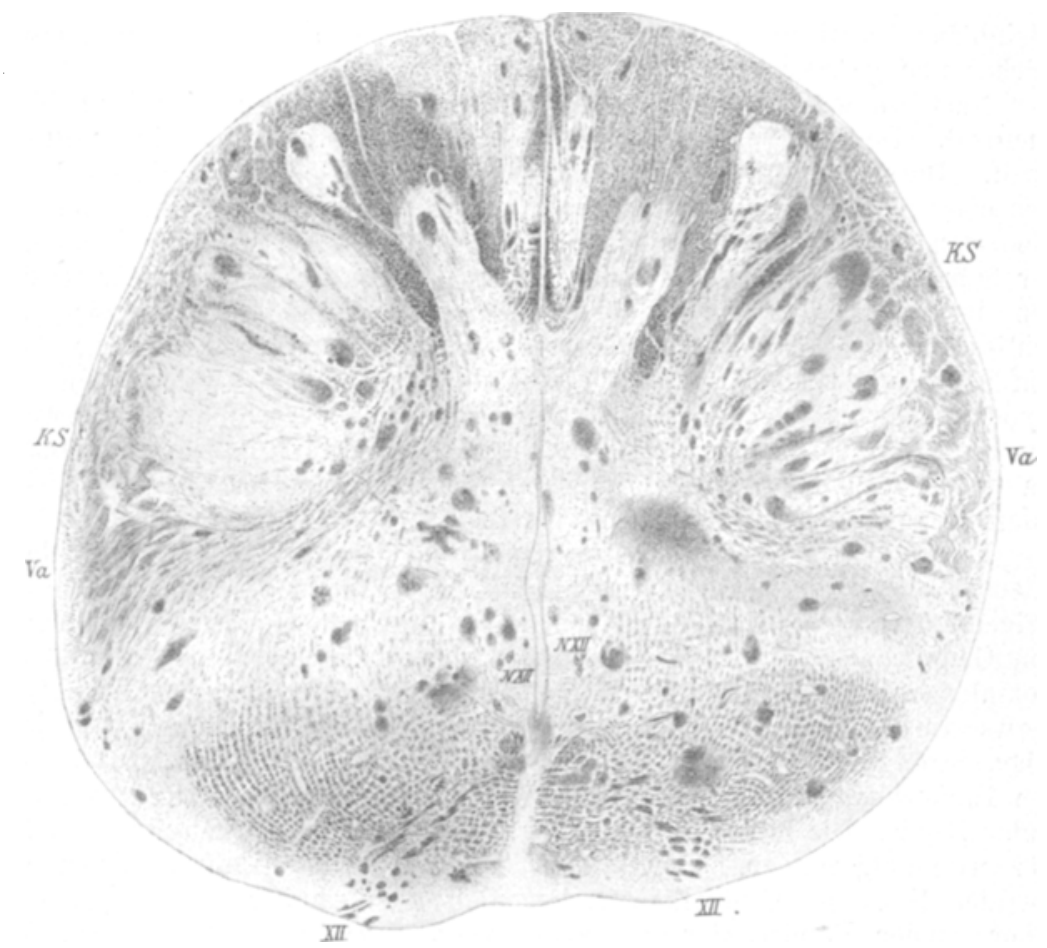

Fig. 4. Schnitt durch die Hinterstrangkerne. $15 / 1$.

KS Kleinhirnseitenstrangbahn. $\nabla a$ spinale Trigeminuswurzel. XII Hypoglossus. NXII Hypoglossiskern. Zablreiche Blutungen.

Die spinale Trigeminuswurzel nimmt ein verhältnissmässig grosses Gebiet der Peripherie ein. An ihrem äusseren Rande zieht, wie in den caudaleren Ebenen, ein markloser Saum von der Kleinhirnseitenstrangbahn zum Burdach'schen Strang.

Die Hypoglossuskerne liegen zu beiden Seiten des spaltförmigen Centralkanals, und zwar seiner ventralen Hälfte. In der dorsalen Hälfte dieses Gebietes liegen einige wenige Ganglienzellen. Der Hypoglossuskern enthält ein spärliches Geflecht von Markfasern. Vollständig fehlen die Fibrae arcuatae internae um den Kern. Die Fasern, welche aus den Burdach'schen Strängen zum Hinterhoru ziehen, verlieren sich daselbst and lassen sich rentral von der spinalen Trigeminuswurzel nicht mehr verfolgen. 
In den folgenden Schnitten wird das helle Gebiet im Gollschen Strang grösser, auch tritt im Burdach'schen Strang ein helles Feld von der Lage und Form des Monakow'schen Kernes auf. Die Ganglienzellengruppe dorsal vom Hypoglossuskern wird stellenweise grösser. Die Kleinhirnseitenstrangbahn rückt dorsalwärts, an den Rand der spinalen Trigeminuswurzel. Auch hier liegt an der. Peripherie zunächst ein schmaler markloser Saum, dann die spärlichen dunkelgefärbten Fasern der Kleinhirnseitenstrangbahn. Die spinale Trigeminuswurzel wird faserreicher und grösser.

Nach aufwärts von den Monakow'schen Kernen wird der Schnitt queroval. Der Centralkanal ist noch allseits geschlossen, ein sagittaler Spalt. Dorsal von dem Querschnitt der Medulla oblongata liegen $3 \mathrm{Ge}$ websmassen, welche mit der Medulla nicht zusammenhängen und von gesonderten Häuten umhüllt sind. Sie erweisen sich bei weiterer Verfolgung der Schnittreihe als Rudimente des Kleinhirns. Das Gebiet zwischen den intramedullären Hypoglossuswurzeln besteht so gut wie ausschliesslich aus Längsfasern und hebt sich durch dunklere Färbung stark von der angrenzenden Substantia reticularis grisea ab, welche von den Hypoglossuswurzeln bis zur spinalen Trigeminuswurzel, beziehungsweise den mit ihr verbundenen Feldern reicht. Vereinzelte bogenförmige Fasern ziehen durch die sonst leeren Bogenfurchen der Substantia reticularis, namentlich im ventralen Theil.

Ein der Olive entsprechendes Gebiet ist nicht vorbanden. Im lateralen Theil der Substantia reticularis grisea, in der Nähe der spinalen Trigeminuswurzel, liegt gegen den Rand des Schnittes zu eine Gruppe von Ganglienzellen, welche den Seitenstrangkernen angehören dürfte. Dorsal davon findet sich eine Gruppe grösserer Ganglienzellen, der $\mathrm{Nu}$ cleus ambiguus. An der ganzen Peripherie, mit Ausnahme der Gollschen Stränge, liegt ein zusammenhängender markloser Saum, welcher an den Einkerbungen tiefer ins Innere reicht. Am breitesten ist er am ventralen Rande. Die Kleinhirnseitenstrangbahn ist im Burdach'schen Strange aufgegangen. Ventral ron den Goll'schen Strängen, neben dem dorsalen Ende des Centralkanals, liegen die Querschnitte zweier symmetrischer runder Bündel, der spinalen Glossopharyngeuswurzeln. Fibrae arcuatae externae anteriores sind nicht vorhanden, ebensowenig die posteriores.

Auf den folgenden Schnitten schiebt sich von der Gegend des Centralkanals her ein markloses Gebiet zwischen die beiden Goll'schen Stränge ein. Im ventralen Theil des Vorderstranggebietes sind etwas mehr Querfasern vorhanden, auch eine Andeutung einer Raphe sichtbar. Das marklose Feld zwischen den Goll'schen Strängen verbreitert sich rasch.

Die Gewebsmassen dorsal von der Medulla oblongata vereinigen sich zu einem einheitlichen Gebilde, welches in seiner rechten Hälfte einen Hohlraum enthält.

\section{Beginn des Corpus restiforme.}

Der Schnitt ist queroval. Der Kleinhirnrest liegt der Medulla oblongata dorsal wie eine Kuppe an, die beiderseitigen Meningen scheinen sich zu berühren. Der Centralkanal bildet einen sagittalen Spalt ron 
2,45 mm Länge, der etwas dorsalwärts von der Mitte eine rautenförmige Erweiterung besitzt.

Von markfaserhaltigen Gebilden treten deutlich hervor: am dorsalen Rande die Corpora restiformia, am lateralen die spinale Trigeminuswurzel, ventral vom Corpus restiforme die spinaleGlossopharyngeuswarzel, ventral vom Centralkanal die Substantia reticularis alba mit den Hypoglossuswurzeln and daneben die sehr faserarme Substantia reticularis grisea. Alles Uebrige ist fast marklos.

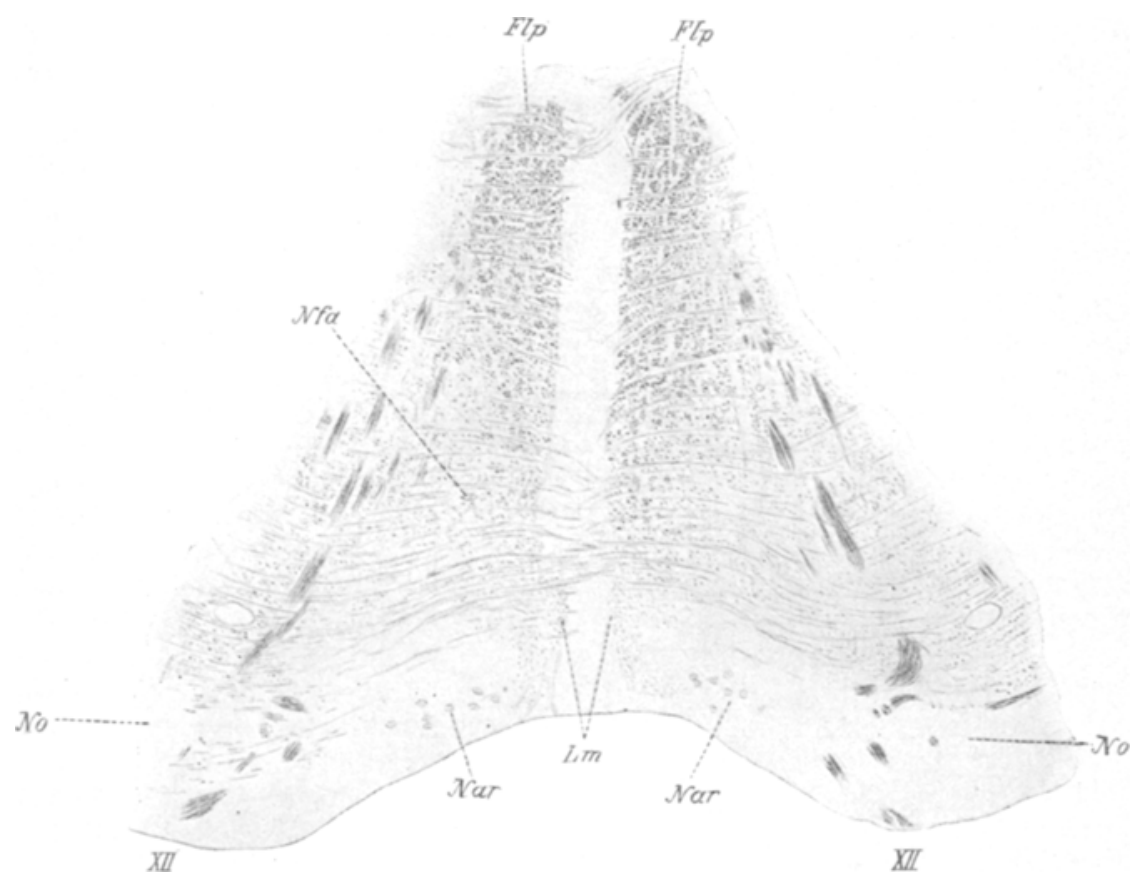

Fig. 5. Die Substantia reticularis alba am caudalen Theil des Corpus restiforme. $4 \% / 1$.

Flp Faseicalus longitudinalis posterior. Nfa Ganglienzellen des Vorderstranglzerns. No Gliafeld, der Olive entsprechend. Lm Olivenzwischenschicht (Schleifenantheil). XII Hypoglossus. Nor Nucleus areuatus.

Die Corpora restiformia sind am dunkelsten gefärbt, jedoch faserarm, stark zerklüftet, ihr medialer Antheil enthält ein Feld, welches dem oberen Ende des Goll'schen Kernes entspricht. Die Substantia gelatinosa der spinalen Trigeminuswurzel ist in ihrer ventralen Hälfte in ein grosses and mehrere kleinere, an den verschiedenen Schnitten ihre Gestalt wechselnde und theilweise zusammenfliessende Felder getheilt, welche von locker aneinander gereihten Längsbündeln umgrenzt sind.

Die Substantia reticularis alba zeigt drei in sagittaler Richtung auf einander folgende Schichten. Den dorsalsten Theil bildet ein dunkel gefärbtes Fasergebiet, welches die typische keulenförmige Gestalt des 
hinteren Längsbündels hat. (In dem abgebildeten Schnitte insbesondere rechts - im Bilde links - deutlich.) Seine ventrale Spitze verliert sich ohne deutliche Abgrenzung am medialen Rande. Ventral vom hinteren Längsbündel und zugleich lateral von dessen ventraler Spitze liegt ein an Längsfasern ärmeres Feld, in welchem vereinzelte grosse Ganglienzellen zu finden sind, die wohl dem Vorderstrangkern angehören. In diesem Theile, dessen sagittale Ausdehnung ungefähr die Hälfte von der des hinteren Längsbündels beträgt, sind auch quer verlaufende dünne Bogenfasern vorhanden, spärlich in seinem dorsalen Abschnitte, dichter im ventralen. Ventral von diesen Bogenfasern liegt ein Bündel sehr spärlicher dünner Längsfasern (Olivenzwischenschicht, Rudiment der Schleife). In dem Winkel zwischen diesem Längsfaserbündel und den Hypoglossuswurzeln, ganz nahe am ventralen Rande des Schnittes, befindet sich eine sehr deutliche, wohl begrenzte Gruppe von Ganglienzellen, wahrscheinlich der Nucleus arcuatus.

Die Stelle der Raphe nimmt ein fast durchweg markloses, $0,12 \mathrm{~mm}$ breites Feld ein. Nur die erwähnten Bogenfasern bilden eine Art kümmerlicher Raphe im unteren Drittel.

In die Substantia reticularis grisea lassen sich die Bogenfasern nur eine kurze Strecke weit verfolgen. Am ventralen Rande der Substantia reticularis grisea liegt ein schmales markloses Feld, welches sich mit leicht bogenförmiger Krümmung von den Hypoglossuswurzeln bis etwa zur Mitte des Abstandes dieser Wurzeln von der spinalen Trigeminuswurzel erstreckt. Von dem marklosen Rande des Schnittes ist es durch ein ganz dünnes Säumchen zerstreut stehender Längsfasern getrennt und durch solche Fasern in manchen Schnitten etwas gefeldert. Ganglienzellen sind darin nicht auffindbar.

Weiter lateral von dem eben beschriebenen marklosen Felde liegt in der Substantia grisea, gegen den ventralen Rand des Schnittes zu, die den Seitenstrangkernen angehörige Ganglienzellengruppe. Dorsal und zugleich etwas lateral davon, nahe der Substantia gelatinosa der spinalen Trigeminuswurzel, befindet sich eine Gruppe von grossen Ganglienzellen, von einigen markhaltigen Fasern durchzogen - der Nucleus ambigu us. Der Hypoglossuskern ist stärker entwickelt, in sagittaler Richtung gestreckt. Die dorsal von ihm gelegene Zellgruppe ist wenig deutlich. Von der spinalen Glossopharyngeuswurzel ziehen Fasern in frontaler Richtung gegen den dorsalen Theil der spinalen Trigeminuswurzel.

In den folgenden Schnitten weichen die Corpora restiformia immer mehr auseinander. Der Centralkanal bleibt geschlossen. Das Kleinhirn nähert sich mehr and mehr der Oblongata. Die spinale Trigeminuswurzel wird von den austretenden Bündeln des Vagus durchsetzt.

Weiter aufwärts zeigt sich eine Zunahme der Bogenfasern im ventralen Antheile der Substantia reticularis alba. Auch treten vereinzelte Fibrae arcuatae internae auf, welche vom Corpus restiforme an dem dorsalen Rande der spinalen Glossopharyngeuswurzel vorbei gegen das hintere Längsbündel ziehen. Die meisten gehen dann dorsal vom hinteren Längsbündel zur Mittellinie, einige durchbrechen das genannte Bündel. Die Faserung der Raphe ist reichlicher. Der Centralkanal theilt sich dorsalwärts gabelig. Dorsal davon finden sich noch ganz kleine spalt- 
Ueb. einen Hemicephalus, mitBeitr. z. Phys. d. menschl. Centralnervensyst. 233

förmige, von Epithel ausgekleidete, Hohlräume. Zu beiden Seiten derselben wird die schon früher $a b$ und zu stärker ausgebildete Zellgruppe dorsal vom Hypoglossuskern nun deutlich zum sensiblen Vaguskern.

Die Kle in hirn m a ss e vereinigt sich zunächst in ihrem rechten, dann auch in ihrem linken Theil mit dem Gewebe dorsal vom Centralkanal. Gleichzeitig rückt der in ihr befindliche Hohlraum immer mehr in die Medianlinie und an den dorsalen Rand, so dass ihn hier nur eine dünne Gewebsschicht von den Meningen scheidet. In dieser Höhe verschwinden die Hypoglossuswurzeln.

\section{Austritt des Glossopharyngeus.}

Medulla oblongata und Kleinhirn sind mit einander vollständig vereinigt und in gemeinsame Meningen gehüllt. Die Verwachsungsstelle, die Grenze zwischen Corpus restiforme und Kleinhirnrudiment, ist jederseits durch ein grösseres Gefäss gekennzeichnet. Die Kleinhirn masse enthält einen grossen Hohlraum von annähernd dreieckigem Querschnitt, dessen Basis am dorsalen Rande liegt. Seine Spitze ist ventralwärts gerichtet und liegt nahezu in der Medianlinie, so dass der Hohlraum nach Gestalt und Lage an den normalen vierten Ventrikel erinnert. Die dorsale Decke des Hohlraums ist dünn und verliert sich rechts oben ganz. Hier wird der Hohlraum nur durch die Pia mater abgeschlossen. In seinem Innern liegen nahe der linken dorsalen Ecke einige Durchschnitte von Plexusschlingen.

An Stelle des Centralkanals finden sich mehrere von Epithel ausgekleidete grössere und kleinere Spalträume.

Das Corpus restiforme liegt am lateralen Rande. Es ist sehr klein, seine Fasern dunkel gefärbt. Die spinale Trigeminuswurzel liegt theils am lateralen, theils am ventralen Rande und ist stark entwickelt. Etwas dorsalwärts von ihrer Mitte durchsetzt sie ein starkes Bündel von Glossopharyngeusfasern, das auf der rechten Seite des Schnittes in unmittelbarem Zusammenhang mit der spinalen Glossopharyngeuswurzel steht. Diese bildet hier ein relativ mächtiges Gebilde, an Faserzahl ungefähr dem Corpus restiforme gleich. Der Rollersche Glossopharyngeuskern ist als rundliche Masse zu erkennen. Ventral vom Glossopharyngeus bricht der Vagus durch die spinale Trigeminuswurzel. Seine Fasern ziehen im Bogen zu dem grosse Ganglienzellen enthaltenden $\mathrm{Nucleus}$ ambiguus. Ventral davon liegt in der Substantia reticularis eine kleine Gruppe von Ganglienzellen (Seitenstrangkern). Der Hypoglossuskern ist noch getroffen. Lateral davon liegt jetzt der sehr grosse sensible Vaguskern, seine dorsale Spitze reicht hoch hinauf. Das hintere Längsbündel ist sehr deutlich. Im Uebrigen ist die Substantia reticularis sehr faserarm. Lateral und ventral vom hinteren Längsbündel sind zahlreiche Ganglienzellen eingeffochten, welche dem $\mathrm{Nu}$ cleus centralis inferior entsprechen. Er geht caudalwärts ohne bestimmte Grenze in den Vorderstrangkern über. Das Feld der Schleife misst in sagittaler Richtung ungefähr ein Viertel von der Ausdehnung des hinteren Längsbündels und ist sehr arm an Markfasern. Die Bogenfasern sind wieder geringer an Zahl, eine Raphe ist nur zwischen den dorsalen Dritteln des hinteren Längsbündels vorhanden. Das schmale marklose Feld am ventralen Rande der Substantia reticularis grisea ist 
noch schmäler geworden und mehr dorsalwärts gerückt, so dass es von dem Rande des Schnittes durch ein nahezu ebenso breites Markgebiet getrennt ist.

In den folgenden Schnitten erscheint der dreieckige Hohlraum im Kleinhirn immer grösser. Sein dorsaler Abschluss wird nur von den Meningen gebildet. Die Plexusschlingen in seinem Innern nehmen zu und treten mit den dorsalen Meningen in Verbindung. Man hat jetzt das Bild der Rautengrube.

Weiter aufwärts öffnet sich die Rautengrube immer weiter stumpfwinklig. Thre seitliche Begrenzung bildet überhängende Wülste, Ihr Boden trägt cubisches Epithel. Der Nervus intermedius Wrisbergi bricht in diesen Schnitten als mächtiges Faserbündel theils durch den dorsalen Theil der spinalen Trigeminuswurzel, theils zwischen dieser und dem Corpus restiforme nach aussen. Lateral vom Hypoglossuskern tritt ein aus zahlreichen Ganglienzellen bestehender Kern auf, der nach Form und Lage als dreieckiger Acusticuskern angesprochen werden kann. Aus den spärlichen Bogenfasern, welche dorsal vom hinteren Längsbündel und durch dasselbe zur Raphe ziehen, lösen sich einige am medialen Winkel des dreieckigen Acusticuskernes $a b$ und ziehen dorsal von ihm gegen das Corpus restiforme zu. Medial vom Corpus restiforme sind einige Längsfaserbündel und die reticuläre Substanz der spinalen Acusticuswurzel erkennbar. Der Nucleus ambiguus wird kleiner, die dem Seitenstrangkern entsprechenden Ganglienzellen bilden keine umschriebene Gruppe mehr. Doch sind in dem an die spinale Trigeminuswurzel anstossenden Theile der Substantia reticularis grisea vereinzelte Ganglienzellen anzutreffen. Der Nucleus centralis inferior wird sehr gross. Ventral von ihm sind nur wenige Markfasern, dagegen enthält die Substantia reticularis lateral davon ein umschriebenes dunkel gefärbtes Gebiet: die Schleife ist hier wahrscheinlich bereits lateralwärts verschoben.

\section{Beginn des Facialiskernes.}

Zu beiden Seiten der Rautengrube liegen die verhältnissmässig stark entwickelten Kleinhirnreste, welche medianwärts etwas convergiren. Die Decke des Ventrikels wird von den weichen Hirnhäuten gebildet, von welchen reichliche Plexusschlingen in den Hohlraum hineinragen.

An der freien Peripherie der beschriebenen, dem Kleinhirn entsprechenden Bildungen finden sich reichlich kurze, nach Weigert-Pal schwarz gefärbte, senkrecht zur Oberfläche gestellte, scharf begrenzte Fäserchen und $z$ wischen ihnen reichlich Ganglienzellen, die in ihrer Form sehr häufig den Purkinje'schen Zellen gleichen. An dem der Rautengrube zugewendeten Rand dieser Kleinhirnanlage sind die erwähnten Fasern und Ganglienzellen nicht auffindbar, die Rautengrube selbst ist allenthalben von ziemlich hohem Epithel ausgekleidet, welches der Bedeckung der Plexusschlingen gleicht.

Ein wenig ventralwärts vom Boden der Rautengrube und mit ihm parallel dringt beiderseits ein grosses Gefäss in frontaler Richtung vom lateralen Rande her tief gegen die Mitte ein. Diese Gefässe bezeichnen ungefähr die Grenze der Medulla oblongata gegen das Kleinhirn- 
Ueb. einen Hemicephalus, mit Beitr. z. Phys. d. menschl. Centralnervensyst. 235

rudiment, Das Gewebe dorsal von ihnen enthält stellenweise dicht gedrängte Gliazellen, namentlich an den lateralen Ecken des vierten Ventrikels, ferner einzelne Fasern mit Markscheidenfärbung, bei welchen aber meist das starre Aussehen und der geschwungene Verlauf eher an Gliafasern als an Nervenfasern erinnern. Nahe unter dem Boden des Ventrikels und ungefähr parallel mit ihm angeordnet, befindet sich ein System von Hohlräumen, welche den Verlauf des Centralkanals fortsetzen. Die medialen liegen ungefähr in einer Flucht mit den erwähnten grossen Gefässen, die lateralen liegen dorsal von diesen, die äussersten liegen an der Basis der Kleinhirnrudimente, lateralwärts von der Rautengrube.

In der Medulla oblongata ist der sichelförmige Querschnitt der spinalen Trigeminuswurzel das grösste und faserreichste Gebilde. Er liegt zunächst dem ventralen und lateralen Rande. Dorsal davon liegt der Rest des Corpus restiforme und die stark ausgebildete spinale Acusticuswurzel. Auf der rechten Seite tritt der Nervus intermedius Wrisbergi dorsal von der spinalen Trigeminuswurzel aus. Die Substantia gelatinosa der Quintuswurzel umsäumen lockere Längsfaserbündel. Medial davon liegt der ausgedehnte unb zellreiche Facialiskern, namentlich links deutlich. Einzelne Fasern ziehen durch ihn dorsalwärts. Der Nucleus centralis inferior liegt ventral unmittelbar unter der oberfläche. Er enthält sehr zahlreiche Ganglienzellen. Innerhalb des Kernes liegen einige spärliche Nervenfasern, ventralwärts gegen den Rand des Schnittes zu vereinzelt dickere bogenförmig verla ufende Fasern. Lateral von diesem Kernlager, nahe dem ventralen Rande des Medulla, zugleich ein wenig medial vom Facialiskern liegt eine deutlich abgegrenzte Gruppe kleinerer Ganglienzellen - die obere Olive, wie aus der Verfolgung der Serie mit Sicherheit hervorgeht. Die Bogenfasern am ventralen Rande der Oblongata lassen sich auf jeder Seite bis in die obere Olive verfolgen und kreuzen sich in der Mitte, woran man sie als Beginn des Corpus trapezoides erkennen kann.

Medial von der spinalen Acusticuswurzel liegt der nasale Theil des früher als dreieckigen Acusticuskernes bezeichneten Gebildes, das somit hier nicht an die Medianlinie herangerückt ist. Eine Raphe ist nur im Bereiche des hinteren Längsbündels und andeutungsweise im Corpus trapezoides vorhanden, im Uebrigen enthält die Medianlinie sagittal gerichtete Fasern, von denen einzelne Markscheidenfärbung annehmen. Der Hypoglossuskern ist nicht mehr getroffen. Am dorsalen Rande des hinteren Längsbündels, und zwar gegen das laterale Eck ist ein kleiner Kern eingelagert. Einzelne Ganglienzellen sind ins hintere Längsbündel eingestreut und zwar stets mit den Bogenfasern.

Die Faserung der Substantia reticularis ist im Allgemeinen gering. Die Längsfasern sind in den medialen Theilen etwas dichter, in den lateralen Theilen überaus spärlich. Die Bogenfasern sind vorwiegend auf den dorsalen Theil des Haubenfeldes beschränkt, die dorsoventralen Fasern hauptsächlich auf das Gebiet medial vom Facialiskern. Sehr zahlreiche Ganglienzellen sind überall eingestreut.

In den folgenden Schnitten wird das Kleinhirn in mehrere Theile zerklüftet, Der Kernschenkel des Facialis wird deutlicher, de ${ }^{\circ}$ Abducenskern tritt auf und zwar sehr zellenreich. Der Stiel der oberen Olive fehlt völlig. Das Corpus trapezoides wächst an. Ventral von 
ihm liegt ein markloser Saum, der immer mehr an Breite zunimmt: das Rudiment des Pons. Medial und ventral von der oberen Olive liegt innerhalb des Corpus trapezoides ein kleines helles Feld, welches nach seiner Lage dem Trapezkerne entspricht. Lateral von der spinalen Trigemiñuswurzel zieht zum Kleinhirn ein breiter markloser Saum. Die Wurzeln des Abducens lassen sich deutlich verfolgen. Der Deiters'sche Kern wird dnrch seine Lage und einzelne grosse Zellen erkennbar. Das Corpus restiforme ist verschwunden.

Die marklose Peripherie des Schnittes ist, wie man an Carminpräparaten sieht, sehr zellreich. Die Zellen haben einen grossen Kern und oft auch ein breites Protoplasma, an welchem Fortsätze erkennbar sind. Einzelne der Zellen, und zwar hauptsächlich im dorsalen Theil, entsprechen vollständig Ganglienzellen.

In den weiteren Schnitten sind vom Kleinhirn nur noch zwei kleine Fortsätze des lateralen Randes der Oblongata getroffen. Die kleinen Hohlräume, welche den Centralkanal hier fortsetzen, fliessen stellenweise zu grösseren zusammen und communiciren mehrfach mit dem Ventrikel. Der Austritt der Facialiswurzeln ist deutlich, ferner der Eintritt des Acusticus und der accessorische Acusticuskern. Medial-ventral von der oberen Olive wird die mediale Schleife als stärkere Anhäufung von Längsbündeln erkennbar.

\section{Eintritt des Acusticus, Knie des Facialis.}

Der Querschnitt ist ungefähr halbmondförmig, mit dorsalwärts gerichteter Concavität. Die Breite beträgt $11,83 \mathrm{~mm}$, der Sagittaldurchmesser $4,08 \mathrm{~mm}$. Der dorsale Rand hat in der Mitte eine Concavität, daneben zwei flache Erhabenheiten, entsprechend den grosszelligen Acusticuskernen. Lateral davon findet sich an der früher vom Kleinhirnrest eingenommenen Stelle ein nach Weigert-Pal ungefärbt gebliebenes Gewebe, in dem nur an einer Stelle eine Gruppe markhaltiger Fasern erkennbar ist (im Bilde auf der linken Seite deutlich).

Der ventrale Theil des Querschnitts wird von einem marklosen Felde eingenommen, welches in der Mitte am breitesten ist $-1,02 \mathrm{~mm}$ - und sich an den Seiten stark verschmälert: Ponsrudiment.

Das Corpus trapezoides ist sehr gut entwickelt und dunkel gefärbt. Rechts durchsetzt sein lateraler Antheil, in mehrere Bündel gespalten, die ganze spinale Trigeminuswurzel and strahlt in den accessorischen Acusticuskern ein; auf der linken Seite durchsetzen die Trapezbündel nur den ventralen Theil der spinalen Trigeminuswurzel und kreuzen dann die Fasern der Wurzel des Vestibularis. Am medialen Rande der spinalen Trigeminuswurzel findet sich jederseits eine Durchkreuzung der Trapezfasern. Die oberen Oliven, welche Blutungen enthalten, werden theils von den Trapezfasern durchzogen, theils verlieren sich die Fasern daselbst. Ventral von der Hauptmasse des Trapezkörpers, medial-ventral von der oberen Olive, ist der quergestellte linsenförmige Querschnitt der Schleife erkennbar. Er wird von einigen Bündeln des Corpus trapezoides durchzogen. Andere Bündel treten am medialen Rande in die Schleife ein und verlieren sich anscheinend darin. Die Kreuzung der Trapezfasern in der Raphe ist deutlich ausgebildet. 
Ueb. einen Hemicephalus, mit Beitr. z. Phys. d. menschl.Centralnervensyst. 237
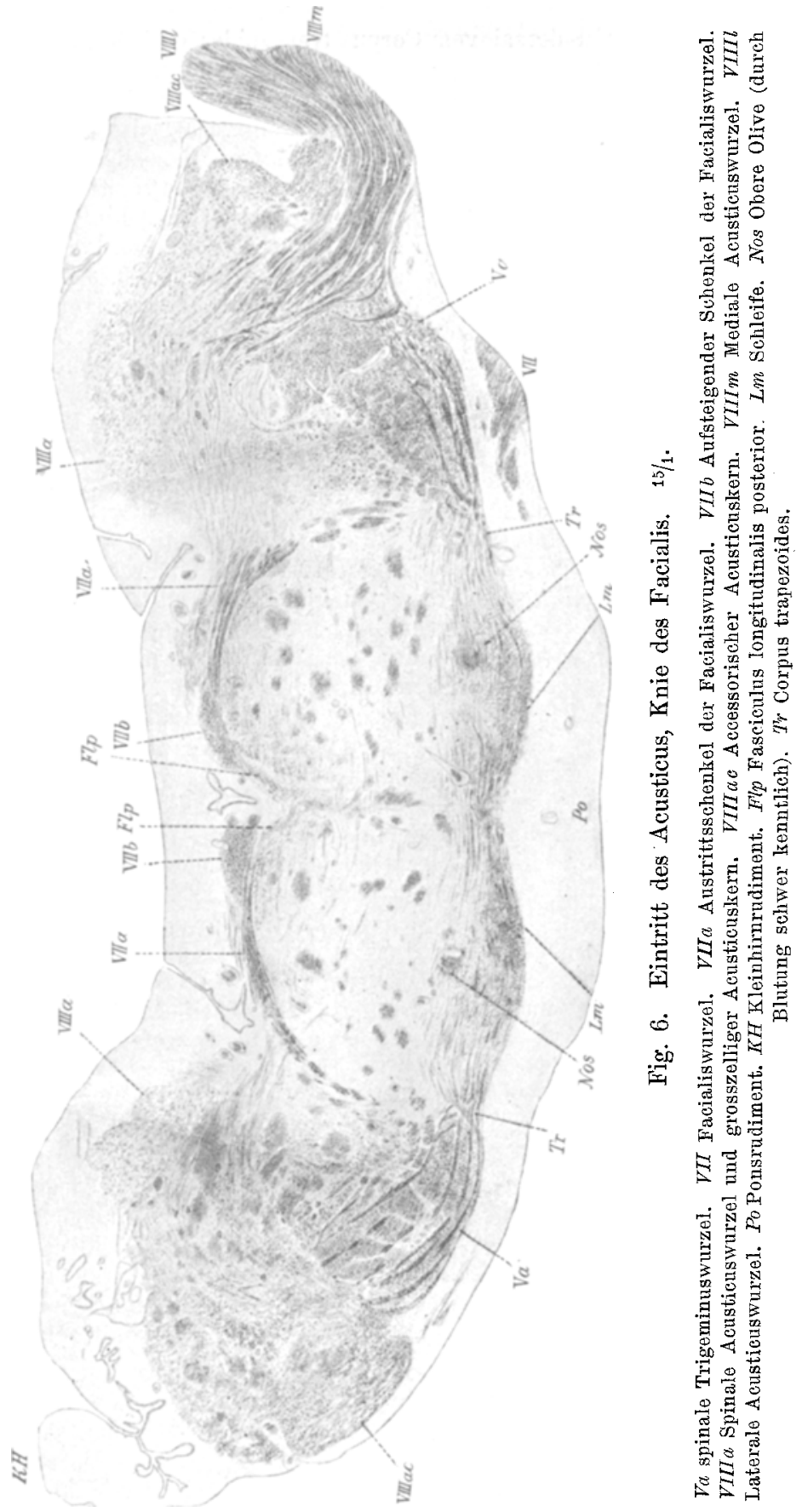
Das Haubenfeld dorsal vom Corpus trapezoides enthält wenig Längsfasern, dagegen zahlreiche Ganglienzellen (Nucleus reticularis tegmenti). Der laterale Theil des Haubenfeldes ist insbesondere äusserst faserarm. Das hintere Längsbündel nimmt ein verhältnissmässig kleines Gebiet ein. Auch zwischen seine Fasern sind Ganglienzellen eingestreut. Es wird ausserdem von verhältnissmässig zahlreichen Bogenfasern durchsetzt, welche sich in der Raphe kreuzen. Dorsal vom hinteren Längsbündel zieht ein Bündel feiner Fasern zur Raphe, von welchen sich einige bis in den Austrittsschenkel des Facialis verfoIgen lassen. Dorsallateral vom hinteren Längsbündel liegt der dicke $Q u e r s c h n i t$ des aufsteigenden Schenkels des Facialis und von hier zieht der faserreiche Austrittsschenkel dieses Nerven im Bogen ventralwärts. Der Abducenskern ist nicht mehr getroffen.

Lateral davon liegt die spinale Trigeminuswurzel. Ihre Längsausdehnung hat abgenommen, ihre Breite zugenommen. Die Substantia gelatinosa enthält ein dichtes Netz feiner Markfasern und im dorsalen Theile ein rundliches Feld, das jederseits von einer Blutung eingenommen ist. Einzelne Ganglienzellen sind in der Substantia gelatinosa nachweisbar.

Dorsal von der spinalen Trigeminuswurzel liegt ein Acusticuskern, der im ventralen Theile sehr grosse Ganglienzellen enthält und dadurch als der Deiters'sche Kern gekennzeichnet ist. Von hier ziehen feine Fasern in breitem Zuge, die Substantia gelatinosa der spinalen Trigeminuswurzel umgreifend, gegen die Mitte. Einzelne davon lassen sich quer durch den Austrittsschenkel des Facialis in das Haubenfeld and hier eine Strecke weit als Bogenfasern verfolgen, andere schliessen sich anscheinend den Fasern des Austrittsschenkels an.

Lateral von der spinalen Trigeminuswurzel und dem grosszelligen Kern liegt rechts der sehr ausgedehnte, ein dichtes Markfasernetz und sehr zahlreiche kleine Ganglienzellen enthaltende accessorische Acusticuskern.

Auf der linken Seite befindet sich lateral von der spinalen Trigeminuswurzel der breite Wurzelfächer des Acusticus. Die beiden Wurzeln sind deutlich zu unterscheiden. Die mediale Wurzel strahlt in das dorsale Kerngebiet ein uud zwar zum grössten Theil in die Gegend der grossen Zellen und ein wenig lateral davon. Die laterale Acusticuswurzel, die dünnere und mehr varicöse Fasern enthält, setzt sich in den accessorischen Acusticuskern fort, der lateral dem Wurzelfächer anliegt.

Die Fortsetzung des Centralkanals besteht aus mehreren Systemen von Hohlränmen. Ein Hohlraum von der Gestalt eines Y liegt unmittelbar über der Raphe. Je ein grösserer Hohlraum liegt in dem Winkel zwischen Deiters'schem Kern, spinaler Trigeminuswurzel and Austrittsschenkel des Facialis. Auf der linken Seite hängt dieser Hohlraum durch zwei Verbindungskanäle mit dem Ventrikel zusammen. Auf der rechten Seite zieht sich von da dorsalwärts eine Reihe kleinerer Hohlräume bis an den Ventrikel. (In dem abgebildeten Schnitte sind nicht alle Hohlräume deutlich sichtbar.)

In den folgenden Schnitten wird der Pons noch ein wenig breiter, bis $1,22 \mathrm{~mm}$. Hie und da enthält er ganz vereinzelte markhaltige Fasern. Der Facialis verschwindet. Die Schleife wird grösser. Vom Corpus trapezoides bleibt noch der medial zwisehen den beiden Schleifenquer- 
Ueb. einen Hemicephalus, mit Beitr. z. Phys. d. menschl.Centralnervensyst. 239

schnitten gelegene Theil sichtbar. Die obere Olive enthält noch immer zahlreiche Ganglienzellen und wird "von Längsfasern durchsetzt und umgeben, welche die Schleife berühren. Der motorische Trigeminuskern tritt auf. Die Fasern der spinalen Trigeminuswurzel sind senkrecht zur Peripherie gerichtet und radiär angeordnet. Die dorsalen Fortsätze der lateralen Antheile sind schmäler und länger geworden, sie enthalten Zellen wie das Ponsrudiment. Ihr medialer Rand ist mit Ependym bekleidet. Vereinzelte sehr lange markhaltige Nervenfasern verlaufen an ihrem lateralen Rande in dorsoventraler Richtung.

Sobald der Acusticus verschwunden ist, ist das hintere Iängsb ändel sehr verkleinert, insbesondere in dorsoventraler Richtung. Zugleich stehen seine noch vorhandenen Fasern lockerer. Die Ganglienzellen der Substantia reticularis nehmen in dem Theile, der an die Raphe angrenzt, an Zahl ab. Bogenfasern sind nur in der dorsalen Hälfte des Haubenfeldes vorhanden. Im Uebrigen enthält die Substantia reticularis zerstreut stehende feine Längsfasern, die nur im dorsalsten Theile, unmittelbar ventral vom Austrittsschenkel des Facialis, etwas dichter angeordnet sind. Im lateralen Theile, nahe dem ventralen Rand, angrenzend an die spinale Trigeminuswurzel, befindet sich ein fast markloses Feld. Der dorsale Theil der Raphe ist verbreitert, indem sich von der Gegend des Centralkanals her ein keilförmiges Bündel von Gliafasern zwischen die beiden Hälften der Medulla oblongata einschiebt.

Austritt des Trigeminus.

Der Schnitt hat im Allgemeinen die Form eines queren 0vals. Die dorsalen Fortsätze sind etwas breiter geworden. Die Breite des Schnittes beträgt $9,79 \mathrm{~mm}$, der Sagittaldurchmesser $3,67 \mathrm{~mm}$.

Den ventralen Theil nimmt das marklose Ponsrudiment ein. Nur ganz vereinzelt sind kurze Markfasern von frontalem Verlaufe darin anzutreffen. Links tritt die sensorische Trigeminuswurzel ein, rechts strahlen die nasalsten Fasern des sensorischen Trigeminus ein und medial davon tritt der motorische Antheil aus. Medial vom Trigeminusaustritt, ungefähr in der Mitte zwischen ihm und der Medianlinie, ist der linsenförmige Querschnitt der Schleife mit seinen dunkelgefärbten Fasern sichtbar. Er nimmt nur einen kleinen Antheil des ventralen Randes des Haubenfeldes ein. Unmittelbar daran schliesst sich lateralwärts die obere Olive.

Der ventrale Theil der Raphe enthält keine Markfasern, im dorsalen Antheile sind solche vorhanden und zwar peripher dichter angeordnet. Diese ziehen im Bogen bis zum motorischen Trigeminus, stellen also die gekreuzte Trigeminuswarzel dar. Das hintere Längsbündel ist ganz klein und enthält locker gereihte Fasern. Lateralwärts davon stehen noch dünne Längsfasern in der typischen Anordnung des Haubenfeldes, von einzelnen Fasern in dorsoventraler Richtung durchzogen. Dieses Gebiet ist durch ein mehr faserarmes von dem motorischen Trigeminuskern getrennt. Unmittelbar ventral vom hinteren Längsbündel, zu beiden Seiten der Raphe, ist das Haubenfeld fast völlig marklos. Zahlreiche Ganglienzellen liegen im Haubenfeld, hauptsächlich am lateralen Rande jenes seitlich vom hinteren Längsbündel gelegenen faserreicheren Gebietes. 
Am lateralen Rande der Substantia reticularis liegt der motorische Trigeminuskern, welcher in dorsoventraler Richtung stark ansgedehnt ist. Er enthält zahlreiche Ganglienzellen und ein lockeres Geflecht gröberer markhaltiger" Nervenfasern, welche zum Theil unmittelbar in den motorischen Quintusast übergehen. In der lateralen Ecke des Haubenfeldes ist links der sensorische Trigeminuskern mit undeutlichen kleinen Ganglienzellen zu sehen und dorsal davon einige locker gereihte Längsfasern - vielleicht Rudiment der cerebralen Trigeminuswurzel. An der correspondirenden Stelle rechts zieht ein dünnes Bündel spärlicher Markfasern in den dorsalen Forsatz, in welchem sich ein dichter Haufen von Markfasern befindet.

In den folgenden Ebenen treten die Ganglienzellen im ventralen Theile des Haubenfeldes grösstentheils näher zusammen (Nucleus tegmenti). Einzelne grosse Ganglienzellen liegen ganz dorsal, über den Fasern der gekreuzten Trigeminuswurzel und im Bereich des hinteren Längsbündels. Die Schleife vergrössert sich ein wenig. Das Höhlensystem unter dem Ventrikelboden communicirt hier wieder durch seitliche Kanäle mit dem Ventrikel.

Noch bevor der Trigeminus völlig ausgetreten ist, verschwindet das hintere Längsbündel bis auf vereinzelte Fasern im dorsalsten Antheil. Die übrigen Längsfasern des Haubenfeldes werden äusserst spärlich. Die Raphe enthält in ihrem dorsalen Theil noch einzelne Fasern. Dorsomedial vom motorischen Trigeminuskern treten grosse Ganglienzellen auf (Beginn des Locus coeruleus). Der mediane Antheil des Centralkanals mündet durch einen schmalen Spalt dorsalwärts aus. Der Keil von Gliafasern im dorsalen Theil der Raphe hat eine tonnenförmige Gestalt, einige Fasern lassen sich deutlich als ventrale Fortsätze von Ependymzellen nachweisen.

\section{Locus coeruleus.}

Das Ponsrudiment ist verkleinert, seine Breite beträgt in der Mittellinie $0,8 \mathrm{~mm}$. Von markhaltigen Gebilden sind die nasalsten Trigeminusfasern, die Schleife, die dorsalen Fasern der Raphe, ein minimaler Rest des hinteren Längsbündels und auf der linken Seite die vielleicht als cerebrale Trigeminuswurzel zu deutenden Längsfasern vorhanden, Alles wesentlich faserärmer, als in den caudaleren Abschnitten. Auf der linken Seite ist noch der motorische Trigeminuskern sichtbar, rechts ist er nicht mehr getroffen. Nahe unter der dorsalen Oberfläche liegt eine grosse Gruppe von Ganglienzellen, die in frontaler Richtung angeordnet ist und nach Form und Lage als Locus coeruleus angesprochen werden muss. Dorsal von der Schleife ist noch eine Gruppe von Ganglienzellen vorhanden, welche der Lage nach der oberen Olive entspricht. Medial-dorsal von der Schleife liegen vereinzelte Ganglienzellen - Nucleus centralis superior. An Stelle des medianen Centrallanalrestes befindet sich ein dorsal ausmündender Spalt, seitlich davon liegen noch einige kleine mit Ependym ausgekleidete Höhlen unmittelbal unter dem Ventrikelboden. Im dorsalen Anhange sieht man an einer Stelle der Peripherie, in einem annähernd ovalen Felde, eine dichte Anhäufung von Zellen, von welchen einzelne zahlreiche Protoplasmaausläufer aufweisen. 
In den folgenden Ebenen sind nur mehr einige Bogenfasern im dorsalen Theil der Raphe und die sehr lockeren Bündel der Schleife markhaltig. Der motorische Trigeminuskern ist beiderseits verschwunden, der Locus coeruleus sehr deutlich ausgebildet. Allenthalben sind kleine Blutungen verstreut.

In dem einen breiteren (Schnittführung?) dorsalen Fortsatz finden sich längs der ganzen Peripherie zwei bis drei Reihen ziemlich grosser Zellen mit relativ grossem Kerne und Kernkörperchen und deutlichem, im Verhältniss zum Kern schmalem, Protoplasma, von welchem sich nicht selten zarte, wellig gebogene Ausläufer nach allen Richtunger erstrecken, die sich oft mit Ausläufern anderer Zellen durchflechten und ein Netzwerk bilden (Spinnenzellen). Von der Peripherie nach innen zu nehmen diese Zellen an Zahl ab und liegen mehr verstreut im Gewebe. Zwischen diesen Zellen finden sich nicht selten typische Ganglienzellen, die oft von einem schmalen Spaltraum umgeben zu sein scheinen. Verstreut finden sich, und zwar mehr in den centralen Antheilen dieser Fortsätze, zarte auf den Schnitten der Länge nach getroffene markhaltige Nervenfasern.

In den weiteren Schnitten nimmt gar nichts mehr ausser dem Reste der Schleife die Markscheidenfärbung an. Die dorsalen seitlichen Anhänge sind ein wenig grösser. In unmittelbarer Nähe der Medianspalte tritt asymmetrisch auf der linken Seite ein grosser rundlicher aus zahlreichen kleinen, ganglienzellenähnlichen Gebilden bestehender Kern auf, an dessen Stelle sich weiter oben drei kleinere Kerne finden, welche zur Seite der Medianspalte liegen. Die Kerne verschwinden sehr bald wieder. Ausserdem treten dicht unter dem Ependym des Medianspaltes grosse Ganglienzellen auf, welche nach dem Verschwinden der kleinzelligen Kerne $z$ wei symmetrische Lager zu beiden Seiten des Medianspaltes bilden.

Ungefähr in gleicher Höhe mit dem Verschwinden der eben erwähnten kleinzelligen Kerne verschwindet der letzte Rest der Schleife. Undeutliche Reste der oberen Olive (Nucleus lemnisci?) begleiten sie bis ans Ende.

\section{Endschnitte.}

Der Medianspalt' schliesst sich wieder zu einem mit Epithel ausgekleideten Kanal. In seiner Ungebung liegen einige Ganglienzellen. Den medialen Rand des dorsalen Anhanges bekleidet Ependym. Der ganze Theil ist sehr zellreich und zeigt den gleichen Aufbau wie früher nur der periphere Antheil.

In den nasalsten Schnitten öffnet sich der Centralkanal noch ein letztes Mal am dorsalen Rande. Die Ganglienzellen sind aus seiner Umgebung verschwunden.

Vom Centralnervensystem ist nach dem rorliegenden Befunde das Rückenmark und die Oblongata bis in die Gegend des Locus coeruleus ausgebildet. Weiter aufwärts geht der ausgebildete Theil des Centralnervensystems durch atypisch entwickelte Hirnantheile in die häutige Masse der Area cerebro-vasculosa über, welche die im Sectionsbefund erwähnten, mikroskopisch nicht untersuchten, höckrigen 
Knollen enthält. An der Oblongata hängt ein Rudiment des Kleinhirns, wie aus dem Verhalten der Meningen, der Plexus chorioidei, der Bildung eines 4. Ventrikels und an einzelnen Stellen anch aus dem histologischen Bar der peripheren Schichten zu erschliessen ist. Es besteht aus einem Querwulst mit seitlichen Anhängen und hat weder Bindearme noch Brückenarme.

Ganz kleine Reste desselben reichen als laterale Anhänge der Oblongata bis nahe an ihr cerebrales Ende.

Das Rücken mark zeigt beträchtliche Mikromyelie. Im Brustmarke findet sich die eingangs dieser Arbeit erwähnte seitliche Einkerbung der äusseren Oberfläche, die auf der einen Seite eine tiefe, auf der anderen eine seichte Furche bildet.

Die äussere Form der Medulla oblongata weicht im unteren Theile durch das Fehlen der Pyramiden und des charakteristischen Feldes der Oliven, sowie das Gesehlossenbleiben des Centralkanals erheblich vom Normalen ab. Im oberen Theil der Oblongata ist die Brücke auf ein schmales markloses Gebilde reducirt. Dadurch ist der sagittale Durchmesser der Oblongata stark verkürzt und das mächtige Corpus trapezoides liegt nahe der ventralen Oberfläche. Das Ganze hat eine gewisse Thierähnlichkeit (Fig. 6).

In hohem Grade wird die Gesammtform des Querschnittes der Oblongata durch das eigenthümliche Verhalten des Centralkanals beeinflusst. Der Centralkanal öffnet sich eigentlich an gar keiner Stelle völlig zum 4. Ventrikel. Im unteren Theil der Oblongata erweitert sich der Centralkanal beträchtlich, bleibt aber in dem Segment, wo die Hinterstränge auseinanderweichen und die Corpora restiformia schon gebildet sind, noch völlig geschlossen. Die dorsale Bedeckung des Centralkanals ist hier ein ausgedehntes markfaserloses Stratum, das allem Anscheine nach aus Glia besteht. Mit diesem Stratum hängt der Querwulst des Kleinhirnrudiments zusammen. Oberhalb desselben liegt der 4. Ventrikel. Er wird ventralwärts vom dorsalen Rande der Medulla oblongata, seitlich von den Antheilen des Kleinhirns und dorsalwärts von den Meningen begrenzt, die zwischen den Kleinhirnantheilen ausgespannt sind. In diesen 4. Ventrikel mündet aber der Centralkanal nicht ein, sondern setzt sich als ein System von Hohlgängen unter dem Boden der Rautengrube cerebralwärts fort. Erst am cerebralen Ende der Rautengrube münden einige dieser Kanäle in den 4. Ventrikel. Hier zeichnet sich unter dem Kanalsystem wieder ein medianer Hauptkanal aus, der zuletzt allein übrig bleibt und an den Endschnitten offenbar dem Aquaeductus Sylvii entspricht.

Dass sich der Centralkanal erst höher cerebralwärts öffnet, als 
normal, kommt bei Hemicephalie öfters vor (Schürhoff, v. Muralt). Mehrfache Höhlenbildungen in der Umgebung der Rautengrube finden sich übrigens bei verschiedenartigen Missbildungen des Centralnervensystems, sie wurden auch bei Porencephalie beobachtet (Obersteiner.)

In unserem Falle reichte vom 4: Ventrikel eine caudalwärts gerichtete Ausstülpung in den Querwulst des Kleinhirnrudiments hinein. Plexusschlingen waren jedoch nur im eigentlichen vierten Ventrikel vorhanden. Aehnliches hat Schürhoff beobachtet.

Die eigenthümlichen Veränderungen am Centralkanal und der Rautengrube sind, wie eingangs erwähnt, bereits mehrfach für die Genese der Syringomyelie verwerthet worden. Es ist sehr wahrscheinlich, dass sie auf frühembryonale Vorgänge, vielleicht schon beim Schlusse des Medullarrohrs, zurückzuführen sind. Darauf weist in unserem Falle auch der Keil von Gliafasern in der Raphe am cerebralen Ende der Oblongata hin, der ebenfalls einem frühembryonalen Gebilde, dem "hinteren Keilstück" von Retzius entspricht, um so mehr, als sich der Zusammenhang einiger dieser Gliafasern mit Ependymzellen des Centralkanals nachweisen lässt.

Das ganze Centralnervensystem ist von kleinen Blutungen durchsetzt, welche von unten nach oben immer zunehmen und namentlic die graue Substanz stark betreffen. Stellenweise sind sie symmetrisch, z. B. in beiden oberen Oliven.

Betrachten wir nun den inneren Bau, wie er sich an der Serie von Schnitten darstellt.

Im Rückenmarke ist die Zeichnung der grauen Substanz dadurch wesentlich verändert, dass der Centralkanal und mit ihm die Commissuren sehr stark ventralwärts verschoben sind. Dadurch ist wieder insbesondere die Form des Seitenhorns vollständig verändert, denn seine Basis ist mit dem Centralkanal vorwärts gerückt, während seine Spitze durch die Einkerbung nach hinten verzogen ist. So hat das Seitenhorn im Dorsalmark eine rückwärts gewandte Spitze. Im Cervicalmark liegt es scheinbar ganz im Bereiche des Hinterhorns. Der Contour der grauen Substanz ist wesentlich plumper, die feinen Zacken und Fortsätze, die sich beim normalen Neugeborenen in die weisse Substanz hineinerstrecken, fehlen zum grössten Theil. Das Aussehen des Hemicephalen-Rückenmarks erinnert an die Bilder vom embyronalen Marke, sowohl was den glatten Contour der grauen Substanz als den nahezu gleich breiten Saum der Vorderseitenstränge betrifft.

In der weissen Substanz überwiegen die Hinterstränge. Sie sind wohl im Ganzen auch an der Mikromyelie betheiligt, doch lässt 
sich kein Ausfall bestimmter Fasergattungen nachweisen. Es besteht keine Trennung der embryonalen Zonen.

Faserarm und schmal sind die Vorderseitenstränge. In diesen fehlt gänzlich das helle Feld der Pyranidenseitenstrangbahn, die in dieser Zeit noch marklos sein muss. Auch von einem der Pyramidenvorderstrangbahn entsprechenden Felde ist in den höheren Theilen des Rückenmarks nichts zu sehen, vielmehr ist gerade der eigentliche Vorderstrang noch verhältnissmässig am reichsten an Markfasern.

Von der Kleinhirnseitenstrangbahn ist ein ganz kleiner Rest erhalten, kenntlich an seiner Lage und der tiefen Schwärzung seiner Fasern bei Markscheidenfärbung. Ein ganz schmaler markloser Streif liegt hier an dem peripheren Rande und ist wohl zum Theil als Ausdruck des Defectes weiterer Fasern der Kleinhirnseitenstrangbahn zu deuten. Möglicherweise entspricht der ventrale Antheil dieses marklosen Streifchens im Lenden- und Brustmark einem Defect des Gowers'schen Bündels.

Der Seitenstrang ist aber so klein und faserarm, dass auch das Fehlen des Gowers'schen Bündels noch nicht zur Erklärung des Befundes genügt. Da die im Seitenstrange exhaltenen Fasern sämmtlich — mit Ausnahme des Rudiments der Kleinhirnseitenstrangbahn - sehr dünn sind, haben wir allen Grund, auch einen Ausfall des dickfaserigen Monakow'schen Bündels (Fasciculus intermediolateralis) zu vermuthen. Der Befund in der Oblongata würde dem nicht wider. sprechen.

Zeichnet man an einem normalen Rückenmarksquerschnitt die Eintheilung der Vorderseitenstränge in Bahnen ein und denkt sich das Areal der Pyramidenbahn, Kleinhirnseitenstrangbahn, des Gowers'schen Bündels und des Monakow'schen Bündels weg (vgl. die betreffenden Figuren im Lehrbuche von Obersteiner ${ }^{1}$ ) oder bei Edinger ${ }^{2}$ )), so bleibt jenes nahezu gleichbreite Band der Vorderseitenstränge um das Rückenmarksgrau übrig, das die Bilder unseres Falles thatsächlich zeigen.

Wahrscheinlich fehlen auch noch andere Fasern in den Seitensträngen (Tractus spino-thalamicus von Edinger, kurze Bahnen u. s. w.). Sicherlich sind die kurzen intraspinalen Bahnen reducirt, weil der Processus reticularjs stark verkleinert ist.

1) H. Obersteiner, Anleitung beim Studium des Baues der nervösen Centralorgane. Wien 1901.

2) L. Edinger, Vorlesungen über den Bau der nervösen Centralorgane. Leipzig 1901. 
Die Wurzeln sind etwas dünner, die Lissauer'sche Randzone ist markhaltig, ihre Ausdehnung an der Peripherie etwas vergrössert, was der plumperen Form des Hinterhorns entspricht.

Die graue Substanz hat überall nur ein spärliches Markfasergeflecht. Die Vorderhornzellen scheinen an Zahl etwas verringert; eingehendere Erörterungen über die Ganglienzellen sind wegen der Schwierigkeiten der Färbung an unseren Präparaten unthunlich. Die Seitenhornzellen sind reichlich vorhanden. Im Lendenmark ist die Gegend der Clarke'schen Säulen durch Eimbuchtung der Hinterstränge, und Einstrahlung von Fasern gekennzeichnet. Einige Ganglienzellen sind daselbst sowie im Brustmarke nachweisbar, wahrscheinlich sind auch die an der entsprechenden Stelle des Halsmarks gelegenen Ganglienzellen als Stilling'sche Zellen zu deuten.

Vergleicht man den Rückenmarksbefund unseres Falles mit dem, was in der Literatur verzeichnet ist, so zeigt sich, dass wohl in den Grundziigen des Aufbaues Uebereinstimmung herrscht, dass aber in den Einzelheiten manche nicht unbeträchtliche Abweichungen bestehen.

Gemeinsam und typisch ist die verhältnissmässig gute Ausbildung der Hinterstränge, die Verkleinerung der Vorderseitenstränge, die Faserarmuth der grauen Substanz. In allen Fällen mit Ausnahme des Falles von Arnold fehlte die Pyramidenbahn. Bereits die Gebrüder Petrén und v. Muralt haben jedoch Zweifel erhoben, ob das von Arnold als Pyramidenseitenstrangbahn gedeutete faserarme Fleckchen auch in der That so aufzufassen sei, und wir müssen uns diesen Zweifeln anschliessen, da die Ergebnisse der elektrischen Reizung, auf die Arnold das Hauptgewicht legt, nach unseren jetzigen Kenntnissen nichts für die Existenz einer Pyramidenbahn beweisen.

Das Verhalten der Clarke'schen Säulen und der Kleinhirnseitenstrangbahn ist variabel. Arnold fand die ersteren so gut wie normal, die Kleinhirnseitenstrangbahn bildete, obgleich verschmälert, einen hervorragenden Bestandtheil der Seitenstränge. Veraguth sah in einem Falle (IX) die Clarke'schen Säulen deutlich. Ueber die Kleinhirnseitenstrangbahn spricht er sich nicht aus; doch ist aus der Abbildung (Fig. 23) zu ersehen, dass sie in geringem Grade, doch etwas stärker als in unserem Falle, angelegt ist. Schürhoff fand in mehreren Fällen spärliche Ganglienzellen an der Stelle der Clarke'schen Säulen, aber diese selbst nicht in der charakteristischen Form ausgebildet. Die Kleinhirnseitenstrangbahn war gering. Darvas zeichnet eine reducirte Kleinhirnseitenstrangbahn, macht aber über die Ganglienzellen keine Angaben. In den Fällen von Leonowa, von Brüdern Petrén und Raffone fehlten beide Gebilde. Im Falle v. Muralt's fehlte jede 
Andeutung einer Clarke'schen Säule, jedoch verlief ein Faserbündel an der Stelle der Kleinhirnseitenstrangbahn bis in den Brusttheil. In dem sehr wenig ausgebildeten Falle von Bulloch waren vereinzelte Ganglienzellen in den Clarke'schen Säulen vorhanden, eine Kleinhirnseitenstrangbahn nicht nachweisbar.

Variabel ist auch das Verhalten der Lissauer'schen Randzone. Sie ist bei den Anencephalen Leonow a's und Bulloch's ebenso marklos, wie bei dem hoch entwickelten Hemicephalen v. Muralt's. Dagegen war sie in unserem Falle und den sehr verschieden ausgebildeten Fällen Schürhoff's markhaltig. Das beruht, wie auch v. Muralt wahrscheinlich macht, wohl einfach auf Verschiedenheiten in der Entwicklung der Markscheiden, nicht auf Defecten der Fasern.

DerProcessus reticularis variirt ebenfalls in seiner Entwicklung.

Am Uebergang des Rückenmarks zur Medulla oblongata ist das Fehlen der Pyramidenkreuzung die wichtigste Erscheinung. Weiter aufwärts fehlt ebenso die Schleifenkreuzung. Aus dem Burdach'schen Strange lassen sich nur spärliche Fasern ins Hinterhorn, aber keine ventralwärts vom Centralkanal verfolgen. Die Fasern, die aus dem Goll'schen Strange ventralwärts riehen sollten, fehlen gänzlich. Dass die Faserkreuzung, die wir im Bereiche des 1. Cervicalis beobachten, der vorderen Commissur und nicht der Schleifenkreuzung entspricht, geht aus den topographischen Beziehungen zum 1. Cervicalis und zum Accessorius mit Sicherheit hervor. Wie der Hypoglossuskern auftritt, erweitert sich der spaltförmige Centralkanal so weit ventralwärts, dass zwischen den Resten des Vorderstranges und ihm gar kein Platz für die Schleifenkreuzung bleibt.

Wie die Bogenfasern der Schleifenkreuzung, fehlen auch die Fibrae arcuatae externae dorsales vollständig. Ihrem Defect, der bedeutenden Verminderung der Kleinhirnseitenstrangbahn, vielleicht auch des Gowers'schen Bündels entspricht der marklose Saum am lateralen Rande, der sich dorsalwärts bis an die Goll'schen Stränge erstreckt.

Höher oben fehlen die lateral von der spinalen Trigeminuswurzel verlaufenden Fasern der Cerebello-olivarbahn. Daher setzt sich der marklose Rand continuirlich aufwärts fort.

Am ventralen Rand der Vorderstränge liegt in dieser Höhe ein fast markloses Gebiet, welches an einer Stelle den Sulcus longitudinalis anterior ausfüllt und zwei flache symmetrische Buckel bildet, die medialwärts von dem Austritte der Hypoglossuswurzeln liegen. Dem Helweg'schen Bündel entspricht es nicht, denn dieses liegt lateral von den Hypoglossuswurzeln. Vielleicht ist das markarme 
Feld, das Arnold in seinem Falle an der entsprechenden Stelle, medial von den Olivenrudimenten und ventral von dem Vorderstrange, abbildet und als rudimentäre Pyramiden deutet, damit identisch. In unserem Falle handelt es sich sicherlich nicht um die Pyramiden, denn das ganze Gebilde reicht nicht ganz bis in die Höhe des Glossopharyngeusaustrittes.

In der Substantia reticularis grisea ist eine Zellgruppe von der Lage der Seitenstrangkerne rorhanden (medial-ventral von der spinalen Trigeminuswurzel, nahe der Peripherie der Oblongata, ventral vom Nucleus ambiguus). Die Kleinhirnseitenstrangbahn hat allerdings in dieser Höhe bereits ihr Ende gefunden und das Gebiet um die fraglichen Kerne ist sehr arm an Markfasern.

Proximalwärts von der zu erwartenden Schleifenkreuzung sind auch nur ganz vereinzelte Bogenfasern vorhanden. Die Fasern der Vorder- und Seitenstränge aber sind von leeren Feldern bogenförmig durchfurcht. Auch fehlen vollständig die Fibrae arcuatae externae ventrales. Dass die Fasern, die im obersten Halsmark aus der vorderen Commissur an den ventralen Rand der Vorderstränge ziehen, nichts mit den Fibrae arcuatae externae zu thun haben, ist klar.

Das schmale marklose Feld im ventralen Theile der Medulla oblongata, das sich in seinem caudalen Theil von den Hypoglossuswurzeln bis ungefähr zur Mitte ihres Abstandes von der spinalen Trigeminuswurzel erstreckt, in der Höhe des Glossopharyngeusaustrittes vom ventralen Rande ab ein wenig ins Innere rückt und weiter aufwärts verschwindet, muss wohl als Rudiment der Oliven gedeutet werden. Das gleiche, ebenfalls ganglienzellenlose, Gebilde fanden Darvas und v. Muralt. Sohürhoff beobachtete verschiedene Grade der Ausbildung der Oliven, die in seinen Abbildungen sehr schön reproducirt sind. Fig. 4 (Fall I), Fig. 7 (Fall II) und Fig. 15 (Fall V) entsprechen unserem Befunde, während Fig. 10 (Fall III) und Fig. 13 (Fall IV) das Gebilde etwas mehr ausgebildet zeigen, und in Fig. 24 (Fall IX) eine relativ hoch entwickelte Olive vorhanden ist. Im Falle von Arnold waren einige Ganglienzellen und Fasern nachweisbar.

Die Aplasie der Olive beim Vorhandensein der anderen Gebilde dieses Abschnittes ist entwicklungsgeschichtlich zu begründen. Nach den Ermittelungen von $\mathrm{His}^{1}$ ) entstammt die Olive einer Lippe der dorsalen Wand des Medullarrohres, die sich umlegt und ventralwärts gegen die Mittellinie vorwächst. Hier bildet sich eine winkelig gebogene Platte als Anlage des Olivenkerns und seiner Nebengebilde,

1) W. His, Ueber die Entwicklung des Riechlappens und des Riechganglions und über diejenige des verlängerten Markes. Verhandlungen der anatom. Gesellschaft 1889. Ergänzungsheft zum Anatomischen Anzeiger 1889. S. 63. 
während die benachbarten Kerne (Seitenstrangkern und Keilstrangkern) aus einem mehr lateralwärts gelegenen Zellhaufen hervorgehen. Da die Zellen der Olive also erst von der dorsalen Hügelplatte secundär an die Ventralfäche des Medullarrohrs gelangen, ist nicht nur das Verhalten des Gebildes, sondern auch ein Zusammenhang seiner Störungen mit denen beim Schlusse des Medullarrohrs begreiflich. Durch das Fehlen einer wirklichen Olive und der Fibrae arcuatae externae ventrales erklärt sich die hochgradige Verminderung der Fibrae arcuatae internae in dieser Region.

Das Wenige, was von Bogenfasern vorhanden ist, kann demnach gedeutet werden als: 1. Fasern von den Vagus- und Glossopharyngeuskernen, oder 2. eigene Fasern der Substantia reticularis, oder 3. vielleicht auch noch aIs einzelne Fasern von Hinterstrangkernen zur Schleife, die sich höher oben kreuzen. Da diese Bogenfasern in der Höhe des Beginns der Corpora restiformia fast nur im Gebiete der Ganglienzellen des Vorderstrangkerns zu finden sind, werden es wohl hauptsächlich eigene Fasern der Substantia reticularis sein.

Das kleine Bündel von Schleifenfasern, das sich hier im ventralen Theil der Substantia reticularis alba abgrenzt, dürfte daher vorwiegend aus dem Vorderstrang stammen (Fig. 5).

Ventral ron der Schleife, im Winkel zwischen ihr und den Hypoglossuswurzeln liegt eine kleine Gruppe von Ganglienzellen, sehr wahrscheinlich der Nucleus arcuatus.

Die Hinterstrangkerne waren in unserem Falle kleiner und ihre Ganglienzellen undeutlich. Es ist nicht wahrscheinlich, dass der letztere Befund eine blosse Folge der mangelhaften Färbbarkeit, also eines Mangels der Untersuchungsmethode ist; denn dieselbe Beobachtung ist in allen untersuchten. Fällen gemacht worden (Schürhoff, Arnold, v. Muralt etc.).

Die bedeutende Reduction des Corpas restiforme ist nach den dargelegten Verhältnissen in dem Fehlen eines grossen Theils seiner Bestandtheile begründet.

Das hintere Längsbündel grenzt sich schon verhältnissmässig tief von den anderen Längsfaserzïgen ab (Fig. 5).

Die spinale Trigeminus.wurzel ist im unteren Theile der Medulla oblongata das mächtigste Gebilde (Fig. 4). Gut ausgebildet sind: Glossopharyngeus mit seiner spinalen Wurzel, Vagus, Accessorius und der Nervus intermedius Wrisbergi. Die Hypoglossuswurzeln sind dünn. Sie haben wegen des Fehlens der Pyramiden und der Oliven einen sehr kurzen intraspinalen Verlauf. Ueber feinere Einzelheiten der Hirnnervenkerne lässt sich nichts Genaues aussagen. 
Leb. einen Hemicephalus, mitBeitr. z. Phys. d. menschl. Centralnervensyst. 249

Gegen den Facialiskern zu wird die Substantia reticularis sehr reich an Ganglienzellen. Ausser dem Nucleus centralis inferior sind überall Ganglienzellen eingestreut. Dorsal-lateral vom hinteren Längsbündel liegt ein kleiner Kern, der nicht gedeutet werden konnte. Mit dem Nucleus funiculi teretis hat er offenbar nichts zu thun.

Während die Ganglienzellen des Haubenfeldes hier zahlreicher werden, nehmen seine Fasern rasch an Zahl ab. Der laterale Theil ist, wie schon in den caudaleren Abschnitten, äusserst faserarm. Insbesondere liegen zwischen Facialiskern und spinaler Trigeminuswurzel nur wenige und dünne Längsfasern. Das unterstützt die schon beim Rückenmark ausgesprochene Ansicht, dass das Monakow'sche und der grösste Theil des Gowers'schen Bündels fehlen.

Bekanntlich wird in neuester Zeit noch mancher wichtige Faserzug in dem lateralen Abschnitte des Haubenfeldes beschrieben (vgl. z. B. die Besprechung eines Defects an einer etwas caudaleren Stelle dieses Gebietes bei A. Wallenberg $\left.{ }^{1}\right)$ ). Da jedoch der Verlauf dieser Züge beim Menschen noch nicht hinreichend sichergestellt ist, ist eine Erörterung derselben bei unserer Missbildung nicht am Platze.

Facialis und Abducens sind gut ausgebildet, ihre Kerne zellenreich. Der sonst schon im 7. Monate markhaltige Stiel der oberen Olive vom Abducenskern ist nicht nachweisbar.

Ein sehr stark entwickeltes Gebilde ist der Acusticus. Sowohl Vestibularis als Cochlearis sind faserreich. Die Fasern des ersteren sind dicker, die des letzteren varicös. Der dreieckige Acusticuskern ist nicht mit voller Sicherheit, aber doch mit einer gewissen Wahrscheinlichkeit zu identificiren. Die spinale Acusticuswurzel reicht tief hinab. Der grosszellige Kern kann nicht in den Deiters'schen und Bechterew'sehen Kern zerlegt werden. Aus dem grosszelligen Kern ziehen zahlreiche Fasern medianwärts. Ein Theil davon lässt sich durch den Austrittsschenkel des Facialis ins dorsale Haubengebiet verfolgen, ein Theil zieht anscheinend mit den Facialisfasern zur Mittellinie. Der accessorische Acusticuskern ist gross. Striae medullares sind natürlich nicht nachweisbar, da sie beim Neugeborenen noch marklos sind. Es ist aber für sie auch nur sehr wenig Platz vorhanden, denn das Höhlensystem des Centralkunals reicht hier hart an das dorsale markhaltige Gebiet (Austrittsschenkel des Facialis), so dass es wahrseheinlich ist, dass sie gar nicht angelegt sind.

Das Corpus trapezoides ist gut ausgebildet, die Lage des Trapezkerns durch ein helles Feld gekennzeishnet.

1) A. Wallenberg, Anatomischer Befund in einem als acute Bulbäraffection beschriebenen Falle. Arch. f. Psychiatrie und Nervenkrankh. Bd.34. (1901.) S. 923 . 
Die obere Olive reicht hinab bis ans caudale Ende des Facialiskerns und hinauf bis über den Locus coeruleus. Es sind in ihr Ganglienzellen nachweisbar. Ihr caudaler Theil hat keinen Markmantel, vom Corpus trapezoides an steigen aber mit ihr Bündel aufwärts.

Die Brücke ist ein kleines Gebilde, sie enthält keine Fasern, welche ihre Ganglienzellen mit anderen Gebilden verknüpfen. Die ganz vereinzelten Querfasern, welche hie und da in einem Schnitte zu sehen sind, entbehren offenbar jeglicher Bedeutung.

In der Höhe des Acusticus wird das hintere Längsbündel sehr stark vermindert. Da es hier zugleich von zahlreicheren Bogenfasern als in den caudaleren Theilen durchsetzt wird, und da sich in diesen Theil des Haubenfeldes Fasern aus der Gegend des Deitersschen Kernes verfolgen lassen, so ist es wahrscheinlich, dass hier Fasern des hinteren Längsbündels zahlreich in die frontale Richtung umbiegen und endigen. ${ }^{1}$ ) Wahrscheinlich gehört ein Theil der Fasern des hinteren Längsbündels eigentlich dem prädorsalen Längsbündel an, jenen in der letzten Zeit eingehender studirten absteigenden Vorderstrangbahnen.

Die Schleife wird, wie es scheint, schon in der Höhe des Nervus intermedius Wrisbergi von ihrer Lage neben der Raphe lateralwärts verschoben, entsprechend der Verkürzung des sagittalen Durchmessers der Oblongata. Sie bildet ein kleines und faserarmes Bündel, ist innerhalb des Corpus trapezoides gat zu verfolgen und wächst oberhalb desselben an, gleichzeitig mit den Lüngsfasern der oberen Olive, denen sich ihre Fasern anlegen.

Das Gebiet des Trigeminus ist der oberste Theil des verlängerten Marks, der noch völlig ansgebildet ist. Der motorische Quintuskern, der motorische Ast und sein gekreuzter Antheil sind nebst der mächtigen spinalen Wurzel und dem sensiblen Kern deutlich. Vielleicht ist auch die cerebrale Wurzel vorhanden.

Die Ganglienzellen des Haubenfeldes sind anch in dieser Höbe zahlreich. Ein Theil bildet den Nucleus reticularis tegmenti.

In der Höhe des Trigeminusaustrittes verschwindet wieder ein grosser Theil des hinteren Längsbündels.

Die Schleife wächst im caudalen Theil des Trigeminusgebietes noch etwas an, ihr Querschnitt nimmt jedoch anch hier nur einen kleinen Theil vom ventralen Rand des Haubenfeldes ein. Noch innerhalb des Trigeminusanstrittes verkleinert sich die Schleife wieder und

1) Vgl. die Untersuchungen über das hintere Längsbündel menschlicher Embryonen von $\mathrm{O}$. Hösel, Beiträge zur Markscheidenentwicklung im Gehirn und in der Medulla oblongata des Menschen. Monatsschr. f. Psychiatrie und Neurologie VI. (1899.) S. 161, VII. (1900.) S. 265 u. 345. 
Ueb. einen Hemicephalus, mit Beitr. z. Phys. d. menschl. Centralnervensyst. 251

die Fasern des restlichen Theiles stehen lockerer. Sie lassen sich dann noch weit hinauf, fast bis ans oberste Ende der Oblongata verfolgen, wo sie das Einzige sind, was noch Markscheidenfärbung annimmt. Reste der oberen Olive (oder vielleicht schon Schleifenkern?) finden sich auch in dieser Höhe. Hier verlieren sich die Längssbündel der Schleife, ohne dass sich Querfasern anschliessen.

Oberhalb des Trigeminusgebietes lassen sich noch die Ganglienzellen des Locus coeruleus sicher agnosciren. Hier endet das Wenige, was vom hinteren Längsbündel und vom dorsalsten Theile der Bogenfasern und der Raphe übrig geblieben ist.

Höher hinauf finden sich atypische Kerne, zuletzt Ganglienzellen um den Centralkanal. Es handelt sich wohl um Reste ron Augenmuskelkernen. Nervenverbindungen sind hier nicht nachzuweisen.

Vom inneren Bau des Kleinhirnrudiments ist wenig zu sagen. Von der Rinde sind stellenweise deutliche Reste mit Purkinje'schen Zellen vorhanden, meist aber ist der Rand ganz atypisch. Die mehr cerebralwärts an der Oblongata hängenden schmalen Fortsätze enthalten in den lateralen Theilen zahlreiche Spinnenzellen und Ganglienzellen mit pericellulärem Spaltraum, im Innern markhaltige Nervenfasern. Das Bild erinnert hier sogar einigermassen an die Grosshirnrinde. -

Um die Organis ation dieses Centralnervensystems zu überblicken, stellen wir nun zusammen, was ihm von wichtigeren Bahnen und Centren im Vergleich zum Normalen fehlt und was bei ihm nachweisbar ist.

Es fehlen: Vorderhirn, Zwischenhirn und Mittelhirn.

Von ihren spinalen Verbindungen fehlen Pyramidenbahn und Monakow'sches Bündel.

Das Kleinhirn ist auf einen kleinen Rest reducirt. Es fehlen Bindearme und Brückenfasern, seine Verbindung ist auf das Corpus restiforme beschränkt.

Das Corpus restiforme enthält nur einen Theil des ungekreuzten Rückenmarksantheils, nämlich eine sehr spärliche Kleinhirnseitenstrangbahn aus den rudimentären Clarke'schen Säulen und ungekreuzte directe Fasern aus den Burdach'schen Kernen. Vom Rückenmarksantheil fehlen die Fibrae areuatae externae dorsales aus den Goll'schen Strängen und die Fibrae arcuatae externae ventrales, also die gekreuzte Hinterstrangsverbindung, ferner der ganze Olivenantheil und die untere Olive.

Das Gowers'sche Bündel fehlt wahrscheinlich grösstentheils.

Die Schleife ist sehr reducirt. Nachweisbar ist die Abstammung von Fasern aus den Vordersträngen und der oberen Olive, wahrschein- 
lich aus den Hirnnervenkernen (der Zusammenhang mit dem Corpus trapezoides wird bestritten). Es fehlt die gekreuzte Verbindung mit den Hinterstrangskernen sicher, soweit sie in der grossen Schleifenkreuzung verläuft.

Von Hirnnerven fehlen (beziehungsweise stehen mit dem ausgebildeten Theil des Centralnervensystems nicht im Zusammenhang): Olfactorins, Opticus, Oculomotorius und Trochlearis.

Von Hirnnerven sind nachweisbar:

Trigeminus: spinale Wurzel, sensorischer Kern, motorischer Kern, motorische Wurzel mit ihren gekrenzten Fasern, Locus coeruleus, vielleicht auch ein Rest der cerebralen Wurzel;

Abducens: Wurzel und Kern, es fehlt der Stiel zur oberen Olive;

Facialis: Wurzel und Kern, wahrscheinlich auch der gekreuzte Antheil;

Acusticus: Nerrus vestibularis und Cochlearis, dreieckiger Kern (wahrscheinlich), spinale. Wurzel, grosszelliger Kern, accessorischer Acusticuskern, Corpus trapezoides, Trapezkern, obere Olive;

Intermedius Wrisbergi: Wurzel und Roller'scher Glossopharyngeuskern;

Glossopharyngeus-Vagus: Wurzeln, sensorischer Kern, spinale Glossopharyngeuswurzel mit dem Glossopharyngeusherd, Nucleus ambiguus;

Accessorius: Wurzelfasern und Krause'sches Respirationsbündel;

Hypoglossus: Wurzelfasern und Kerne.

Die Hinterstrangkerne sind schwächer ausgebildet, Seitenstrang kerne deutlich.

In der Substantia reticularis sind gut ausgebildet: Vorderstrangkern, Nucleus centralis inferior und Nucleus reticularis tegmenti, ausserdem sind zablreiche Ganglienzellen eingestreut. Die Deutung einiger Kerne ist unsicher.

Die Verbindung der Oblongata mit dem Rückenmarke vermitteln: hinteres Längsbündel und prädorsales Längsbündel, Vorderstrangantheil der Schleife und wohl auch Seitenstrangfasern der Substantia reticularis. Weitere Analyse des Faserverlaufes ist nicht möglich.

Im Rückenmark sind ausgebildet: reichlich die Hinterstränge, weniger die Vorderstränge, sehr schmal und faserarm die Seitenstränge. Vordere Wurzeln dünner, Vorderhornzellen weniger zahlreich. Clarkesche Säulen und Processus reticularis rudimentär. Es fehlen Pyramidenbahn und Monakow'sches Bündel, Kleinhirnseitenstrangbahn ist 
Ueb. einen Hemicephalus, mitBeitr. z. Phys. d. menschl. Centralnervensyst. 253

äusserst reducirt, Gowers'sches Bündel fehlt mindestens zum grössten Theil, die intraspinalen Bahnen sind reducirt.

Es ist also der Bauplan dieses Centralnervensystems gegen den des normalen Gehirns vereinfacht. Dabei sind aber keine abnormen Bahnen oder Verbindungen und auch keine Verlagerungen vorhanden, welche die segmentale Topographie wesentlich verändern würden. Das ist wichtig, weil nur dann Schlüsse aus deu Functionen des missbildeten Centralnervensystems auf die Physiologie des normalen Hirns gestattet sind, wenn der anatomische Befund eine Vergleichung bis ins Detail zulässt. Schon um dieser Frage willen musste die anatomische Untersuchung der Missgeburt so eingehend als möglich vorgenommen werden.

Wie im Rückenmark, so sind auch in der Medulla oblongata einige Verhältnisse typisch für den Hemicephalen.

So überwiegt beim Corpus restiforme, wenn es äberhaupt vorhanden ist, stets der ungekreuzte Antheil über den gekreuzten (Schürhoff, Arnold).

Die Schleife war in mehreren Fällen angelegt (Leonowa, Arnold). Da nasalwärts keine Endstätten für ihre Fasern vorhanden sind, haben wir hier ein ähnliches Verhalten, wie die Entwicklung der hinteren Wurzeln bei Amyelie. Es findet dadurch in der Oblongata eine "Selbstdifferenzirung" centripetaler Fasern, allerdings nur unvollkommen, nur bis zu einem gewissen Grade, statt, die unabhängig von der Ausbildung der zugehörigen Hirntheile ist.

Bei der Besprechung der äusseren Form des Brückentheils der Oblongata ist auf eine gewisse Thierähnlichkeit hingewiesen worden. Bereits Edinger ${ }^{1}$ ) hat auf die Thierähnlichkeit aufmerksam gemacht, die die Oblongata der Hemicephalen durch das Fehlen der Pyramidenbabn erbält. Diese Thierähnlichkeit ist mehr als eine oberflächliche Aehnlichkeit, sie zeigt sich vielmehr in vielen Einzelheiten des Aufbaus. Das Fehlen der Pyramiden, das Fehlen der Oliven ist ebenso den niederen Vertebraten mit den Hemicephalen gemein, wie die mächtige Entwicklung des Acusticusgebietes im Vergleich zur übrigen Oblongata.

Bemerkenswerth ist auch das Verhalten der oberen Olive. Während beim normalen Menschen die obere Olive von der unteren an Grösse weit überragt wird, ist bei unserem Hemicephalus die obere Olive räumlich sehr ausgedehnt. Ebenso verhielt sie sich im Falle v. Muralt's. Nun ist aber die obere Olive ein phylogenetisch altes

1) L. Edinger, Vorlesungen über den Bau der nervösen Centralorgane. Leipzig 1896. S. 79 . 
Gebilde. Dasselbe gilt von dem verhältnissmässig grossen Raum, den das hintere Längsbündel auf dem Querschnitte des unteren Theils der Oblongata einnimmt.

Die Thierähnlichkeit des Nervensystems der Hemicephalen ist also in seiner Organisation tief begründet. Diese ist in gewisser Beziehung ein Denkmal der Phylogenese. Das beruht offenbar darauf, das manche phylogenetisch alten Gebilde bei einer Störung der Ontogenese weniger geschädigt werden und so einige phylogenetisch alte Beziehungen mehr hervortreten, als bei normaler Entwicklung. Für die Entstehung der Monstren weist das, wie so viele andere Momente, auf eine sehr frühzeitige Schädigung der Entwicklung hin.

Herrn Professor Dr. Richard Paltauf und Herrn Prosectorsadjuncten, Privatdocenten Dr. Carl Sternberg bin ich für die Vornahme der Section, die Ueberlassung des Materials und freundliche Unterstützung bei seiner Bearbeitung, Herrn Professor Dr. Heinrich Obersteiner für die Durchsicht meiner Präparate zu Dank verpflichtet.

II. Klinisch-physiologischer Theil.

Von

\section{Privatdocent Dr. Maximilian Sternberg und Privatdocent Dr. Wilhelm Latzko in Wien.}

Von den hirnlosen Missgeburten kommt eine ganz beträchtliche Zahl lebend zur Welt und lässt sich eine Zeit lang, im Durchschnitte bis zu drei Tagen, am Leben erhalten. Sie bieten eine ausgezeichnete Gelegenheit, beim Menschen eine Anzahl von Reflexbewegungen ohne den Einfluss der höheren Hirntheile zu studiren und können daher für die Physiologie des Centralnervensystems werthvolle Aufschlüsse liefern.

Bisherige Beobachtungen lebender Hemicephalen.

Diese Bedeutung der Monstren ist schon früh erkannt worden, und der erste Versuch, die Beobachtung eines lebenden Anencephalus für die Physiologie der motorischen Nervencentren zu verwerthen, stammt bereits aus dem 17. Jahrhundert. Damals herrschte die Lehre des Descartes von der Zirbeldrüse und dem Hirn als Ursprungsstätten der Bewegung, und eine lebende hirnlose Missgeburt musste diese Theorie nothwendig erschüttern. Wir lesen in den "Philosophical 
Ueb. einen Hemicephalus, mit Beitr. z.Phys. d. menschl. Centralnervensyst. 255

Transactions" vom Jahre 1667 folgenden interessanten Bericht aus Paris ${ }^{1}$ ):

„An Infant come to maturity having instead of a Head and Brain, a Mass of flesh like any Liver; and was found to move. And this Foetus occasioned a Question for the Cartesians, how the motion could be performed, and yet the Glandula pinealis or Conarium be wanting, nor any Nerves visible, which come from the Brain? The marrow in the Spine was of the some substance. It liv'd four days and then dyed. It was anatomized by M. Emmerez in presence of the Assembly".

Ein Jahrhundert später wies Soemmering auf die Wichtigkeit hin, welche der Versuch für die Physiologie hätte, einen Anencephalus durch besondere Sorgfalt eine Zeit lang am Leben zu erhalten und zu beobachten.

Leider scheinen nur wenige solcher Missbildungen in die Hände aufmerksamer Beobachter gekommen zu sein. Die meisten der überaus zablreichen älteren und neueren casuistischen Mittheilungen beschränken sich auf die Angabe, dass das Neugeborene eine gewisse Zeit gelebt, geschrieen und getrunken habe. ${ }^{2}$ ) Wir haben nur spärliche Beobachtungen gefunden, aus denen man Genaueres über die Lebensäusserungen dieser merkwẗrdigen Geschöpfe erfahren kann. Sie sind im Folgenden zusammengestellt und zwar zum grössten Theile wörtlich widergegeben.

Ollivier ${ }^{3}$, ,sahe das hirnlose Kind zwei Stunden nach der Entbindung. Die Augen waren fortgehend geschlossen, und es stiess häufige Schreie aus, welche man durch Einbringung des kleinen Fingers in den Mund bald stillen konnte, wobei es wiederholt Saugbewegungen machte; die Gliedmassen bewegte es mit ziemlicher Kraft". Tod $20 \%$ Stunden nach der Geburt.

Panizza ${ }^{4}$ ) beobachtete Verzerren des Gesichts mit Zeichen des Widerwillens bei Einführung einer bitteren Substanz in den Mund, Stechen der Haut, Berührung mit einem Schlüssel; in den letzteren Fällen auch krampfartige Bewegungen der Extremitäten.

1) Philosophical Transaction 1667. Nr. 26. p. 480.

2) z. B. ein alter typischer Bericht von Saviard: „vixit quatuor dies, sese movebat, sugebat, clamabat". Referirt bei Sandifort 1. c. p. 45 .

3) G. P. Ollivier, Ueber das Rückenmark und seine Krankheiten. Uebers. v. J. Radins. Leipzig 1824. S. 94.

4) B. Panizza, Storia d'un mostro umano anencefalo che visse 18 ore, con relative considerazioni. Giornale dell' Istituto Lombardo. 1841. Tom. I. p. 142 (citirt nach C. Taruffi, Storia della teratologia. T. VI. Bologna 1891. p. 140). 
Flechsig ${ }^{1}$ : „Dieses Kind ist auch insofern von Interesse, als es trotz jenes umfänglichen Defectes im Mittelhirn $1 \frac{1}{2}$ Tage lebte; auf mechanische Reize von selbst geringer Intensität reagirte es mit Bewegungen in allen Extremitäten, wimmerte, verzog das Gesicht schmerzhaft u. s. w. Pulv. chin. in Dosen auf die Zunge gebracht, welche bei gesunden Kindern sofort heftiges Schreien und sonstige Zeichen von Missbehagen zur Folge hatten, blieben bei jenem indess ohne alle Wirkung. Leider wurden durch das frühzeitige Ende der Missgeburt weitere genauere Versuche unmöglich gemacht." Es war nur die Medulla oblongata bis zur oberen Brückenhälfte ausgebildet.

0. v. Leonowa ${ }^{2}$ ) untersuchte einen Anencephalus von $1620 \mathrm{~g}$ Gewicht und $45 \mathrm{~cm}$ Länge, welcher 17 Stunden 20 Minuten gelebt hatte. Die Medulla oblongata war nur bis zum Hypoglossuskern entwickelt. Der Vaguskern fehlte. Es müssen also schon im Rückenmark Einrichtungen zur Unterhaltung regelmässiger Athmung vorhanden sein.

Kehrer und Hoffmann ${ }^{3}$ ): Länge $50 \mathrm{~cm}$, Gewicht $3210 \mathrm{~g}$. "Athmung und Puls boten keine Anomalie dar. Beim Einführen des Fingers in den Mund wurden Saugbewegungen vorgenommen. Wasser und Milch konnten geschluckt werden, doch trat zuweilen Regurgitation ein. Harn- und Meconiumentleerung erfolgten in normaler Weise. Die Pupillen reagirten nicht. Das Kind schrie selten, wimmerte in den folgenden Tagen viel."

„Wenn das Kind entkleidet und hingelegt wird, gerathen die Extremitäten in lebhaft zappelnde Bewegungen. Lässt man es ruhig liegen, so werden spontane Bewegungen kaum ausgeführt, offenbar werden durch die nicht zu vermeidenden Hautreize reflectorische Bewegungen ausgelöst. Es ist dies um so wahrscheinlicher, als nicht allein die Sehnenreflexe, sondern auch die Hautreflexe durchweg sehr gesteigert sind. Ueberhaupt besteht eine allgemein erhöhte Reflexerregbarkeit; denn die an einem Gliede reflectorisch erzeugten Bewegungen (Nadelstiche, Streichen der Haut) bleiben nicht localisirt, sondern springen auf die anderen Glieder über. Beim Auslösen der Reflexe durch Nadelstiche schreit das Kind nicht."

1) P. Flechsig, Die Leitungsbahnen im Gehirn und Rückenmark des Menschen. Leipzig 1876. S. 120.

2) O. v. Leon owa, Ein Fall von Anencephalie. Archiv für Anatomie und Physiologie, Anatomische Abtheilung. 1890. \$. 403.

3) Es ist das der von Arnold anatomisch untersuchte Fall. J. Arnold, Gehirn, Rückenmark und Schädel eines Hemicephalen ron dreitägiger. Lebensdaner. Ziegler's Beiträge zur pathologischen Anatomie und zur allgemeinen Pathologie. 1892. Bd. 11. S. 407. 
Durch elektrische Reizung der freiliegenden Antheile des Centralnervensystems wurden einige Contractionen der Muskeln des Körpers hervorgerufen.

L. v. Muralt $\left.{ }^{1}\right)$ : „Während seines zweitägigen Lebens habe es kräftig geschrieen, habe geschluckt und normale Muskelbewegungen und Reflexe gezeigt." Der ausgebildete Theil der Oblongatá reichte bis einschliesslich des Trigeminusaustritts, ähnlich wie in unseren Falle.

Veraguth ${ }^{2}$ ): Länge $32 \mathrm{~cm}$, Lebensdauer $53.3 / 4$ Stunden. „Das Kind wurde ins Kinderspital verbracht, weil es immer-schrie. Daselbst versuchte man ihm Milch einzugiessen; dabei machte es keine Saugbewegungen, konnte aber etwas Weniges schlucken. Das Schreien liess allmählich nach und ging in ein leises, beständiges Winmern über. Die Athmung war unregelmässig, bald beschleunigt, bald ruhiger. Arme und Beine bewegte das Kind, und zwar recht kräftig. Zeitweise aber waren die Extremitäten contracturirt. Kurz ante mortem wurde etwas Meconium entleert. Urin wurde nicht beobachtet. Ueber den Puls fehlen Angaben, ebenso über die Pupille. Das Auge wurde nie geöffnet." Die Medulla oblongata war bis in die Gegend des Trigeminusaustrittes ausgebildet, dieser selbst schon undeutlich.

Veraguth ${ }^{3}$ ) giebt von einem zweiten Falle, in dem nur der obere Theil des Rückenmarks bandartig ansgebildet war, an, das die Frucht einige Stunden stenotisch geathmet hat.

Vaschide und Vurpas ${ }^{4}$ ): Männliches Geschlecht. Wurde scheintodt geboren, durch heisse Bäder und Abreibungen belebt, lebte 39 Stunden. Gewicht 2620. Temperatur $28^{\circ}$ im Rectum. Athmung von Cheyne-Stokes'schem Typus, durchschnittlich 9 Athemzüge in der Minute. Puls 138. Das Herz schlug im Beginn der respiratorischen Periode schneller. Keine Pupillenveränderung während der Dyspnoe oder Apnoe. Allgemeine Cyanose.

Die Patellarreflexe schwierig zu untersuchen, weil die Beine steif waren, die Reflexe am Vorderarm gesteigert. Idiomusculäre Zuckung vorhanden.

Protrusio bulbi, sehr starker Strabimus divergens. Pupillen

1) L. v. Muralt, Ueber das Nervensystem eines Hemicephalen. Archiv für Psychiatrie und Nervenkrankheiten. Bd. 34. (1901.) S. 869.

2) O. Veraguth, Ueber nieder differenzirte Missbildungen des Centralnervensystems. Archiv für Entwicklungsmechanik der Organismen. Bd. 12. (1901.) S. 53. Fall IX.

3) Fall VII.

4) Vaschide et Vurpas, Contribution à l'étude psychophysiologique des actes vitaux en l'absence totale du cerveau chez un enfant. Comptes rendus 1901. p. 641 .

Deutsche Zeitschr. f. Nervenheilkunde. XXIV. Bd. 
stark erweitert, namentlich rechts, unbeweglich, keine Reaction auf licht.

20 Stunden nach der Geburt allgemeine Krämpfe, beginnend im linken Arm und mit Urinentleerung endigend.

Abwehrbewegungen (réactions de défense) vorhanden, nämlich Beugung der Kniee und Zurückziehen des Körpers bei unangenehmen Reizen.

Kein Reflex, nachdem Chinin. bromic. auf die Zunge gebracht worden war. Kampher, unter die Nase gehalten, verursachte keine Reaction. Auf Ammoniak erfolgte Zurückziehen des Kopfes, Lärm und Lichtreize obne Reaction. Mehrmals Schreien, aber kein wirkliches Weinen. Einige nicht näher beschriebene spontane Bewegungen wurden ausgeführt. Saugen und Schlucken erfolgte. Die Oblongata reichte bis an die Vierhügel.

W. Sternberg ${ }^{1}$ ) hat die Geschmacksreactionen bei einem Anencephalus 26 Stuuden nach der Geburt eingehend untersucht.

„Die Missgeburt führte nicht, wie dies normale Kinder sehon im Mutterleibe stets thun, Saugbewegungen beim Einführen des Fingers in den Mund aus, so dass dieselbe trotz mehrfach ausgeführter Bemühungen seitens der Eltern den ganzen Tag noch gar keine Nahrung hatte zu sich nehmen wollen. Nachdem die süsse Lösung auf die Zunge gebracht war, schlug das Kind die Augen auf, spitzt den Mund, schluckt zum ersten Mal und mit sichtlichem Behagen, führt Saugbewegungen aus und beisst sogar anf den Pinsel, denselben mit den Kiefern festhaltend, so dass derselbe nur mit einiger Mühe aus dem Munde entfernt werden kann. Wurde alsdann die bittere Chininlösung auf die Zunge gebracht, so verzieht sich sofort das Gesicht, das Kind wendet den Kopf ab, hebt denselben wiederholt etwas hoch, öffnet den Mund weit, speichelt stark und bringt mit dem Speichel einen Theil der eingebrachten Flüssigkeit mit Würgbewegungen zurück; dabei fängt das Kind an zu wimmern und öffnet bei Wiederholung dieses Versuches den Mund nicht so leicht. Wurde hiernach mit der Zuckerlösung die Zunge eingepinselt, so wehrte das Kind bei den erstmaligen Versuchen zunächst stets $a b$, sodann aber schluckt es wieder, beisst wieder mit Behagen zu und beruhigt sich."

Aehnliche Grimassen und Ausweichbewegungen traten bei Bepinselung der Zunge mit Essig und mit concentrirter Kochsalzlösung auf. Luebte 10 Tage. „Bei der Section fand sich die wenig ausgebildete Schädelhöhle mit einer kleinhirnartigen Masse erfüllt."

1) W. Sternberg, Geschmacksempfindung eines Anencephalus (Zeitschr. f. Psychologie und Physiologie der Sinnesorgane. Bd. 27. S. 77). 
Das Buch von Preyer ${ }^{1}$ ) bringt endlich noch einige Angaben über Lidbewegung und Hautreflexe, sowie die Beobachtung von Gähnen bei einem Anencephalus.

Man kann zur Ergänzung noch. Beobachtungen heranziehen, welche bei anderen Formen von ausgedehnten Hirndefecten gemacht worden sind. Es ist insbesondere zu verweisen auf die Arbeiten von Heydenreich ${ }^{2}$ ), Anton ${ }^{3}$ ), Balint4), Zappert und Hitschmann ${ }^{5}$ ), Ilberg ${ }^{6}$ ), Sehupfer. ${ }^{7}$ )

Schliesslich existiren noch einige Angaben über das Verhalten von Kindern, die bei der Geburt perforirt werden mussten, aber noch athmend extrahirt wurden. Die beste Beobachtung rührt von Kehrer her.

Das Kind athmete nach der Extraction etwa 6 mal in der Minute. Nach einem Schnitt durch die Mitte des Calamus scriptorius „wurden auf mechanische Reizung der Handteller und Fusssohlen (Kitzeln und Kneifen) Bewegungen der entsprechenden Extremitäten, Beugung und Streckung der Finger und Zehen, Beugung der Unter- und Vorderarme und der Beine ausgeführt". Der Schnitt war - wie Ilberg feststellte - dicht unterhalb jener Stelle des verlängerten Markes, wo Pyramiden und Oliven an die Brücke grenzen, gezogen. Er traf noch den linken dorsalen Acusticuskern und die untersten Partien des linken Facialiskerns. Nach einem zweiten Schnitt am unteren Fnde der Oblongata hörten Reflexe und Athmung auf.

\section{Eigene Beobachtung.}

Der Hemicephalus, dessen Centralnervensystem im ersten Theil dieser Arbeit beschrieben ist, kam gleichfalls lebend zur.Welt. Der

1) W. Preyer, Die Seele des Kindes. III. Aufl. Leipzig 1890. S. 23, 82, $160,200$.

2) L. Heyden reich, Hemicrania, Encephalon trilobulare und Schistoprosopus. Virchow's Archiv. Bd. 100. (1885.) S. 241.

3) G. Anton, Ueber angeborene Erkrankungen des Centralneryensystems. Sammlung medicinischer Schriften. Wien 1890. Heft XV.

4) R. Balint, Ueber einen Fall von anormaler Gehirnentwicklung. Archiv für Psychiatrie und Nervenkrankheiten. Bd. 32. (1899.) S. 627.

5) J. Zappert und F. Hitschmann, Ueber eine ungewöhnliche Form des angeborenen Hydrocephalus. Jahrbücher für Psychiatrie und Neurologie. Bd. 18. (1899.) S. 225.

6) G. I] berg, Beschreibung des Centralnervensystems eines sechstägigen syphilitischen Kindes mit unentwickeltem Grosshirn bei ausgebildetem Schädel, mit Asymmetrie des Kleinhirns sowie anderer Hirntheile und mit Aplasie der Nebennieren. Archiv für Psychiatrie und Nervenkrankheiten. 34. (1901.) S. 140.

7) F. Schupfer, Ueber Porencephalie. Monatsschrift für Psychiatrie und Neurologie. Bd. 10. (1901.) S. 32.

8) F. A. Kehrer, Ein Versuch bei einem neugeborenen Kinde über die Lage der Athmungscentren. Zeitschrift für Biologie. Bd. 28. (1891.) S. 450. 
Eine von uns leitete seine Geburt und wir hatten später Gelegenheit, eine Anzahl von Beobachtungen an ibm anzustellen.

Ueber Schwangerschaft und Geburt ist Folgendes mitzutheilen:

Die Mutter, 21 Jahre alt, Primipara, klein, gracil gebaut, sonst kräftig und gesund, stammt aus gesunder Familie, in der keine Missbildungen vorgekommen sind. Ebenso ist der Vater gesund und stammt aus gesunder Familie. Bei keinem der beiden Gatten ist Syphilis nachweisbar. Die letzte Menstruation der Mutter trat am 20. December 1898 ein. Wann die ersten Kindsbewegungen wahrgenommen wurden, ist nicht sicherzustellen. Der Verlauf der Schwangerschaft war normal. Die ersten. Wehen traten am Abend des 22. November 1899, d. i. nach 11 Monaten, ein.

Bei der Geburt war der Bauch stark ausgedehnt. Der schwangere Uterus reichte bis 2 Querfinger unterhalb des Processus xiphoideus, war in den Wehenpausen ziemlich gespannt, enthielt also offenbar viel Fruchtwasser. Der Foetus in I. Position, Schädellage. Der Schädel konnte oberhalb der Symphyse nur undeutlich getastet werden, Herztöne links vom Nabel. Innere Untersuchung unterblieb.

Der Geburtsverlauf war zunächst langsam, aber sonst normal. Blasensprung am 23. November um 4 Uhr Nachmittags. Bei der nun vorgenommenen inneren Untersuchung zeigte sich das Gesicht mit nach rechts gerichtetem Kinn eingestellt. Gegen $7 \mathrm{Uhr}$ trat das Gesicht anf den Beckenboden. Bei nochmaliger innerer Untersuchung fiel die grosse Beweglichkeit des Kopfes auf. Der noch ungeborene Foetus reagirte auf Einführung des Fingers in den Mund mit kräftigen Saugbewegungen. Nachdem während der Wehe bei nach vorn gezogenem Kinn kein Schädel vom Hinterdamm aus zu tasten war, wurde die Diagnose auf Anencephalus gestellt.

Die Ursache der Verzögerung der Geburt lag offenbar an den Schultern. Die Extraction gelang erst, nachdem der Schädel durch Zug am Unterkiefer und den vorspringenden Rändern der Schädelbasis entwickelt war, and erforderte eine halbe Stunde.

Der extrahirte Hemicephalus, ein Mädchen, war leicht asphyktisch, erholte sich aber rasch ohne Hülfeleistung und begann kräftig zu schreien. Er wurde mittels der Saugflasche mit Gärtner'scher Fettmilch ernährt. Er kündigte sein Nahrungbedürfniss durch Schreien an und wurde durch. Trinken beruhigt. Beim Saugen entleerten sich jedesmal einige Tropfen einer klaren Flüssigkeit aus dem Schädeldefect. Harn und Meconium wurden normal entleert.

Aus äusseren Gründen war eine genauere Untersuchung erst am 25. November um 7 Uhr 30 Minuten Abends möglich. Es wurden folgende Beobachtungen aufgezeichnet.

„Rectaltemperatur 34,8 ${ }^{\circ}$, Puls 96, Respiration 48. Das Kind ist kräftig und wohlgenährt, das Gesicht leicht cyanotisch. Es liegt (angekleidet) ruhig auf dem Rücken. Die Augenlider sind halb geöffnet, es schliesst die Lider während der Beobachtung spontan auf eine 
Ueb. einen Hemicephalus, mitBeitr. z.Phys, d. menschl.Centralnervensyst. 261

wenige Millimeter breite Spalte. Der Mund ist geöffnet, von Zeit zu Zeit erfolgt ein leises Wimmern und der Mund schliesst sich.

Auf Berührung des linken Augenlides erfolgt prompter Augenschluss. Ebenso rechts. Dabei wird die Lidhaut deutlich gerunzelt:

Auf Berührung der Wangen mit dem Finger keine Reaction. Auf Berührung der linken Wange mit Eis tiefe Inspiration. Auftropfen heissen Stearins auf die Wange ruft keine Reaction hervor. Ein leichter Nadelstich auf der linken Wange verursacht ein leichtes Herabziehen der Unterlippe auf derselben Seite.

Kitzeln des linken Naseneingangs mit einem Wattebäuschchen ohne Reaction. Rechts wird die Nasenschleimhant etwas weiter innen gekitzelt, darauf schliesst das Kind sofort die Augen, verzieht den Mund zu einer unwilligen Grimasse und weicht mit dem Kopfe nach rückwärts.

Die Pupillen erweitern sich nicht bei irgend welchen Reizen an anderen Körpertheilen. Verengerung bei Licht ist nicht wahrnehmbar. Die Bulbi divergiren leicht. Bewegungen sind nicht mit Sicherheit erkennbar.

Auf Schallreize keinerlei Reaction. Beim Aufdecken und Berähren der Extremitäten verzieht das Kind ein wenig die Mundwinkel nach abwärts und wimmert. Der gleiche Versuch gelingt ein zweites Mal ebenso.

Das rechte Händchen ist zur Faust geschlossen. Das linke zeigt Andeutung von „Klauenhand“, die Grundphalangen sind dorsalflectirt, die anderen Fingergelenke nur wenig gebeugt, der Daumen ist nicht angeschlossen. Das Handgelenk ist linkerseits leicht gebeugt und radialwärts flectirt.

Führt man den Zeigefinger in die Vola, so schliesst das Kind die Fingerchen um denselben und hält ihn durch einige Secunden fest. Links erfolgen die Greifbewegungen in leichter Krallenstellung.

Aufheben der linken Hand verursacht ein "Schnauferl“ (Verziehen des Mundes). Berühren des Handrückens mit Eis verursacht tiefe Inspiration mit hörbarem Seufzer. Sofortiges Erblassen der berührten Haut. Blosse Berührung des Handrückens reactionslos.

Nach dem Auszieben des Hemdchens bleiben die Arme etwa. $1 / 2$ Minute horizontal ausgebreitet (Kreuzstellung), werden dann spontan an den Stamm gelegt. Zieht man die Arme abermals ab, so wird nur der rechte Arm hinuntergeschlagen. Bei einem dritten Versuche bleiben die Arme mehrere Minuten in der gegebenen Stellung liegen.

Alle passiven Bewegungen stossen auf einen gewissen Widerstand. Die rechte obere Extremität zeigt mehr Tonus als die linke. Beiderseits kräftiger Tricepsreflex. 
Die Beine werden zusammengelegt gehalten, wie gewöhnlich bei Neugeborenen. Abduction der Oberschenkel stösst auf bedeutenden Widerstand. Auf leichtes Streichen an der rechten Fusssohle werden beide Beine an den Stamm gezogen, der linke Arm etwas gebeugt, der Mund verzogen und es erfolgt eine tiefe Inspiration. Die Beine bleiben einige Secunden angezogen, werden dann wieder mehr gestreckt. Wenn die Beine gebeugt gehalten werden, so stösst Streckung im Knie auf einen sehr kräftigen Widerstand.

Antropfen mit heissem Stearin und Nadelstiche verursachen am Oberschenkel keine Reaction.

Der Patellarreflex besteht in kräftiger Streckung des Beines und beiderseitiger Adduction der Oberschenkel. Achillessehnenreflexe nicht auslösbar.

Beim Aufsetzen des Kindes entsteht immer Weinen, durch Wiegen auf den Armen ist das Kind nicht zu beruhigen. Es hört auf, wenn man es niederlegt und ruhig liegen lässt."

Am 26. November um 4 Uhr Morgens trat der Tod ein.

Unsere Beobachtung ist in mehrfacher Beziehung unvollständig. Aus äusseren Gründen (die Missgeburt entstammte der Privatpraxis) konnten wir erst am dritten Lebenstage eine genaue Untersuchung vornehmen, als die Temperatur und damit zweifellos die Energie der Lebensäusserungen bereits erheblich gesunken waren. Auch diese Untersuchung musste, eben mit Rücksicht auf die unter unseren Augen zunehmende Schwäche, die namentlich nach dem Auskleiden des Kindes deutlich wurde, möglichst beschleunigt werden. Daher enthält sie wesentliche Lücken (elektrische Reizung, graphische Registrirung von Athmung und Puls, Momentphotographien des Gesichtsausdrucks, ophthalmoskopische Untersuchung etc.). Auf die Geschmacksprüfung hatten wir verzichtet, da uns Kussmaul's Angabe erinnerlich war, dass diese bei Neugeborenen häufig fehlschlage. Jedenfalls war der genaueren Beobachtung unseres Falles der Umstand hinderlich, dass bisher keine Zusammenstellung der Physiologie solcher Monstren existirt. Es wäre möglich gewesen, einen besseren Plan für die Untersuchung aufzustellen und manche Fragen eingehender zu beantworten, die sich später bei Ueberlegung des Ganzen und Vergleich mit den Angaben der Literatur aufdrängten.

Trotz dieser Mängel lehrt unsere Beobachtung, namentlich wenn wir sie mit dem Ergebnisse der anatomischen Untersuchung und den oben angeführten Beobachtungen anderer Forscher zusammenhalten, einige neue Thatsachen kennen und andere in das rechte Licht bringen, die für die Physiologie und Pathologie des menschlichen Centralnervensystems von Wichtigkeit sind. 
Wir haben insbesondere zu besprechen: das Saugen und Schreien und ihre Localisation, die Schmerz- und Unlustreactionen, unter denen die mimischen Reflexe und ihre Localisation besondere Aufmerksamkeit verdienen, das Seufzen, den Lidschluss, der bei höchst rudimentären Oculomotoriuskernen erfolgte, die $\mathrm{Be}$ wegungen der oberen Extremitäten, unter denen der Greifreflex bisher beim Hemicephalen nicht bekannt war, die Reflexe der unteren Extremitäten und jene normalen Reflexe, welche den Hemicephalen fehlen.

Saugen, Schreien, Stimmcentrum.

Von Bedeutung ist das allgemeine Verhalten nach der Geburt. Die Missgeburt schreit kräftig, ebenso wie alle gesunden Kinder. Berührung der inneren Fläche der Lippen löst kräftiges Saugen aus; das von uns beobachtete Geschöpf saugte sogar, als sich der Kopf noch im Uterus befand.

Der Saugreflex ist nach den experimentellen Erfahrungen beim Thiere in der Oblongata gelegen.

Grainger ${ }^{1}$ ) sah den Saugreflex bei neugeborenen Hunden erhalten, denen er das Grosshirn abgetragen hatte. Der Reflex rerschwand nach Zerstörung der Medulla oblongata.

Soltmann ${ }^{2}$ fand ebenfalls den Saugreflex beim neugeborenen Hunde erhalten, dem Hemisphären und Streifenhügel entfernt waren.

Die Beobachtungen am Hemicephalen bestätigen diese Angaben für den Menschen: Der Saugreflex hat sein Centrum in der Medulla oblongata und dem Halsmark (für die Unterkiefersaugung ${ }^{3}$ )).

Der erste Schrei, den das normale Kind mit dem Hemicephalen gemein hat, muss auch auf einem tief localisirten Reflexe beruhen. Es scheint, dass die Meinung verbreitet ist, das Schreien des Kindes hänge vom Sehhügel ab.

So stellt Joukoursky4) es als Thatsache hin, dass Missgeburten

1) Grainger, Observations on the structure and the functions of the spinal cord. 1837. p. 80 (citirt nach H. Milne-Edwards, Leçons sur la physiologie comparée. Paris 1878-1879. XIII. p. 145).

2) C. Soltmann, Experimentelle Studien über die Functionen der Grosshirnrinde der Neugeborenen. Jahrbuch für Kinderheilkunde IX. 1875. S. 106.

3) vgl. L. A uerbach, Zur Mechanik des Saugens und der Inspiration (Arch. f. Anatomie u. Physiologie. Physiol. Abtheilung 1888. S. 59) und Escherich, Ueber die Saugbewegungen beim Neugeborenen (Münch. med. Wochenschr. 1888. S. 687).

4) V. Joukoursky, Hydrocéphalie et tumeur congénitale de la glande pinéale chez un nouveau-né. Revue mensuelle de l'enfance. Vol. XIX. 1901. p. 197. 
mit unausgebildetem Sehhügel niemals schrieen, sondern blos wimmerten. Dies ergiebt sich aber als offenbar unrichtig, wenn man das Beobachtungsmaterial überblickt, das wir zusammengestellt haben. Es ist sicher, dass Hemicephalen auch ohne Sehhügel schreien.

Kehrer und Hoffmann constatiren, dass das Kind viel wimmerte, aber "selten schrie". Es ist also zwischen Wimmern und Schreien genau unterschieden worden, und das Kind hat, wenn auch selten, wirklich geschrieen.

Der Fall v. Muralt's schrie kräftig.

Der Hemicephale Veraguth's wurde ins Kinderspital gebracht, weil er immer schrie. Dieses Schreien ljess allmählich nach und ging in ein beständiges leises Wimmern über. Also auch bier ist genau zwischen Wimmern und Schreien unterschieden worden; das Kind hat anfangs wirklich geschrieen.

Auch der von uns beobachtete Hemicephale hat kräftig geschrieen.

Ónodi1) hat in mehreren Arbeiten durch Thierversuche das „primäre Stimmbandeentrum" in einem Gebiet gefunden, das $12 \mathrm{~mm}$ von den hinteren Corpora quadrigemina bis zum Vagusgebiete reicht. Ex hat auch Beobachtungen an Hemicephalen zur Stütze seiner Ansicht herangezogen. Bechterew ${ }^{2}$ ) ist "zu dem Schlusse gekommen, dass in der Gegend des hinteren Vierhügels bei den Säugethieren ein Stimmcentrum vorhanden ist, welches seiner Entwicklung nach in offenbarem Zusammenhange steht mit dem zu der Region des hinteren Vierhügels gleichfalls in nächsten Beziehungen stehenden Gehörcentrum". Und zwar nimmt Bechterew an, dass der Kern des hinteren Vierhügels zu diesem Stimmcentrum gehöre. Schon die Beobachtung v. Muralt's aber, in welcher der Kern des hinteren Vierhügels stark rudimentär ist, spricht gegen diese specielle Localisation.

Nach unserer Beobachtung, in der oberhalb des Locus coeruleus nur mehr ganz atypische, nicht zu agnoscirende Gebilde sich befanden, ist es wahrscheinlich, dass die obere Grenze des Phonationscentrums noch ein kleines Stückchen tiefer liegt, als sie v. Bechterew und Cnodi ziehen, so nämlich, dass der Kern des hinteren Vierhügels nicht mehr dazu gehört.

1) A. C'nodi, Die Phonation im Gehirn. Berliner klinische Wochenschrift 1894. S. 1089.

Derselbe, Die Lehre von der centralen Innervation des Kehlkopfes. Wiener klinische Rundschau 1902. S. 304.

2) W. v. Bechterew, Ueber eine Affection der Varol'schen Brúcke mit bilateraler Lähmung der willkürlichen Augenbewegungen, Zwangslachen und Zwangsweinen, sowie frühzeitiger Atrophie der rechtsseitigen Unterschenkelmuskeln. Deutsche Zeitschrift für Nervenheilkunde. Bd. 17. (1900.) S. 221. 
Ueb. einen Hemicephalus, mitBeitr. z. Phys. d. menschl. Centralnervensyst. 265

Die grosse Anlage der oberen Olive in unserem und v. Muralt's Falle sprechen im Uebrigen für die citirte Ansicht Bechterew's, dass das Phonationscentrum ron vornherein durch innige Beziehungen mit dem centralèn Hörapparat verknüpft sei.

\section{Hemmung des Schreiens.}

Wenn die von uns beobachtete Missgeburt zu trinken oder zu saugen (Einführung des Fingers) bekam, schrie sie nicht mehr.

Das Aufhören des Schreiens durch Anregung des Saugens ist beim Hemicephalen schon von Ollivier beschrieben worden. Die Erscheinung gehört nach dieser und unserer Beobachtung zu den Erscheinungen der Reflexhemmung und ist gleichfalls in die Medulla oblongata zu verlegen. Sie erklärt die prompte Wirkung des „Schnullers" beim normalen Kinde und die Beliebtheit dieser Vorrichtung. Sie steht nicht auf derselben Stufe mit den anderen Einflüssen, durch die ein Neugeborenes beruhigt werden kann, wie z. B. Wiegen oder grelle Lichterscheinungen, denn diese sind beim Hemicephalen unwirksam.

Diese Beruhigungsmittel setzen wahrscheinlich Mechanismen voraus, die bei defecten Gehirnen geschädigt oder nicht ausgebildet sind. Beim Hemicephalen ist im Falle von Veraguth ein unaufbörliches, nicht zu stillendes Schreien beobachtet worden. Das besser ausgebildete Monstrum von Balint weinte auch stets, im Falle von Anton bestand fast kein Schlafbedürfniss und sehr viel Weinen. Den alten Kinderärzten war es übrigens schon bekannt, dass manche ,idiotische" kleine Kinder Tag und Nacht ununterbrochen weinen und schreien.

\section{Sehmerz- und Unlustreactionen.}

Eine Gruppe von Reflexen können wir als Schmerz- und Unlustreactionen herausgreifen.

Im Allgemeinen reagiren die Hemicephalen anf Reize, die der normale Mensch unangenehm zu empfinden pflegt, in derselben Weise wie dieser, nämlich durch Schreien oder Wimmern, schmerzliches oder unwilliges Verziehen des Mundes, Zurückziehen des Kopfes und, in einzelnen Fällen, durch tiefe seufzende Inspiration. Diese Reactionen beobachten wir beim Erwachsenen oft als den letzten Rest der Hirnthätigkeit im tiefen Coma.

Als ,unangenehme" Reize haben wir gefunden: Aufsetzen, Aufdecken und Berührung der Extremitäten, Aufheben eines Arms, Berührung der Wange oder des Handrückens mit Eis. Die Reaction ist bei verschiedenen Individuen verschieden stark. Flechsig's Misgeburt reagirte schon auf schmerzhafte Reize "von geringer Intensität", Hofmann's Fall schrie dagegen nịcht auf Nadelstiche. 
Wichtig sind die Schmerz- und Unlustreactionen am Munde. Wir haben mehrere Bewegungen beobachtet, denen offenbar ganz verschiedene Bedeutung zukommt.

Ein rein localer Reflex vom Trigeminus auf den Facialis ist wohl das einseitige Herabziehen der Unterlippe auf Nadelstich in die linke Wange.

Andere Bewegungen sind dagegen wirkliche mimische Reflexe, die einer eingehenderen Betrachtung bedürfen.

\section{Mimische Reflexe. Mimische Centren.}

Die hirnlose Missgeburt führt eine Anzahl von mimischen Reflexen ebenso wie der normale Mensch aus. Dahin gehören: das Herabziehen der Mundwinkel, das Herabziehen der Unterlippe, das Verziehen des Mundes zu einem "Schnäuzchen".

Die erstgenannten verleihen dem Gesichte den Ausdruck des Schmerzes oder des Leidens - das „schmerzhafte. Verziehen des Gesichts", das Flechsig beobachtete, wird wohl dieselbe Ausdrucksweise gewesen sein - , das letztere den Ausdruck des Unwillens oder Schmollens.

Dieses „Schnäuzchen" (in Wien „Schnauferl" genannt), welches im Vorstrecken der Lippen in einer röhrenartigen Form bis zu einer förmlichen Aufstülpung besteht, ist eine sehr charakteristische Grimasse und wurde von unserem Hemicephalus auf das Deutlichste ausgeführt. Nach Darwin ${ }^{1}$ ) ist es bei kleinen Kindern als Ausdruck des mürrischen Schmollens fast über die ganze Erde verbreitet, insbesondere unter den wilden Rassen, und geht bei Erwachsenen, mindestens bei Europäern, bis auf eine gelegentlich zu bemerkende Spur verloren. Kaffern und Neuseeländer, unter den letzteren namentlich die Frauen, gebrauchen es noch im reiferen Alter. „Diese Ausdrucksform ist deshalb merkwürdig" sagt Darwin, ,als sie, soweit mir bekannt ist, beinahe die einzige ist, welche viel deutlicher während der Kindbeit als während des erwachsenen Alters dargeboten wird." Dieselbe Ausdrucksweise gebrauchen auch junge Orangs und Chimpansen ${ }^{2}$ ). Es ist wohl bemerkenswerth, dass diese phylogenetisch alte Grimasse auf einem tief localisirten Reflex beruht.

Das Vorhandensein mimischer Reflexe beim Hemicephalen steht scheinbar in einem Gegensatze zu der Lehre Bechterew's und Nothnagel's, die auf Thierexperimenten und Krankenbeobachtungen

1) Oh. Darwin, Der Ausdruck der Gemüthsbewegungen bei dem Menschen und den Thieren. Uebers, v. J. V. Carus. Stuttgart 1872. S. 236.

2) Derselbe, 1.c. S. 141 (mit Abbildung). 
Ueb. einen Hemicephalen, mit Beitr. z. Phys. d. menschl. Centralnervensyst. 267

aufgebaut ist und im Sehhügel das mimische Centrum erblickt. ${ }^{1}$ )

Schon oft ist aber erörtert worden, dass sich nicht alle Krankenbeobachtungen, namentlich nicht bei Kindern, mit der Localisation der Mimik im Sehhügel vereinigen lassen. Es würde zu weit führen und ist auch für unseren Zweck überflüssig, hier nochmals alle einzelnen Fälle zu discutiren. Die Divergenzen sind sicherlich anatomisch und physiologisch wohl begründet.

Die Sache liegt offenbar so: Es giebt sehr verschiedene mimische Reflexe und es existiren mehrere Schaltstationen dafür. Nach der verschiedenen Inanspruchnahme der einzelnen Gesichtsmuskeln muss ja schon im Facialiskern selbst ein coordinatorischer Mechanismus dafür vorhanden sein.

Von den verschiedenen Ausdrucksweisen ist ein Theil angeboren und reicht auch phylogenetisch weit zurick, wie die eben besprochenen Bewegungen.

Andere Ausdrucksweisen werden später erworben. Wir wissen ja, dass Gewohnheit, Erziehung und Milieu die Mimik des Gesichtes im höchsten Grade beeinflussen. Diese Ausdrucksweisen können aber erst dann erworben werden, wenn die höheren Hirntheile ihre Ausbildung erfahren haben. Es hat also wohl einen anatomischen Grund, dass das "Schnauferl" im späteren Alter in den Hintergrund tritt: mit der Ausbildung des Grosshirns und seiner Bahnen werden neue Ausdrucksweisen gewonnen, die die alten verdrängen.

Was nun die Localisation betrifft, so ist durch die Beobachtung von Flechsig und durch unseren Fall sichergestellt, dass einige angeborene und phylogenetisch alte Ausdrucksformen ihre Schaltstation schon in der Medulla oblongata besitzen. Bei kleinen Kindern können diese daher unversehrt bleiben, wenn Erkrankungen höherer Abschnitte im Uebrigen eine Facialisparese verursachen.

Andere Ausdrucksformen, bamentlich auch solche, die mehr dem Erwachsenen eigen sind, werden höher oben umgeschaltet und durch Läsionen des Sehhügels geschädigt. Hierher gehören die bekannten Beobachtungen.

Endlich unterliegt es nach Thierversuchen, so insbesondere nach den geistrollen Beobachtungen von $\operatorname{Franz}^{2}$ ), keinem Zweifel, dass nach

1) Neueste Zusammenstellung der einschlägigen Literatur bei Kirchhoff, Ein mimisches Centrum im medialen Kern des Sehhügels. Archiv für Psychiatrie. Bd. 35. (1902.) S. 814.

2) S. J. Franz, On the functions of the Cerebrum. I. The frontal lobes in relation to the production and retention of simple sensory-motor habits. American Journal of Physiology. VIII. 1902, October. 
Rindenläsionen, und zwar im Bereiche der Stirnlappen, neu erlernte Bewegungscombinationen wieder vergessen werden, ohne dass sonst eine motorische Störung besteht. So könnte es sich bei Kindern wohl auch mit erworbenen mimischen Ausdrucksformen verhalien.

Dass gerade bei Kindern die Mimik von versehiedenen Hirntheilen mehr beeinflusst wird als beim Erwachsenen, liegt wohl daran, dass eben die Kinder, wie dargelegt, physiologischer Weise zum Theil eine andere Mimik haben und ihre Mimik daher auch theilweise eine andere Innervation hat. Letzteren Gedanken hat übrigens schon Freud ${ }^{1}$ ) ausgesprochen.

Ueberlegt man nun unter Berücksichtigung der Erfahrungen an Hemicephalen die Beobachtungen, die über die mimischen Reflexe am Krankenbette gemacht worden sind, so ergiebt sich, dass die eigentlichen "psychisch-reflectorischen" Reactionen doch mit dem Sehhügel zusammenhängen. Insbesondere gilt das vom Lächeln. Die Nothnagel-Bechterew'sche Localisation ist also im Wesentlichen aufrechtzuerhalten. Die scheinbaren Widersprüche erklären sieh dadurch, dass man die bulbären Schmerz- und Unlustreactionen nicht von jenen Ausdrucksformen unterschieden hat. Die Begründung dieser Erkenntniss durch kritische Erörterung der gesammten einschlägigen Literatur wird in einer besonderen Arbeit²) erfolgen.

\section{Seufzen.}

Bemerkenswerth ist noch, dass einige der mimischen Reflexe der Oblongata beim Hemicephalen mehrmals mit einer tiefen Inspiration und dem Geräusche des Seufzens verbunden waren. Die primäre Verbindung mit einem respiratorischen Reflexe weist auch für jene mimischen Bewegungen auf einen Ursprung aus der Athmung hin. Dass das Seufzen als Schmerzreaction nicht höher als in der Oblongata ausgelöst wird, ist übrigens unseres Wissens eine bisher nicht bekannte Thatsache.

\section{Der erste Schrei.}

Halten wir die besprochenen Unlustreactionen mit dem Wimmern des Hemicephalus beim Aufdecken und dem Seufzen bei Berührung des Handrückens mit Eis zusammen, so haben wir den ersten Kindesschrei offenbar auch in diese Gruppe von Ausdrucks- und Respirationsreflexen einzureihen und werden ihn in Uebereinstimmung

1) S. Freud, Die infantile Cerebrallähmung. Specielle Pathologie und Therapie, herausgegeb. von Nothnagel. Bd. IX. II, 2. Wien 1897. S. 58.

2) Erscheint demnächst in der „Zeitschrift für klinische Medicin“. 
Ueb. einen Hemicephalus, mit Beitr. z. Phys. d. menschl. Centralnervensyst. 269

mit der Deutung, die Kussmaul ${ }^{1}$ ) in seinem klassischen Büchlein über den Neugeborenen gegeben hat, als Reflex auf den plötzlichen Eindruck der äusseren kalten Luft aufzufassen haben.

\section{Lidschluss. Augenfacialis.}

Von den anderen Bewegungen im Gesichte sind die Bewegungen der Lider besonders wichtig. Wir haben ,spontane" und reflectorische beobachtet. Die Lidspalte wurde nie ganz geöffnet, wohl aber, scheinbar spontan, auf eine schmale Spalte verengt. Prompter Lidschluss erfolgte sowohl als "Blinzelreflex" bei Berührung der Lider selbst, als auch als entfernter Reflex bei Kitzeln der Nasenschleimhaut. Es fehlte somit die Oculomotoriuswirkung (die Erseheinungen glichen denen bei congenitaler Ptosis), dagegen functionirte der Augenast des Facialis.

Bekanntlich hat Mendel ${ }^{2}$ ) die Ansicht aufgestellt, dass der Augenast des Facialis seinen Ursprung im Oculomotoriuskern habe. Nun waren in unserem Falle die Augenmuskelkerne nicht ausgebildet, sondern von ihrer Region nur ganz atypische Theile vorhanden, die sicherlich nicht dureh Markfasern mit den Facialiswurzeln in Verbindung standen. Unsere Beobachtung spricht also ganz entschieden gegen die Annahme Mendel's und unterstützt sehr wesentlich die Ansicht, dass der Facialiskern auch dem oberen Facialisaste als Urs prungsstätte diene - eine Ansicht, die unlängst Marinesco ${ }^{3}$ ) auf Grund von Experimenten und Präparaten mit Nissl-Färbung vertreten hat.

Bewegungen der oberen Extremitäten.

Die Bewegungen, welche man an den oberen Extremitäten solcher Missgeburten gesehen hat, sind dreifacher Art: lebhafte zappelnde Bewegungen unter dem Einflusse von Hautreizen (Hoffmann, Veraguth), Zurücklegen des Armes, wenn er aus seiner gewohnten Stellung gebracht wurde, endlich Greifbewegungen der Hände. Wir haben nur die beiden zuletzt genannten Bewegungen beobachtet.

Beide Bewegungen erfordern eine Coordination vieler Muskeln, welche der Hemicephale ohne die Mitwirkung der Pyramidenbahn, der Sehhügel und Vierhägel und mit einem äusserst rudimentären

1) A. Kussmaul, Untersuchungen über das Seelenleben des neugeborenen Menschen. Leipzig und Heidelberg 1859. \$. 27.

2) E. Mendel, Ueber den Kernursprung des Augenfacialis. Neurologisches Centralblatt 1887. S. 537.

3) G. Marinesco, L'origine du faciale supérieur. Revue neurologique VI, 1898. p. 30 . 
Kleinhirn genau so zu Stande bringt, wie das normale Neugeborene. Die Bedeutung der "Extrapyramidenbahnen" ist auch für die Bewegungen des Menschen höher einzuschätzen, als wir es bisher gewohnt sind.

Welche Wege die sensorische Regulirung der Bewegungen hier einschlägt, ob durch das spärliche Kleinhirn oder die Schleifenbahn oder andere aufsteigende Bahnen in die Oblongata, oder ob ein intraspinaler Mechanismus genügt, lässt sich freilich nicht erörtern, sicher ist, dass sie, soweit eine Beurtheilung möglich, völlig ausreichend ist.

Die linke obere Extremität zeigte eine Andeutung von Ulnarisparese, wahrscheinlich auf die zahlreichen Blutungen im Centralnervensystem zurückzuführen.

\section{Greifreflex.}

Eine Bemerkung verdient die bisher an Hemicephalen nicht beschriebene Greifbewegung. Wenn man einem kleinen Kinde den Finger oder einen anderen Gegenstand in die Hand schiebt, so umfasst es ihn bekanntlich und hält ihn längere Zeit fest. Das ist eine Handlung, die man an Kindern von der Geburt bis ins zweite Lebensjahr hinein beobachten kann. Später thun es die Kinder nicht mehr. Eltern and Kinderfrauen pflegen diese Bewegung sehr "nett" und „herzig“ zu finden. Es ist gewiss interessant, dass der Hemicephale diese Bewegung mit dem normalen Kinde gemein hat, dass sie also ein recht tiefstehender Reflex ist.

Dieser Reflex geht auch nur scheinbar verloren. Im späteren Alter tritt er noch immer ein, aber nur unter besonderen Umständen, nämlich wenn man in Gefahr ist, zu stürzen. Dann klammert man sich "krampfhaft" an alle berührten Gegenstände, selbst an unzweckmässige.

Auch dieser Greifreflex ist wohl ein phylogenetisch alter Reflex. Ein reflectorisches Festhalten eines jeden in die Hohlhand gelangenden Gegenstandes musste sehr werthvoll für ein Wesen sein, das auf Bäumen lebte und von Ast zu Ast sprang.

\section{Reflexe an den unteren Extremitäten.}

Die Reflexbewegungen der unteren Extremitäten erfolgten doppelseitig, wie in der Regel bei Kindern.

Auf Kitzeln einer Fusssohle wurden beide Beine nicht nur an den Stamm gezogen, sondern auch längere Zeit angezogen gehalten und zwar mit ziemlicher Kraft.

Es ist sehr wahrscheinlich, dass diese Verstärkung des Reflexes mit dem Fehlen der Pyramideribahn zusammenhängt, denn wir kennen ihn in dieser mehr tonischen Form bei vielen spinalen Erkrankungen 
mit Läsion der Pyramidenbahn und er führt bei ihnen schliesslich zur permanenten Beugecontractur der Beine.

Bemerkenswerth ist die weite Verbreitung der übrigen Reflexbewegungen, die den Fusssohlenreflex begleiten. Die Missgeburt beugte dabei den linken Arm, verzog den Mund und inspirirte tief. Die Nervenleitung ging also bei ihr, trotz des reducirten Vorderseitenstrangs und der spärlichen Schleife, ganz prompt von der Fusssohle bis zum Facialiskern.

\section{Tonus. Sehnenreflexe.}

Der Tonus der Extremitätenmuskeln war erhöht, der Tricepsreflex am Arme kräftig, der Patellarreflex, wie beim Kaninchen, mit Adduction beider Beine verbunden. Der erhöhte Tonus und die gesteigerten Sehnenreflexe sind regelmässig bei Agenesie der Pyramidenbahnen vorhanden und beruhen auf Wegfall der Hemmung von Seite der höheren Hirnantheile, wie der Eine von uns schon vor vielen Jahren auseinandergesetzt hat ${ }^{1}$ ).

\section{Fehlende Reflexe.}

Die bisher besprochenen Reflexbewegungen zeigen keinen oder doch keinen wesentlichen Unterschied gegenüber dem normalen Neugeborenen. Wir haben nun diejenigen Punkte zu erörtern, in welchen sich der Hemicephalus von dem normalen Neugeborenen unterscheidet.

In unserem Falle fehlten die Pupillarreaction, die Schallreaction und die Beruhigung des Kindes durch Wiegen.

Das Fehlen der Pupillarreaction erklärt sich einfach durch das Fehlen der optischen Bahnen. Das völlige Fehlen der Schallreaction beruht wohl auf Defecten im Labyrinth, wie sie von Veraguth beobachtet worden sind. Wohin die Beruhigung durch Wiegen zu verlegen ist und ob ihr Wegfall vielleicht auch durch Labyrinthdefect zu erklären ist, entzieht sich vorläufig der Beurtheilung.

Fehlen der Abwehrbewegungen der oberen Extremitäten.

Der wichtigste principielle Unterschied im Gebahren eines Hemicephalen von dem des normalen Kindes ergab sich aber beim Kitzeln der Nasenschleimhaut. Unsere Missgeburt schloss dabei die Augen, verzog deu Mund unwillig und bog den Kopf ein wenig zarück. Normale Neugeborene thun in diesem Falle das Gleiche, ạber ausserdem noch etwas: sie fahren mit den Händen nach dem

1) M. Sternberg, Die Sehnenreflexe und ihre Bedeutung für die Pathologie des Nervensystems. Leipzig und Wien 1893. S. 129. 
Gesicht, wie Kussmaul'1) zuerst hervorgehoben hat. Der Hemicephale, mit einer Oblongata bis "zum Locus coeruleus, verfügt also über Gesichtsreflexe und über eine Ausweichbewegung des Nackens, es fehlt ihm dagegen die Abwehrbewegung der oberen Extremitäten.

Vaschide und Vurpas behaupten zwar, dass die von ihnen beobachtete Missgeburt ,réactions de défense" besessen habe. Sie beobachteten aber nur dieselben Reflexe wie wir. Das sind theils locale Reflexe, theils "Ausweichbewegungen". Bewegungen einer "défense" kann man das nicht gut nennen, denn Davonlaufen ist keine Vertheidigung. Es ist sicherlich nicht unnöthig, hier auf eine genaue Terminologie zu dringen, weil es sich um einen so bedeutenden und principiellen Unterschied handelt und Missverständnisse nur durch exacte Bezeichnung zu vermeiden sind.

Es liegt wohl der Schluss nahe, dass die Abwehrbewegungen der Extremitäten die Mitwirkung höherer Hirntheile und anderer Bahnen erfordern, als die Hemicephalen mit der Oblongata bis zum Locus coeruleus besitzen. Trotzdem kann dieser Schluss atas den bisher vorliegenden Beobachtungen noch nicht gezogen werden. Denn sicher beweisend für die Function sind nur die positiven Befunde. Das Fehlen gewisser Bewegungen könnte auch auf den zahlreichen kleinen Blutungen beruhen, die das Centralnervensystem der Missgeburten durchsetzen. Erst wenn künftige reichlichere Beobachtungen stets das Ausbleiben der Abwehrbewegungen bei der gleichen Hirnentwicklung, aber ihr Vorhandensein bei besser ausgebildeten, aber noch immer defecten Hirnen sicherstellen sollten, werden wir auch diese Bewegungen localisiren können.

Allgemeines über die Physiologie der Hemicephalen.

Ueberblicken wir nochmals die Lebensäusserungen des Hemicephalen, so sehen wir, dass er sich in einem grossen Theil derselben nicht von dem normalen Kinde unterscheidet. Gemeinsam sind beiden der erste Kindesschrei, das Saugen, die Beruhigung des Schreiens durch Saugen, eine Anzahl von Unlustreactionen und mimischen Reflexen, die Greifbewegung der Hände und die Ausweichbewegung des Stammes, endlich die localen Reflexe. Vom teleologischen Standpunkte muss man das eigentlich voraussetzen. Das Schädeldach des Kindes wird bei der normalen Geburt so bedeutenden Gewaltwirkungen unterworfen, gequetscht und deformirt, dass die ersten Lebensäusserungen des Kindes von jenen Antheilen des Centralnervensystems, welche bei der Deformation des Schädels zweifellos in Mitleidenschaft gezogen werden, unabhängig und daher auf Functionen der Medulla oblongata und des Rückenmarks beschränkt sein müssen.

1) Kussmaul, I. c. S. 22 . 
Unterschieden sind die Missgeburten, welche blos die Oblongata ausgebildet haben, von dem normalen Kinde durch die ungenügende Wärmeregulirung (unser Fall mass 34,8 im Rectum, andere noch weniger), den Defect der höheren Sinnesnerven and vielleicht auch das Fehlen der Abwehrbewegungen.

Wir haben in der anatomisehen Darstellung gesehen, dass in der Organisation dieser Missbildung gewisse phylogenetisch alte Verhältnisse wieder ans Tageslicht treten. Es ist beachtenswerth, dass auch in den Bewegungen des Hemicephalen phylogenetisch alte Reflexe erhalten sind. Trotzdem kann die Missbildung nicht etwa als eine Varietät des Genus homo mit niederer Organisation betrachtet werden. Denn die Entwicklung ihres übrigen Körpers entspricht nicht der Organisation des Centralnervensystems; vielmehr ist dieser so angelegt, dass er nur bei einem ausgebildeten Centralnervensystem zum Fortleben geeignet wäre. Insbesondere entspricht dem Fehlen der Wärmeregulirung durch das Vorderhirn und Zwischenhirn kein anderweitiger besserer Wärmeschutz, ebensowenig dem Fehlen der Abwehrbewegungen irgend welche eigene Schutzvorrichtungen.

Es ist daher der Gedanke verfehlt - der hie und da ausgesprochen worden ist -, dass bestimmte Gebilde im Centralnervensystem des Hemicephalen für denselben ,wichtig“ oder „von Bedeutung" seien, weil sie mit einer gewissen Regelmässigkeit ansgebildet sind, etwa wie die „hintere Kreuzung" von Schürhoff oder die stets sehr schön entwickelten Ganglienzellen des Haubenfeldes. Ein derartiger Schluss aus der Form auf die functionelle Bedentung ist beim ausgebildeten Thiere berechtigt, weil hier die Erhaltung einer zweckmässigen Form durch Auslese möglich ist. Beim Hemicephalen aber findet keine Auslese nach der Zweckmässigkeit für ihn statt, sondern seine Organe entwickeln sich nach vererbten Wachsthumsbedingungen, die allerdings auch eine Auslese nach der Zweckmässigkeit erfahren haben mögen, aber nach der für das vollentwickelte Individuum.

Dass solche Geschöpfe in Wahrheit Missgeburten und zum Fortleben unfähig sind, beruht also einerseits auf den Mängeln ihrer Organisation und dem Fehlen wichtiger Lebensäusserungen, andererseits aber sicherlich auch auf den zahlreichen Blutung en, welche den erhaltenen Rest des Centralnervensystems in hohem Grade schädigen.

Die Arbeit wurde im Sommer 1903 abgeschlossen. Mehrere werthvolle Arbeiten von 1902 und 1903 (so von Zingerle, Ilberg; Anton [Hirnhypertrophie], Wichura, Neumann u. A.) konnten beim Drucke nicht mehr berücksichtigt werden. 